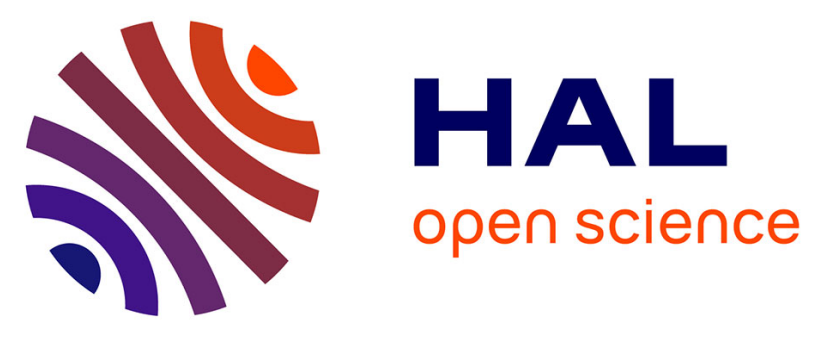

\title{
Synthesis and Biological Evaluation of $\mathrm{N}$ -[2-(4-Hydroxyphenylamino)-pyridin-3-yl]-4-methoxy- benzenesulfonamide (ABT-751) Tricyclic Analogues as Antimitotic and Antivascular Agents with Potent in Vivo Antitumor Activity
}

Zacharie Segaoula, Julien Leclercq, Valérie Verones, Nathalie Flouquet, Marie Lecoeur, Lionel Ach, Nicolas Renault, Amelie Barczyk, Patricia Melnyk, Pascal Berthelot, et al.

\section{- To cite this version:}

Zacharie Segaoula, Julien Leclercq, Valérie Verones, Nathalie Flouquet, Marie Lecoeur, et al. Synthesis and Biological Evaluation of N -[2-(4-Hydroxyphenylamino)-pyridin-3-yl]-4-methoxybenzenesulfonamide (ABT-751) Tricyclic Analogues as Antimitotic and Antivascular Agents with Potent in Vivo Antitumor Activity. Journal of Medicinal Chemistry, 2016, 59 (18), pp.8422-8440. 10.1021/acs.jmedchem.6b00847 . hal-02060584

\section{HAL Id: hal-02060584 https://hal.science/hal-02060584}

Submitted on 8 Mar 2019

HAL is a multi-disciplinary open access archive for the deposit and dissemination of scientific research documents, whether they are published or not. The documents may come from teaching and research institutions in France or abroad, or from public or private research centers.
L'archive ouverte pluridisciplinaire HAL, est destinée au dépôt et à la diffusion de documents scientifiques de niveau recherche, publiés ou non, émanant des établissements d'enseignement et de recherche français ou étrangers, des laboratoires publics ou privés. 
Journal of Medicinal Chemistry, 2016, 59(18), 8422-40.

doi: $10.1021 /$ acs.jmedchem.6b00847.

\title{
Synthesis and Biological Evaluation of $N$-[2-(4-
}

\author{
Hydroxyphenylamino)-pyridin-3-yl]-4-methoxy-
}

\author{
benzenesulfonamide (ABT-751) Tricyclic
}

\section{Analogues as Antimitotic and Antivascular Agents}

\section{with Potent in Vivo Antitumor Activity.}

Zacharie Segaoula, ${ }^{1,2}$ Julien Leclercq, ${ }^{1}$ Valérie Verones, ${ }^{1}$ Nathalie Flouquet, ${ }^{1}$ Marie lecoeur, ${ }^{3}$ Lionel Ach, ${ }^{3}$ Nicolas Renault, ${ }^{4}$ Amélie Barczyk, ${ }^{4}$ Patricia Melnyk, ${ }^{1}$ Pascal Berthelot, ${ }^{1}$ Xavier Thuru, ${ }^{1}$ Nicolas Lebegue. ${ }^{* 1}$

${ }^{1}$ Univ. Lille, Inserm, CHU Lille, UMR-S 1172 - JPArc - Centre de Recherche Jean-Pierre AUBERT Neurosciences et Cancer, F-59000 Lille, France.

${ }^{2}$ Oncovet Clinical Research, SIRIC ONCOLille, Parc Eurasante, Rue du Dr Alexandre Yersin, F59120 Loos, France.

${ }^{3}$ Univ. Lille, CHU Lille, EA 7365 - GRITA - Groupe de Recherche sur les formes InJectables et les Technologies Associées, F-59000 Lille, France. 
${ }^{4}$ Univ. Lille, Inserm, CHU Lille, U995 - LIRIC - Lille Inflammation Research International Center, F-59000 Lille, France.

KEYWORDS: Quinazolinone, benzothiadiazine, ABT-751, tubulin polymerization, vascular disrupting agent

ABSTRACT: Benzopyridothiadiazepine (2a) and benzopyridooxathiazepine (2b) were modified to produce tricyclic quinazolinone 15-18 or benzothiadiazine 26-27 derivatives. These compounds were evaluated in cytotoxicity and tubulin inhibition assays and led to potent inhibitors of tubulin polymerization. N-[2(4-Methoxyphenyl)ethyl]-1,2-dihydro-pyrimidino[2,1b] quinazolin-6-one (16a), exhibited the best in vitro cytotoxic activity ( $\left.\mathrm{GI}_{50} 10-66.9 \mathrm{nM}\right)$ against the NCI 60 human tumor cell line and significant potency against tubulin assembly $\left(\mathrm{IC}_{50} 0.812\right.$ $\mu \mathrm{M})$. In mechanism studies, 16a was shown to block cell cycle in $\mathrm{G} 2 / \mathrm{M}$ phase, to disrupt microtubule formation, and displayed good antivascular properties as inhibition of cell migration, invasion and endothelial tube formation. Compound 16a was evaluated in C57BL/6 mouse melanoma B16F10 xenograft model to validate its antitumor activity, in comparison with reference ABT-751 (1). Compound 16a displayed strong in vivo antitumor and antivascular activities at a dose of $5 \mathrm{mg} / \mathrm{kg}$ without obvious toxicity, whereas 1 needed a 10 -fold higher concentration to reach similar effects.

\section{Introduction}

Microtubules provide an important framework supporting cellular morphology in interphase, they are the major components of the mitotic spindle which allows the controlled segregation of the chromosomes during mitosis. Spindle poisons are described to interfere with the dynamic instability of microtubules and to induce a cell cycle arrest in the G2/M phase, promoting a 
mitotic catastrophe and finally causing cell death via apoptosis. ${ }^{1}$ Consequently, the microtubule has become an important target for the design of new antimitotic anticancer agents. Amongst these antitumor agents, two maJor groups have been well characterized, microtubule stabilizers such as paclitaxel $^{2}$ and microtubule destabilizers such as vinca alkaloids, ${ }^{3}$ colchicine, ${ }^{4}$ combretastatin A-4 (CA-4), ${ }^{5}$ and sulfonamide ABT-751 (1). ${ }^{6}$ Compound $\mathbf{1}$ is an orally bioavailable sulfonamide molecule that interacts with the colchicine binding site on $\beta$-tubulin, inhibiting microtubule polymerization. It exhibits a broad-spectrum antitumor activity in vitro in a large panel of cancer cell lines including those showing resistance to other antimicrotubule agents. ${ }^{7}$ In addition, $\mathbf{1}$ displays antivascular activity, reducing tumor-associated blood flow and thereby enhancing cytotoxic effects with little influence on normal vasculature. ${ }^{8}$ Compound $\mathbf{1}$ has shown excellent antitumor activity against a variety of xenograft models, such as non-small cell lung cancer (NSCLC) and colon cancer. ${ }^{9}$

As part of our program aiming at the identification of novel cytotoxic agents, a series of benzopyridothiadiazepine (2a) and benzopyridooxathiazepine (2b) derivatives showing antitubulin polymerization activities, that could be considered as constraint analogs of $\mathbf{1}$, and with potent in vitro and moderately in vivo antitumor activities have been earlier described (Figure 1). ${ }^{10,11}$ The relatively low in vivo antitumor activity of compound $\mathbf{2} \mathbf{b} \mathbf{1}$, has been explained by a lack of chemical and metabolic stability while it displayed good oral bioavailability ( $F, \%$ : 54.2) ${ }^{12-14}$ In order to improve the ADME properties, we have then extended our studies to the synthesis of compounds bearing heterocyclic privileged structures which were important scaffolds in medicinal chemistry and in agreement with the structure-activity relationships previously established. ${ }^{11}$ 
A beneficial approach in medicinal chemistry consists of exploration of privileged structures as new tolls in drug discovery. ${ }^{15,16}$ Privileged scaffolds enhance the hit rates of therapeutic targets, leading to compounds with improved drug-like properties and could contribute to the discovery of other biologically targets of interest. ${ }^{16,17}$ Quinazolinone is an heterocyclic core found in a variety of biological active agents with a broad range of activities (antibacterial, antifungal, antiviral, anticonvulsant, antitumor, sedative, antihypertensive...) that have been recently described. ${ }^{18,19}$ Moreover, Quinazolinone skeleton has been demonstrated to generate antimitotic agents, bearing their antitumor activity through the inhibition of the DNA repair processes or by the dysregulation of cell cycle progression of cancer cells. ${ }^{20,21}$ Among the various classes of antimitotics, quinazolin-4-ones constitute an important part of well-established pharmacologically active compounds as they are associated with inhibitory effects on tubulin polymerization and the anticancer activities of 2-styrylquinazolin-4-ones, ${ }^{22}$ 2-aryl and 2,3dihydro-2-arylquinazolin-4-ones $\mathrm{s}^{20,21,23}$ and tetrahydropyrido[2,1-b]quinazolin-10-ones ${ }^{24}$. From these considerations, the quinazolinone skeleton could be considered as a privileged structure. Therefore, this paper describes the synthesis of five or six-membered rings containing nitrogen atoms based on 2,3-fused quinazolin-4-one systems (15-18) and their sulfonyl benzothiadiazine analogues (26-27) as novel, highly potent tubulin polymerization inhibitors.

\section{Results and Discussion}

Chemistry. The synthetic route to 2,3-fused quinazolin-4-one derivatives 15-18 is shown in Scheme 1. The 2-chloro-3H-quinazolin-4-one key intermediate 6 was synthesized by using the general procedure described by Hess and co-workers. ${ }^{25}$ Commercial available anthranilamide 3 was first treated with potassium cyanate to yield quinazoline-2,4-dione 4 which reacted with 
$\mathrm{POCl}_{3}$ in the presence of $\mathrm{N}, \mathrm{N}$-dimethylaniline to provide 2,4-dichloroquinazoline $\mathbf{5}$ in $88 \%$ yield. Selective hydrolysis of $\mathbf{5}$ with $2 \%$ aqueous sodium hydroxide solution at $30^{\circ} \mathrm{C}$ gave the 2 -chloro$3 H$-quinazolin-4-one 6 in 83\% yield. Displacement of the chlorine with amino acetaldehyde or 3aminopropionaldehyde diethyl acetal followed by treatment with concentrated sulfuric acid allowed the linear cyclisation to $1 H$-imidazo[2,1-b]quinazolin-5-one 9 and 1,2-dihydro- $1 H$ pyrimidino[2,1-b] quinazolin-6-one $\mathbf{1 0}$ with respectively $60 \%$ and $89 \%$ yield. ${ }^{26}$ Arylethyl methanesulfonates 14a-d were obtained in three steps from the corresponding benzaldehydes by first, Wittig olefination with methyltriphenylphosphonium iodide followed by hydroboration leading to primary alcohols 13a-d which finally reacted with methanesulfonyl chloride. Treatment of compounds $\mathbf{9}$ and $\mathbf{1 0}$ with sodium hydride in anhydrous DMF followed by addition of the arylethyl methanesulfonates 14a-d provided the corresponding alkylated derivatives 15a-d and 16a-d in low yields resulting in a competition between substitution and elimination reactions. Hydrogenation of the double bond but also hydrogenolysis of the benzyl protection of compounds 15d and 16d was carried out by decomposition of ammonium formate in the presence of palladium catalyst in ethanol leading to compounds 17a-d and 18a-d in moderate yields. Access to unsaturated -phenol derivatives $15 \mathrm{e}$ and $\mathbf{1 6 e}$ was performed by cleavage of the benzyl ether group in strong acid conditions of the acid-insensitive substrates $\mathbf{1 5 d}$ and $\mathbf{1 6 d}$.

The benzothiadiazine analogues $\mathbf{2 6}$ and $\mathbf{2 7}$ were synthesized following the general procedures as detailed below (Scheme 2). 2-Methylthio-imidazolidine hydriodide 20 or 2-benzylthio1,4,5,6-tetrahydropyrimidine hydriodide $\mathbf{2 1}$, obtained from the reaction of the iodide salts of 2 imidazolidinethione or tetrahydro-2-pyrimidinethione with respectively methyl iodide or benzyl bromide, were reacted with 2-nitrobenzenesulfonyl chloride to give the corresponding sulfonamides $\mathbf{2 2}$ and 23. Reduction with zinc in acidic conditions of the nitro group followed by 
a simultaneous nucleophilic displacement of alkylthio group was described to conduct to the intramolecular cyclization with the resulting hydroxylamino group as maJor compound. ${ }^{27} \mathrm{~A}$ modification of this previously procedure using tin (II) chloride in refluxing ethanol with a catalytic amount of hydrochloric acid caused the exclusive formation of the deoxygenated benzothiadiazines 24 and $\mathbf{2 5}$. Condensation of these tricyclic heterocycles with arylethyl methanesulfonates 14a-d and hydrogenolysis of the benzyl protections were performed as described in scheme 1 and provided the target compounds 26-27.

We planned to synthesize the corresponding unsaturated derivatives 28-29 by a key step of oxidative dehydrogenation using $\mathrm{Pd} / \mathrm{C}$ in refluxing xylene but this reaction led only to recovery of starting material. We then decided to use DDQ as aromatization reagent to effect facile dehydrogenation of both simple and complex hydroaromatic heterocyclic compounds. Compounds 26a was then refluxed in toluene with 2 eq. of DDQ and not conducted to the desired unsaturated derivative 28a but to single product which proved to be the cyclocondensed imidazobenzothiadiazines $\mathbf{3 0}$ bearing a chloro substituent and was isolated in only $25 \%$ yield. Several substrates were then prepared and described recently to explore the scope of this reaction..$^{28}$

Biological Studies. Antiproliferative Activity in Cellular Assays. The in vitro cytotoxicity of all synthesized compounds against human colon adenocarcinoma HT29 cell line was investigated, in parallel with compound $\mathbf{2 b 1}$ and $\mathbf{1}$ as positive references, by the MTS assay after the incubation of cells with the compounds for $72 \mathrm{~h}$. Data are expressed as percentage of cell proliferation inhibition at a high single dose $(10 \mu \mathrm{M})$ or $\mathrm{IC}_{50}$ defined as the concentration at which the compounds reduce cell proliferation by $50 \%$ and are shown in Table 1 . The results indicate that inhibition of cell proliferation was highly dependent upon the size of the fused ring 
and the presence of the double bond. Five-membered rings were less active than their sixmembered counterparts in which the presence of a double bond enhanced the antiproliferative activity. Indeed, compounds bearing a dihydro-imidazole as fused ring were not (17a-c) or poorly (17d) active while introduction of a double bond improved antiproliferative activities with $\mathrm{IC}_{50}$ values in the micromolar range $(\mathbf{1 5 a}, \mathbf{e})$. Increasing the ring size by introduction of a tetrahydro-pyrimidine as six-membered ring led to better compounds (e.g., 18a,b vs 17a,b) in which the presence of a double bond enhanced the antiproliferative activity from the submicromolar to the nanomolar potency (e.g., 18a vs 16a). Replacement of the carbonyl group by its sulfonyl bioisostere generated a general decrease of the cytotoxicity as for example, the sulfonyl analogue 27a which was five-fold less potent than its direct carbonyl counterpart 16a. Concerning the arylethyl side chain, the number and position of hydroxyl or methoxy substituents on the phenyl ring had a maJor influence on antiproliferative properties. The presence of a 3-hydroxy-4-methoxyphenyl substitution in both five- and six-membered ring series provided good antiproliferative activities at the micromolar range (15e, 16e, 17d, 18d) but the greatest activities occurred in the presence of a 4-methoxyphenyl substitution in the sixmembered series (16a, 18a). Introduction of a 3,4-dimethoxy- or 3,4-5-trimethoxyphenyl group, a typical pharmacophore found in many inhibitors of tubulin polymerization, ${ }^{29}$ led to less active compounds $(\mathbf{1 5 b}, \mathbf{1 6 b}, \mathbf{1 8 b})$ or a total loss of antiproliferative activity $(15 \mathrm{c}, 16 \mathrm{c}, 17 \mathrm{c}, 18 \mathrm{c})$.

These results allowed to identify four new active antiproliferative compounds $(\mathbf{1 6 a}, \mathbf{1 6 b}, \mathbf{1 8 a}$ and 27a) displaying low $\mathrm{IC}_{50}$ values ranging from 42 to $766 \mathrm{nM}$ (Table 1). Structure-activity relationship (SAR) concluded that (1) a six-membered-ring bearing a double bond is the most tolerant of heterocyclic cores, (2) replacement of the carbonyl group by a sulfonyl moiety did not 
led to positive results, and (3) the 4-methoxy substitution on the phenylethyl side chain is more favorable than a 3-hydroxy-4-methoxy substitution.

NCI's in vitro 60 cell screening. Compounds $16 \mathbf{a}, \mathbf{1 8 a}$ and $\mathbf{2 7 a}$ were selected by the National Cancer Institute (NCI) for screening against 60 human tumor cell lines. ${ }^{30}$ They were initially tested at a high single dose $(10 \mu \mathrm{M})$ in the full 60 -cell panel and have progressed to the 5-dose screen in order to evaluate their GI50 values (Table 2). A mean graph midpoints (MG-MID) was calculated for each derivative selected for $\mathrm{GI}_{50}$ calculation, giving an average activity parameter over all cell lines for the tested compounds. These data indicated that quinazolinone 16a, with an average $\mathrm{GI}_{50}$ of $58.9 \mathrm{nM}$, was more active than its saturated analogue 18a (GI 50 (MG-MID): $199.5 \mathrm{nM}$ ) and benzothiadiazine 27a (GI50 (MG-MID): $645 \mathrm{nM}$ ) which displayed weak growth inhibition potentials in several cancer cell lines as NSCL (NCI-H226), melanoma (UACC-62), ovarian (IGROV1, SK-OV-3) or renal (UO-31) cancers. Exhibiting the best activities comparable to our previously highlighted benzopyridooxathiazepine (2), compound 16a was then selected for further biological evaluations.

Cell Cycle Analysis. The effects of $\mathbf{1 6 a}$, the most active compound on cell division process were evaluated using SK-Mel 28 melanoma cell line. The product was applied at varying concentrations, between $100 \mathrm{nM}$ and $10 \mu \mathrm{M}$ for $24 \mathrm{~h}$ in parallel with vehicle (1\% DMSO). The cells were then stained with propidium iodide (PI) and analyzed by flow cytometry. As represented in figure 2, cell populations treated with 16a were significantly arrested with an accumulation in the G2/M phase and an increase in subG1 apoptotic cells in a dose dependent manner and it was accompanied by a comparable reduction in the proportion of cells in both the G1 and S phases of the cell cycle. No effects on G2/M cell cycle blockade have been reported for the control populations which remained in a G0/ G1 state mainly. These results clearly indicated 
that the cell cycle arrest caused by $\mathbf{1 6 a}$, as evidenced by the ability of the incubated cells to pass through the G2/M phase, was generally observed for antimitotic drugs that bind to tubulin.

Immunocytochemical analysis. To determine the microtubule disrupting effects of the target compounds, we selected 16a as a representative compound in a cell-based phenotypic screening (Figure 3). SK-Mel 28 cells were used to examine the effect of $\mathbf{1 6 a}$ on the reorganization of microtubules during mitosis. Cells were treated for $6 \mathrm{~h}$ with 16a or vehicle (1\% DMSO), and microtubules were visualized by indirect immunofluorescence techniques. An antibody for $\beta$ tubulin was used to visualize interphase and mitotic microtubule structures. Vehicle treated cells displayed a spider's web like network of fibrous filaments (green) wrapped around the cell nucleus (blue) (Figure 3A,B,C). Morphological aspects of untreated vs. 16a treated cells showed a significant difference in the microtubules structure between the two populations and a loss of polarity of 16a treated SK-Mel 28 cells which adopted a spherical configuration due to the disorganization of the microtubule network (Figure 3D,F).

Tubulin content. In order to evaluate whether our compounds affected polymerization or depolymerization of tubulin, an immunoblot analysis on protein extracts was performed to determine the polymerized and soluble tubulin fractions. Cells were treated for six hours with compound 16a $(1 \mu \mathrm{M})$ or vehicle. The results showed a significant decrease in polymerized tubulin fractions between 16a treated group and the related controls (untreated, vehicle) $(36 \% \pm$ 6 vs. $100 \% \pm 20$, p value $=0.0071, \mathrm{n}=4$ ) whereas no significant change have been reported in the soluble fractions between all groups (Figure. 4). Thus, these data confirmed that compound 16a induced its antimitotic effects by inhibiting tubulin polymerization since $\mathrm{s} / \mathrm{p}$ tubulin ratio increased by a fold of two in $\mathbf{1 6 a}$ treated cells indicating more soluble protein form. 
Inhibition of Tubulin Polymerization. Compounds 15-18 were then evaluated for their in vitro inhibition of tubulin polymerization in comparison with compound $\mathbf{2 b} \mathbf{b}$ and $\mathbf{1}$ (Table 1). In this assembly assay, the six-membered ring derivatives 16a,b,e, 18a, 27a,e displayed greater inhibitory activities than the reference compounds $\mathbf{2} \mathbf{b} \mathbf{1}$ and $\mathbf{1}$, with $\mathrm{IC}_{50}$ values ranging from 0.27 to $1.29 \mu \mathrm{M}$ whereas the others seemed to be inactive as inhibitors of tubulin polymerization and did not inhibit tubulin assembly at concentrations as high as $10 \mu \mathrm{M}$. Inhibitions of tubulin polymerization of tested compounds were consistent with their antiproliferative activities. Indeed, compounds bearing a 3,4,5-trimethoxy group were inactive at concentrations as high as $10 \mu \mathrm{M}$ while other variations of substituents within the aryl moiety as 4-methoxy (16a, 18a, 27a), 3,4-dimethoxy (16b) and 3-hydroxy-4-methoxy groups (16e, 27e), led to significant activities with higher potencies than the reference compounds. In contrast with the cell proliferation assays, the carbonyl derivatives 16a,e were less potent than their counterparts 27a,e whose substitution with a sulfonyl group seemed to be most tolerant for tubulin polymerization inhibitory effect. Among all compounds tested, 16a, 18a and 27a were identified as the most active ones in both cell proliferation and tubulin assembly assays. The discrepancy between cytotoxicity and antitubulin activity of compounds $16 \mathrm{e}$ and $27 \mathrm{e}$ can be explained by the high resistance of HT29 cell line to most of tubulin polymerization inhibitors with a 3-hydroxy-4methoxy substitution as for CA-4. ${ }^{31}$ It has been reported that glucuronidation of phenol derivatives as CA-4 is highly observed in HT29 colorectal cancer cells due to an overexpression of glucuronosyl transferase activity and then contributes to drug resistance phenomenon. ${ }^{32}$

Molecular Modeling. Molecular docking tools are used for the structure-based analysis in order to elucidate the interactions of best compounds 16a and 27a of each class of quinazolinone and benzothiadiazine derivatives. The structural similarity between reference compound $\mathbf{1}$ and 
16a and 27a made consistent the docking of these two new molecules into the cavity of the 1bound tubulin crystal structure (PDB ID $3 \mathrm{HKC}) .{ }^{33}$ Using AutodockVina ${ }^{34}$ with a $50 \AA$ edged cubic box including one $\beta$-tubulin subunit and centered onto compound $\mathbf{1}$ binding site allowed to retrieve the first ranked docking pose of each compound very close to the co-crystallized compound 1 (Figure 5) suggesting they could be really considered as constraint analogs of $\mathbf{1}$ According to previous studies, ${ }^{29,35}$ the main receptor-ligand interactions were hydrophobic contacts with Leu240, Leu255, Ala314, Val316 and Ile378 of $\beta$ chain. In comparison with compound 1, an additional interaction was observed between carbonyl of $\mathbf{1 6 a}$ and sulfonyl of 27a and thiol group of Cys239 side chain. Interestingly, this amino acid was shown to be involved in the conformational changes of the various transition states during tubulin polymerization. ${ }^{36}$ Arguing for a prediction of inhibition of polymerization by alpha/beta tubulin disruption rather than the prediction of cellular anti-proliferative activity, it emphasizes an inhibition of polymerization $(0,812 \mu \mathrm{M}$ and $0,27 \mu \mathrm{M})$ in the same order of magnitude by compounds 16a and 27a. By keeping suitable enthalpic contributions in term of intermolecular specificity and decreasing entropic contribution by a strategy of rigidification of compound $\mathbf{1}$, these docking results support the original design aiming at increase the potency of constraint analogs of $\mathbf{1}$.

HUVEC Cell invasion and endothelial tube formation assays. To continue its growth and expansion, a neoplastic tissue requires oxygen and metabolic supplies, that's why, the tumor microenvironment stimulates the development of additional blood vessels from already preexistent branches; this process is well known under the term of angiogenesis. ${ }^{38}$ Recent antitumor strategies are based on the use of chemotherapeutic agents with antiangiogenic or antivascular drugs in order to increase the efficacy of the treatment. Besides the ability to inhibit 
tumor cell proliferation, microtubule-targeting drugs have also been shown to be active against the tumor vasculature by inhibiting endothelial cell invasion and capillary tube formation. ${ }^{39,40}$ Considering that tube formation and invasion are highly relevant properties in the process of tumor vasculature, we investigated the effects of compound 16a and antiangiogenic inhibitor cediranib (31, VEGFR, PDGFR and c-Kit inhibitor) ${ }^{41}$, as the reference substance at several concentrations $(0.001,0.01,0.1$ and $1 \mu \mathrm{M})$ on the invasiveness of human umbilical vein cord endothelial cells (HUVEC) in a Boyden chamber assay. Transwell instets were precoated with basement membrane matrix and the number of HUVEC that penetrated the membrane was quantified. As shown in Figure 6, treatment with compound 16a inhibited HUVEC cell invasion at nontoxic concentrations lower than $0.01 \mu \mathrm{M}(74 \% \pm 0.01$ inhibition, $p$ value $<0.001)$ while 31 displayed similar effects at a more pronounced concentration of $1 \mu \mathrm{M}(74 \% \pm 0.09, p$ value $<$ 0.001). We also studied the effects of compound 16a on vascular tube formation. The antiangiogenic effect was evaluated on HUVEC model by treating the cells with either the reference compound 31 or compound 16a. Cells were seeded on a specific membrane matrix, which is rich in pro-angiogenic factors that stimulate single endothelial cells to assume an extended shape, in order to mimic in vivo HUVEC and treated with several concentrations of $\mathbf{3 1}$ or 16a $(0.001,0.01,0.1$ and $1 \mu \mathrm{M})$. The overall effect results in a reticular similar to a capillary network and offers an in vitro model of angiogenesis. ${ }^{42}$ As shown in Figure 7, compound 16a significantly displayed vascular disrupting effects at $0.1 \mu \mathrm{M}$ with total destruction of the cordlike structures at $1 \mu \mathrm{M}$ and at which $\mathbf{3 1}$ was less effective.

SK-Mel28 cell wound healing assay. The effect of compound 16a on cell migration, which is an important mechanism involved in tumor invasion, was also evaluated by scratching a melanoma SK-Mel28 cell line monolayer and monitoring the percentage of wound closure. As 
shown in Figure 8, compound 16a was very efficient in arresting cell motility. The effect was statistically significant after $9 \mathrm{~h}$ of incubation at the concentration of $1 \mu \mathrm{M}$, in comparison with control cells, keeping the wound nearly intact (wound closure $3 \% \pm 2, p$ value $<0.001$ ).

Druglike properties. The hydrophobic character $(\log \mathrm{P})$ and the in vitro metabolic stability of 16a lead compound have been determined and compared with those of the reference compound 2b1. Quinazolinone 16a exhibited lower $\log P$ value $(2.63 \pm 0.01$ versus $3.10 \pm 0.01)$ and greater metabolic stability in rat liver microsome $\left(\mathrm{t}_{1 / 2}=56\right.$ min versus 38 min) than benzopyridooxathiazepine derivative 2b1. The determination of Michaelis-Menten parameter $\left(\mathrm{K}_{\mathrm{m}}\right)$, which is reciprocally proportional to the enzyme affinity to the substrate, also confirmed the previous results with $\mathrm{K}_{\mathrm{m}}$ values of $5.2 \pm 1.0 \mu \mathrm{M}$ and $27.2 \pm 5.6 \mu \mathrm{M}$ for compounds $2 \mathbf{b} 1$ and 16a, respectively. Its improved druglike properties as well as its antiproliferative and antivascular activities suggest that compound 16a may be a better potential drug candidate than its oxathiazepine analogue $\mathbf{2 b 1}$.

Antitumor Activitiy In Vivo. To further investigate the in vivo effects of compound 16a on tumor growth and vascularization, we used a syngeneic melanoma mouse model (B16F10). ${ }^{43}$ In in vitro preliminary experiments, we demonstrated that compound 16a showed potent cytotoxic activity against melanoma cell lines. C57BL/ 6 mice were then subcutaneously inJected with B16F10 murine melanoma cell lines and when tumor bulging reached a measurable size (about $100 \mathrm{~mm}^{3}$ ); mice were divided and randomly assigned to six groups. Three different doses ranging from $5 \mathrm{mg} / \mathrm{kg} /$ day to $50 \mathrm{mg} / \mathrm{kg}$ /day were tested for $\mathbf{1 6 a}$ compared to a single $50 \mathrm{mg} /$ $\mathrm{kg} /$ day dose for reference $\mathbf{1} .^{44}$ Treatment was delivered continuously using subcutaneous osmotic pumps and in accordance with the pharmacokinetic data. As depicted in figure 9 and 10, product 16a showed a significant decrease in tumor growth and angiogenesis at the starting 5 
$\mathrm{mg} / \mathrm{kg}$ dose as compared with the administration of vehicle $\left(1000 \mathrm{~mm}^{3} \pm 280\right.$ vs. $2400 \mathrm{~mm}^{3} \pm$ $310, p$ value $=0.009)$ and a $60 \%$ decrease in the percentage of microvessel number with no significance to the standard compound 1 treatment $(p$ value $<0.005)$. At the lower dose, no significant difference was observed between 16a and $\mathbf{1}$ on tumor growth inhibition and angiogenesis, but a slight difference was shown at the higher $50 \mathrm{mg} / \mathrm{kg} /$ day with no statistical significance $\left(760 \mathrm{~mm}^{3} \pm 160\right.$ vs. $1200 \mathrm{~mm}^{3} \pm 390, p$ value $=0.25$ and $80 \%$ decrease in microvessel number) in comparison to vehicle $\left(2400 \mathrm{~mm}^{3} \pm 310, p\right.$ value $\left.=0.0007\right)$. Mice monitoring showed no significant difference in mice average weight between all groups before, during and after treatment initiation. Hence, compound 16a showed strong antitumor and antivascular activities on a well-tolerated dose schedule and was as effective as 10 -fold lower dose of reference compound $\mathbf{1}$.

\section{Conclusion}

By structural modifications on the thiadiazepine and oxathiazepine moieties in prior leads $\mathbf{1}$ and 2, a series of 2,3-fused quinazolin-4-one systems (15-18) and their sulfonyl benzothiadiazine analogues (26-27) were synthesized and evaluated in cytotoxicity and tubulin inhibition assays and led to a new class of inhibitors of tubulin polymerization. The most potent compound, 16a exhibited the best in vitro cytotoxic activity in cellular assays with a mean $\mathrm{GI}_{50}$ value of $58.9 \mathrm{nM}$ on the NCI60 human tumour cell line and significant potency against tubulin assembly with an $\mathrm{IC}_{50}$ value of $0.812 \mu \mathrm{M}$. In mechanism studies, 16a was shown to block cell cycle in $\mathrm{G} 2 / \mathrm{M}$ phase, inhibited cell invasion and migration and displayed antiangiogenic effect, thus providing evidence that this tubulin polymerization inhibitor acts as vascular disrupting agents (VDAs). SAR and molecular modeling studies suggested that the presence of a carbonyl or a sulfonyl 
group allowed additional interactions with thiol group of Cys239 side chain which might be responsible for the greater potency of $\mathbf{1 6 a}$ and $\mathbf{2 7 a}$ than the reference 1. Following druglike property assessments, 16a was evaluated in parallel with reference 1 in C57BL/6 mouse melanoma B16F10 xenograft models to evaluate their in vivo activities. Compound 16a exhibited strong in vivo antitumor and antivascular activities, suppressing tumor growth and angiogenesis equally to $\mathbf{1}$ but at a 10 -fold lower dose. In summary, these newly tricyclic quinazolinone or benzothiathiazine derivatives displayed marked biological activities in vitro and in vivo as a novel class of anticancer agents and have potential for further development.

\section{Experimental Section}

1. General Chemistry. All reagents and solvents were purchased and used without further purification. Melting points were determined on a BÜCHI B-540 apparatus and are uncorrected. NMR spectra were recorded on a Bruker Avance 300 spectrometer operating at $300 \mathrm{MHz}\left({ }^{1} \mathrm{H}\right)$ or $75 \mathrm{MHz}\left({ }^{13} \mathrm{C}\right)$. Chemical shifts are in parts per million (ppm) and were referenced to the residual proton peaks in deuterated solvents. Mass spectra were recorded with an LCMS (Waters Alliance Micromass ZQ 2000). LCMS analysis was performed using a Waters XBridge C18 column (5 $\mu \mathrm{m}$ particle size column, dimensions $50 \mathrm{~mm} \times 4.6 \mathrm{~mm}$ ). A gradient starting from $98 \%$ $\mathrm{H}_{2} \mathrm{O} /$ formate buffer $5 \mathrm{mM}(\mathrm{pH} 3.8)$ and reaching $100 \% \mathrm{CH}_{3} \mathrm{CN} /$ formate buffer $5 \mathrm{mM}(\mathrm{pH} 3.8)$ within $4 \mathrm{~min}$ at a flow rate of $2 \mathrm{~mL} / \mathrm{min}$ was used followed by a return to the starting conditions within 1 min. Purities of tested compounds reached at least 95\% and were determined by HPLC using the following instruments and conditions: Waters HPLC system was equipped with a HPLC 600 pump and a 2996 photodiode array detector. The HPLC analysis were performed on a LiChroprep Hibar ${ }^{\circledR}$ column $(25-40 \mu \mathrm{m}$ particle size column, dimensions $250 \mathrm{~mm}$ x $4.6 \mathrm{~mm})$, 
detection at $254 \mathrm{~nm}$, and injection volume of $20 \mu \mathrm{L}$. Mobile elution was conducted with a mixture of petroleum ether (PE):ethyl acetate (EA) (see sup info).

Procedure for synthesis of compound 4. Anthranilic acid 3 (15 g, 0.109 mol) was suspended in water $(500 \mathrm{~mL})$ and glacial acetic acid $(6.75 \mathrm{~mL})$ at $35^{\circ} \mathrm{C}$. A freshly prepared solution of potassium cyanate $(11.5 \mathrm{~g}, 0.142 \mathrm{~mol})$ in water $(100 \mathrm{~mL})$ was added dropwise to the stirred mixture. After $2 \mathrm{~h}$, sodium hydroxide (144 g $3.6 \mathrm{~mol})$ was added in portions, keeping the temperature below $40{ }^{\circ} \mathrm{C}$. A clear solution was obtained momentarily before precipitation of the hydrated sodium salt. After cooling, the precipitate was filtered off and dissolved in hot water then acidified to $\mathrm{pH} 5$, causing precipitation of $1 H$-quinazoline-2,4-dione which was filtered and dried.

1H-quinazoline-2,4-dione (4). Yield 74\%, 13 g. White solid, mp $360-362{ }^{\circ} \mathrm{C}$ (Lit. ${ }^{45} 355$ $\left.358^{\circ} \mathrm{C}\right) .{ }^{1} \mathrm{H}$ NMR (DMSO- $\left.d_{6}, 300 \mathrm{~Hz}\right): 7.15\left(2 \mathrm{H}, \mathrm{m}, \mathrm{CH}\right.$ quina), $7.62\left(1 \mathrm{H}, \mathrm{td},{ }^{4} J=1.5 \mathrm{~Hz}\right.$ and ${ }^{3} J$ $=7.3 \mathrm{~Hz}, \mathrm{CH}$ quina), $7.88\left(1 \mathrm{H}, \mathrm{dd},{ }^{4} J=1.5 \mathrm{~Hz}\right.$ and ${ }^{3} J=8.2 \mathrm{~Hz}, \mathrm{C} H$ quina), $11.2(2 \mathrm{H}, \mathrm{s}, \mathrm{N} H)$. $\mathrm{C}_{8} \mathrm{H}_{6} \mathrm{~N}_{2} \mathrm{O}_{2} ; \mathrm{MW}=162.14 \mathrm{~g} / \mathrm{mol}$.

Procedure for synthesis of compound 5. A mixture of $1 H$-quinazoline-2,4-dione (12 g, 0.074 mol), trichlorophosphate $(41.5 \mathrm{~mL}, 0.445 \mathrm{~mol})$ and $N, N$-dimethylaniline $(6.1 \mathrm{~mL}, 0.048 \mathrm{~mol})$ is refluxed for $5 \mathrm{~h}$. The excess of trichlorophosphate is evaporated and ice is added to the residue. After standing at room temperature overnight, the mixture was filtered to give a solid which was recrystallized from methanol.

2,4-dichloroquinazoline (5). Yield 88\%, 12.95 g. Off-white solid, mp 119-121 ${ }^{\circ} \mathrm{C}$ (Lit. ${ }^{46} 118$ $120^{\circ} \mathrm{C}$ ). ${ }^{1} \mathrm{H}$ NMR (DMSO- $\left.d_{6}, 300 \mathrm{~Hz}\right): 7.91\left(1 \mathrm{H}, \mathrm{td},{ }^{4} J=1.2 \mathrm{~Hz}\right.$ and ${ }^{3} J=6.9 \mathrm{~Hz}, \mathrm{CH}$ quina), $8.05\left(1 \mathrm{H}, \mathrm{dd},{ }^{4} J=1.2 \mathrm{~Hz}\right.$ and ${ }^{3} J=8.3 \mathrm{~Hz}, \mathrm{C} H$ quina), $8.18\left(1 \mathrm{H}, \mathrm{td},{ }^{4} J=1.5\right.$ and ${ }^{3} J=6.9 \mathrm{~Hz}, \mathrm{CH}$ quina), $8.31\left(1 \mathrm{H}, \mathrm{dd},{ }^{4} J=1.5 \mathrm{~Hz}\right.$ and ${ }^{3} J=8.5 \mathrm{~Hz}, \mathrm{CH}$ quina). $\mathrm{C}_{8} \mathrm{H}_{4} \mathrm{~N}_{2} \mathrm{Cl}_{2} ; \mathrm{MW}=199.03 \mathrm{~g} / \mathrm{mol}$. 
Procedure for synthesis of compound 6. A suspension of 2,4-dichloroquinazoline (2.8 g, 14.1 mmol) was stirred in $2 \%$ aqueous sodium hydroxide solution $(50 \mathrm{~mL})$ for $24 \mathrm{~h}$ at $30{ }^{\circ} \mathrm{C}$. The reaction mixture was diluted with water $(100 \mathrm{~mL})$ and filtered to remove unreacted 2,4dichloroquinazoline. The filtrate was neutralized with dilute acetic acid, the precipitate thus obtained was filtered and washed with water.

2-chloro-3H-quinazolin-4-one (6). Yield 83\%, 2.1 g. Off-white solid, mp $218-220{ }^{\circ} \mathrm{C}$ (Lit. ${ }^{47}$ 219-221 ${ }^{\circ} \mathrm{C}$ ). ${ }^{1} \mathrm{H}$ NMR (DMSO- $\left.d_{6}, 300 \mathrm{~Hz}\right): 7.57$ (2H,m, 2H, CH quina), $7.83\left(1 \mathrm{H}, \mathrm{td},{ }^{4} J=1.8\right.$ $\mathrm{Hz}$ and ${ }^{3} J=7.3 \mathrm{~Hz}, \mathrm{CH}$ quina), $8.09\left(1 \mathrm{H}, \mathrm{dd},{ }^{4} J=1.8 \mathrm{~Hz}\right.$ and ${ }^{3} J=7.7 \mathrm{~Hz}, \mathrm{CH}$ quina $), 13.25(1 \mathrm{H}$, s, $\mathrm{N} H) . \mathrm{C}_{8} \mathrm{H}_{5} \mathrm{ClN}_{2} \mathrm{O} ; \mathrm{MW}=180.59 \mathrm{~g} / \mathrm{mol}$.

General Procedure for synthesis of compounds 7 and 8. A mixture of 6 (1.8g, $0.01 \mathrm{~mol})$ and 2,2-diéthoxyethylamine ( $4.35 \mathrm{~mL}, 0.03 \mathrm{mmol})$ or 3,3-diethoxypropylamine $(4.85 \mathrm{~mL}, 0.03 \mathrm{~mol})$ is refluxed in ethanol $(35 \mathrm{~mL})$ for $4 \mathrm{~h}$. After cooling, the reaction mixture is filtered and the filtrate evaporated under vacuum. The residue is precipitated in water, filtered and recrystallized from ethanol.

2-(2,2-diéthoxyéthylamino)-3H-quinazolin-4-one (7). Yield 71\%, 2.0 g. Yellow solid, mp 176$178{ }^{\circ} \mathrm{C}$ (Lit. ${ }^{26} 174-180^{\circ} \mathrm{C}$ ). ${ }^{1} \mathrm{H}$ NMR (DMSO- $\left.d_{6}, 300 \mathrm{~Hz}\right): 1.12\left(6 \mathrm{H}, \mathrm{t},{ }^{3} \mathrm{~J}=7.5 \mathrm{~Hz}, \mathrm{CH}_{3}\right), 3.44$ $\left(2 \mathrm{H}, \mathrm{t},{ }^{3} \mathrm{~J}=5.5 \mathrm{~Hz}, \mathrm{CH}_{2}\right), 3.51\left(2 \mathrm{H}, \mathrm{m}, \mathrm{OCH}_{2}\right), 3.67\left(2 \mathrm{H}, \mathrm{m}, \mathrm{OCH}_{2}\right), 4.64\left(1 \mathrm{H}, \mathrm{t},{ }^{3} J=5.5 \mathrm{~Hz}\right.$, $\mathrm{CH}), 6.17(1 \mathrm{H}, \mathrm{s}, \mathrm{NH}), 7.10\left(1 \mathrm{H}, \mathrm{t},{ }^{3} J=7.8 \mathrm{~Hz}, \mathrm{C} H\right.$ quina), $7.22\left(1 \mathrm{H}, \mathrm{d},{ }^{3} J=8.65 \mathrm{~Hz}, \mathrm{CH}\right.$ quina), $7.56\left(1 \mathrm{H}, \mathrm{t},{ }^{3} J=7.8 \mathrm{~Hz}, \mathrm{CH}\right.$ quina), $7.87\left(1 \mathrm{H}, \mathrm{d},{ }^{3} J=7.8 \mathrm{~Hz}, \mathrm{CH}\right.$ quina), $10.80(1 \mathrm{H}, \mathrm{s}, \mathrm{CON} H)$. $\mathrm{C}_{14} \mathrm{H}_{19} \mathrm{~N}_{3} \mathrm{O}_{3} ; \mathrm{MW}=277.31 \mathrm{~g} / \mathrm{mol}$.

2-(3,3-diéthoxypropylamino)-3H-quinazolin-4-one (8). Yield 88\%, 2.55 g. Yellow solid, mp 99-101 ${ }^{\circ} \mathrm{C} .{ }^{1} \mathrm{H}$ NMR (DMSO- $\left.d_{6}, 300 \mathrm{~Hz}\right): 1.15\left(6 \mathrm{H}, \mathrm{t},{ }^{3} \mathrm{~J}=7.5 \mathrm{~Hz}, \mathrm{CH}_{3}\right), 1.72\left(2 \mathrm{H}, \mathrm{m}, \mathrm{CH}_{2}\right)$, $3.33\left(2 \mathrm{H}, \mathrm{m}, \mathrm{NCH}_{2}\right), 3.46\left(2 \mathrm{H}, \mathrm{m}, \mathrm{OCH}_{2}\right), 3.65\left(2 \mathrm{H}, \mathrm{m}, \mathrm{OCH}_{2}\right), 4.59\left(1 \mathrm{H}, \mathrm{t},{ }^{3} J=5.5 \mathrm{~Hz}, \mathrm{CH}\right)$, 
$6.31(1 \mathrm{H}, \mathrm{s}, \mathrm{N} H), 7.08\left(1 \mathrm{H}, \mathrm{t},{ }^{3} J=8.2 \mathrm{~Hz}, \mathrm{C} H\right.$ quina), $7.22\left(1 \mathrm{H}, \mathrm{d},{ }^{3} J=8.0 \mathrm{~Hz}, \mathrm{C} H\right.$ quina), 7.55 $\left(1 \mathrm{H}, \mathrm{t},{ }^{3} J=7.15 \mathrm{~Hz}, \mathrm{CH}\right.$ quina), $7.86\left(1 \mathrm{H}, \mathrm{d},{ }^{3} J=7.8 \mathrm{~Hz}, \mathrm{CH}\right.$ quina), $10.10(1 \mathrm{H}, \mathrm{s}, \mathrm{N} H) ;{ }^{13} \mathrm{C}$ NMR (DMSO- $\left.d_{6}, 75 \mathrm{~Hz}\right): 15.8,33.4,36.8,61.2,101.1,117.8,122.0,125.0,126.3,134.6,150.9$, 151.5, 162.4. $\mathrm{C}_{15} \mathrm{H}_{21} \mathrm{~N}_{3} \mathrm{O}_{3}, \mathrm{MW}=291.34 \mathrm{~g} / \mathrm{mol} ; t_{\mathrm{R}, \mathrm{LCMS}}=1.73 \mathrm{~min} ; \mathrm{MS}(\mathrm{ESI}+): \mathrm{m} / \mathrm{z}=292$ $[\mathrm{M}+\mathrm{H}]+$.

General Procedure for synthesis of compounds 9 and 10. A solution of compound 7 (2.8 g, $0.01 \mathrm{~mol})$ or $8(2.9 \mathrm{~g}, 0.01 \mathrm{~mol})$ dissolved in sulfuric acid $(40 \mathrm{~mL})$ is stirred at room temperature for $12 \mathrm{~h}$. The reaction mixture is poured in ice, alkalinized with $10 \mathrm{~N}$ aqueous sodium hydroxide solution $(\mathrm{pH} 10)$ and then acidified with diluted acetic acid solution to $\mathrm{pH}$ 5. The resulting precipitate is filtered and recrystallized in ethanol.

1H-imidazo[2,1-b]quinazolin-5-one (9). Yield 60\%, $1.1 \mathrm{~g}$. Off-white solid, mp 300-301 ${ }^{\circ} \mathrm{C}$ (Lit. $\left.{ }^{26} 281-284{ }^{\circ} \mathrm{C}\right) .{ }^{1} \mathrm{H}$ NMR (DMSO- $\left.d_{6}, 300 \mathrm{~Hz}\right): 7.14\left(1 \mathrm{H}, \mathrm{td},{ }^{4} J=1.1 \mathrm{~Hz}\right.$ and ${ }^{3} J=6.9 \mathrm{~Hz}, \mathrm{CH}$ quina), $7.32\left(1 \mathrm{H}, \mathrm{d},{ }^{3} J=2.25 \mathrm{~Hz}, \mathrm{CH}\right), 7.42\left(1 \mathrm{H}, \mathrm{d},{ }^{3} J=8.65 \mathrm{~Hz}, \mathrm{CH}\right.$ quina), $7.57\left(1 \mathrm{H}, \mathrm{d},{ }^{3} J=\right.$ $2.25 \mathrm{~Hz}, \mathrm{NCH}), 7.63\left(1 \mathrm{H}, \mathrm{td},{ }^{4} J=1.6 \mathrm{~Hz}\right.$ and ${ }^{3} J=8.65 \mathrm{~Hz}, \mathrm{CH}$ quina), $8.11\left(1 \mathrm{H}, \mathrm{dd},{ }^{4} J=1.6 \mathrm{~Hz}\right.$ and ${ }^{3} J=8.25 \mathrm{~Hz}, \mathrm{CH}$ quina), $9.32(1 \mathrm{H}, \mathrm{s}, \mathrm{N} H) .{ }^{13} \mathrm{C}$ NMR (DMSO- $\left.d_{6}, 75 \mathrm{~Hz}\right): 106.7,112.6$, $121.1,122.4,124.1,127.1,134.2,146.0,146.9,157.7 . \mathrm{C}_{10} \mathrm{H}_{7} \mathrm{~N}_{3} \mathrm{O}, \mathrm{MW}=185.18 \mathrm{~g} / \mathrm{mol} ; t_{\mathrm{R}, \mathrm{LCMS}}=$ $1.43 \mathrm{~min} ; \mathrm{MS}(\mathrm{ESI}+): \mathrm{m} / \mathrm{z}=186[\mathrm{M}+\mathrm{H}]+$.

1,2-dihydro-1H-pyrimidino[2,1-b]quinazolin-6-one (10). Yield 89\%, $1.75 \mathrm{~g}$. Yellow solid, mp $>400{ }^{\circ} \mathrm{C} .{ }^{1} \mathrm{H}$ NMR (DMSO-d $\left.6,300 \mathrm{~Hz}\right): 4.03(2 \mathrm{H}, \mathrm{m}, \mathrm{CH}), 5.58(1 \mathrm{H}, \mathrm{m}, \mathrm{CH}), 7.07\left(1 \mathrm{H}, \mathrm{td},{ }^{4} J=\right.$ $1.1 \mathrm{~Hz}$ and ${ }^{3} J=7.05 \mathrm{~Hz}, \mathrm{CH}$ quina), $7.15\left(1 \mathrm{H}, \mathrm{dd},{ }^{4} J=1.1 \mathrm{~Hz}\right.$ and ${ }^{3} J=8.25 \mathrm{~Hz}, \mathrm{C} H$ quina), 7.32 $\left(1 \mathrm{H}, \mathrm{dd},{ }^{4} J=2.05 \mathrm{~Hz}\right.$ and $\left.{ }^{3} J=8.5 \mathrm{~Hz}, \mathrm{NCH}\right), 7.54\left(1 \mathrm{H}, \mathrm{td},{ }^{4} J=1.75 \mathrm{~Hz}\right.$ and ${ }^{3} J=8.15 \mathrm{~Hz}, \mathrm{CH}$ quina), $7.69(1 \mathrm{H}, \mathrm{s}, \mathrm{N} H), 7.86\left(1 \mathrm{H}, \mathrm{dd},{ }^{4} J=1.65 \mathrm{~Hz}\right.$ and ${ }^{3} J=7.85 \mathrm{~Hz}, \mathrm{CH}$ quina). ${ }^{13} \mathrm{C}$ NMR 
(DMSO- $\left.d_{6}, 75 \mathrm{~Hz}\right): 39.8,110.0,116.7,119.3,122.1,124.3,127.1,135.1,148.2,150.3,158.6$.

$\mathrm{C}_{11} \mathrm{H}_{9} \mathrm{~N}_{3} \mathrm{O}, \mathrm{MW}=199.20 \mathrm{~g} / \mathrm{mol} ; t_{\mathrm{R}, \mathrm{LCMS}}=1.40 \mathrm{~min} ; \mathrm{MS}(\mathrm{ESI}+): \mathrm{m} / \mathrm{z}=200[\mathrm{M}+\mathrm{H}]+$.

General Procedure for synthesis of compounds 12b-d. To a stirred solution of methyltriphenylphosphonium iodide $(20.7 \mathrm{~g}, 0.051 \mathrm{~mol})$ in $\mathrm{THF}(100 \mathrm{~mL})$ at $0{ }^{\circ} \mathrm{C}$ was added potassium tert-butoxide $(8.5 \mathrm{~g}, 0.076 \mathrm{~mol})$, and the mixture was stirred for another $1 \mathrm{~h}$. Commercial available (11b-c) or synthesized ${ }^{48}(\mathbf{1 1 d})$ benzaldehyde $(0.026 \mathrm{~mol})$ in THF $(25 \mathrm{~mL})$ was added, and the reaction mixture was warmed to room temperature. After $24 \mathrm{~h}$, saturated aqueous ammonium chloride solution $(150 \mathrm{ml})$ was added, the aqueous layer was extracted with EtOAc $(3 \times 150 \mathrm{~mL})$, and the combined organic phase was washed with brine, dried over $\mathrm{Na}_{2} \mathrm{SO}_{4}$, and concentrated in vacuo. The resulting residue was purified by flash column chromatography on silica gel (DCM 100\%).

2-(3,4-dimethoxyphenyl)ethylene (12b). Yield 87\%, 3.7 g. Yellow oil. ${ }^{1} \mathrm{H}$ NMR $\left(\mathrm{CDCl}_{3}, 300\right.$ Hz): $3.90-3.92\left(6 \mathrm{H}, 2 \mathrm{~s}, \mathrm{OCH}_{3}\right), 5.16\left(1 \mathrm{H}, \mathrm{dd},{ }^{3} J=0.8 \mathrm{~Hz}\right.$ and $\left.{ }^{3} J=10.9 \mathrm{~Hz}, \mathrm{CH}\right), 5.63\left(1 \mathrm{H}, \mathrm{dd},{ }^{3} J\right.$ $=0.8 \mathrm{~Hz}$ and $\left.{ }^{2} J=17.5 \mathrm{~Hz}, \mathrm{CH}\right), 6.66\left(1 \mathrm{H}, \mathrm{dd},{ }^{3} J=10.9 \mathrm{~Hz}\right.$ and $\left.{ }^{2} J=17.5 \mathrm{~Hz}, \mathrm{CH}\right), 6.82(1 \mathrm{H}, \mathrm{d}$, $\left.{ }^{3} J=8.0 \mathrm{~Hz}, \operatorname{Ar} H\right), 6.94\left(1 \mathrm{H}, \mathrm{d},{ }^{4} J=1.85 \mathrm{~Hz}, \operatorname{Ar} H\right), 6.98\left(1 \mathrm{H}, \mathrm{dd},{ }^{4} J=1.85 \mathrm{~Hz}\right.$ and ${ }^{3} J=8.0 \mathrm{~Hz}$ ArH). $\mathrm{C}_{10} \mathrm{H}_{12} \mathrm{O}_{2} ; \mathrm{MW}=164.20 \mathrm{~g} / \mathrm{mol}$.

2-(3,4,5-trimethoxyphenyl)ethylene (12c). Yield 90\%, 4.5 g. Yellow oil. ${ }^{1} \mathrm{H}$ NMR $\left(\mathrm{CDCl}_{3}, 300\right.$ Hz): $3.90\left(9 \mathrm{H}, \mathrm{m}, 9 \mathrm{H}, \mathrm{OCH}_{3}\right), 5.23\left(1 \mathrm{H}, \mathrm{dd},{ }^{3} J=1.2 \mathrm{~Hz}\right.$ and $\left.{ }^{3} J=11.2 \mathrm{~Hz}, \mathrm{CH}\right), 5.67\left(1 \mathrm{H}, \mathrm{dd},{ }^{3} J\right.$ $=1.2 \mathrm{~Hz}$ and $\left.{ }^{2} J=18.0 \mathrm{~Hz}, \mathrm{CH}\right), 6.65(3 \mathrm{H}, \mathrm{m}, \mathrm{CH}, \mathrm{Ar} H) . \mathrm{C}_{11} \mathrm{H}_{14} \mathrm{O}_{3} ; \mathrm{MW}=194.22 \mathrm{~g} / \mathrm{mol}$.

2-(3-benzyloxy-4-methoxyphenyl)ethylene (12d). Yield 71\%, $4.4 \mathrm{~g}$. White solid, mp 67-69 ${ }^{\circ} \mathrm{C}$ (Lit. $\left.{ }^{49} 68-69^{\circ} \mathrm{C}\right) .{ }^{1} \mathrm{H} \mathrm{NMR}\left(\mathrm{CDCl}_{3}, 300 \mathrm{~Hz}\right): 3.85\left(3 \mathrm{H}, \mathrm{s}, \mathrm{OCH}_{3}\right), 5.08\left(1 \mathrm{H}, \mathrm{dd},{ }^{3} J=0.85 \mathrm{~Hz}\right.$ and $\left.{ }^{3} J=10.8 \mathrm{~Hz}, \mathrm{CH}\right), 5.25\left(2 \mathrm{H}, \mathrm{s}, \mathrm{OCH}_{2}\right), 5.51\left(1 \mathrm{H}, \mathrm{d},{ }^{3} J=0.85 \mathrm{~Hz}\right.$ and $\left.{ }^{2} J=11.75 \mathrm{~Hz}, \mathrm{CH}\right), 6.58$ $\left(1 \mathrm{H}, \mathrm{dd},{ }^{3} J=10.8 \mathrm{~Hz}\right.$ and $\left.{ }^{2} J=11.75 \mathrm{~Hz}, \mathrm{CH}\right), 6.82\left(1 \mathrm{H}, \mathrm{d},{ }^{3} J=8.3 \mathrm{~Hz}, \mathrm{Ar} H\right), 6.92\left(1 \mathrm{H}, \mathrm{dd},{ }^{4} J=\right.$ 
$1.8 \mathrm{~Hz}$ and $\left.{ }^{3} J=8.45 \mathrm{~Hz}, \mathrm{Ar} H\right), 6.99\left(1 \mathrm{H}, \mathrm{d},{ }^{4} J=1.8 \mathrm{~Hz}, \mathrm{Ar} H\right), 7.20-7.69$ (5H, m, ArH benz). $\mathrm{C}_{16} \mathrm{H}_{16} \mathrm{O}_{2} ; \mathrm{MW}=240.29 \mathrm{~g} / \mathrm{mol}$.

General Procedure for synthesis of compounds $\mathbf{1 3 b}$-d. To a stirred solution of $\mathbf{1 2 b - d}(0.012$ mol) in THF $(30 \mathrm{~mL})$ under a nitrogen atmosphere at $0{ }^{\circ} \mathrm{C}$ is added $\mathrm{BH}_{3} \cdot \mathrm{THF}(12 \mathrm{~mL}, 0.012$ $\mathrm{mol}, 1.0 \mathrm{~mol} / \mathrm{L}$ ), and the mixture is stirred for $3 \mathrm{~h}$ at room temperature. The reaction mixture is cooled to $0{ }^{\circ} \mathrm{C}$ and water $(1.7 \mathrm{~mL})$ is added under magnetic stirring for $10 \mathrm{~min}$ before addition of $10 \%$ aqueous sodium hydroxide solution $(15 \mathrm{~mL}, 0.0375 \mathrm{~mol})$ and $35 \% \mathrm{H}_{2} \mathrm{O}_{2}$ solution $(15 \mathrm{~mL})$. The reaction mixture is stirred for another $30 \mathrm{~min}$, quenched with saturated ammonium chloride solution $(100 \mathrm{~mL})$ and then extracted with diethyl ether $(3 \times 50 \mathrm{~mL})$. The combined organic phase was washed with brine, dried over $\mathrm{Na}_{2} \mathrm{SO}_{4}$, and concentrated in vacuo. The resulting residue was purified by flash column chromatography on silica gel (DCM 100\%).

2-(3,4-dimethoxyphenyl)ethanol (13b). Yield 87\%, 1.9 g. Clear oil. ${ }^{1} \mathrm{H} \mathrm{NMR}\left(\mathrm{CDCl}_{3}, 300 \mathrm{~Hz}\right)$ : $2.84\left(2 \mathrm{H}, \mathrm{t},{ }^{3} \mathrm{~J}=6.5 \mathrm{~Hz}, \mathrm{CH}_{2}\right), 3.84\left(2 \mathrm{H}, \mathrm{t},{ }^{3} J=6.6 \mathrm{~Hz}, \mathrm{CH}_{2}\right), 3.85\left(3 \mathrm{H}, \mathrm{s}, \mathrm{OCH}_{3}\right), 3.87(3 \mathrm{H}, \mathrm{s}$, $\left.\mathrm{OCH}_{3}\right), 6.75-6.83(3 \mathrm{H}, \mathrm{m}, \mathrm{ArH}) . \mathrm{C}_{10} \mathrm{H}_{14} \mathrm{O}_{3} ; \mathrm{MW}=182.21 \mathrm{~g} / \mathrm{mol}$.

2-(3,4,5-trimethoxyphenyl)ethanol (13c). Yield 77\%, 1.95 g. Clear oil. ${ }^{1} \mathrm{H} \mathrm{NMR}\left(\mathrm{CDCl}_{3}, 300\right.$ $\mathrm{Hz}): 2.81\left(2 \mathrm{H}, \mathrm{t},{ }^{3} \mathrm{~J}=6.5 \mathrm{~Hz}, \mathrm{CH}_{2}\right), 3.81\left(3 \mathrm{H}, \mathrm{s}, \mathrm{OCH}_{3}\right), 3.85\left(8 \mathrm{H}, \mathrm{m}, \mathrm{CH}_{2}, \mathrm{CH}_{3}\right), 6.44(2 \mathrm{H}, \mathrm{s}$, $\mathrm{ArH}) . \mathrm{C}_{11} \mathrm{H}_{16} \mathrm{O}_{4} ; \mathrm{MW}=212.24 \mathrm{~g} / \mathrm{mol}$.

2-(3-benzyloxy-4-methoxyphenyl)ethanol (13d). Yield 75\%, $2.3 \mathrm{~g}$. White solid, mp 42-44 ${ }^{\circ} \mathrm{C}$ (Lit. $\left.{ }^{50} 68-69^{\circ} \mathrm{C}\right) .{ }^{1} \mathrm{H}$ NMR $\left(\mathrm{CDCl}_{3}, 300 \mathrm{~Hz}\right): 2.76\left(2 \mathrm{H}, \mathrm{t},{ }^{3} \mathrm{~J}=6.5 \mathrm{~Hz}, \mathrm{CH}_{2}\right), 3.78\left(2 \mathrm{H}, \mathrm{t},{ }^{3} \mathrm{~J}=6.5\right.$ $\left.\mathrm{Hz}, \mathrm{CH}_{2}\right), 3.88\left(3 \mathrm{H}, \mathrm{s}, \mathrm{OCH}_{3}\right), 5.16\left(2 \mathrm{H}, \mathrm{s}, \mathrm{OCH}_{2}\right), 6.80(2 \mathrm{H}, \mathrm{m}, \mathrm{ArH}), 6.86\left(1 \mathrm{H}, \mathrm{d},{ }^{3} \mathrm{~J}=8.8 \mathrm{~Hz}\right.$, $\operatorname{Ar} H), 7.30-7.50$ (5H, m, ArH benz). $\mathrm{C}_{11} \mathrm{H}_{16} \mathrm{O}_{4} ; \mathrm{MW}=212.24 \mathrm{~g} / \mathrm{mol}$

General Procedure for synthesis of compounds 14a-d. A solution of methanesulfonyl chloride $(1 \mathrm{~mL}, 0.01 \mathrm{~mol})$ in DCM $(5 \mathrm{~mL})$ is added dropwise to a solution of the commercial 
available alcohol 13a or synthesized alcohol 13b-d $(0.005 \mathrm{~mol})$ and triethylamine $(1.7 \mathrm{~mL}$, $0.0125 \mathrm{~mol})$ in $\mathrm{DCM}(15 \mathrm{~mL})$ at $0{ }^{\circ} \mathrm{C}$ and stirred for $8 \mathrm{~h}$ at room temperature. The reaction mixture is first washed with $1 \mathrm{~N}$ aqueous hydrochloric acid solution $(10 \mathrm{~mL})$, then saturated sodium bicarbonate solution $(10 \mathrm{~mL})$ and finally water $(10 \mathrm{~mL})$. The organic layer is dried, filtered, concentrated in vacuo, and crystallized from cyclohexane.

2-(4-methoxyphenyl)ethylmethanesulfonate (14a). Yield 72\%, $0.8 \mathrm{~g}$. White solid, $\mathrm{mp} 35-36{ }^{\circ} \mathrm{C}$ $\left(\right.$ Lit. $\left.^{10} 35-36{ }^{\circ} \mathrm{C}\right) .{ }^{1} \mathrm{H} \mathrm{NMR}\left(\mathrm{CDCl}_{3}, 300 \mathrm{~Hz}\right): 2.82\left(3 \mathrm{H}, \mathrm{s}, \mathrm{OSO}_{2} \mathrm{CH}_{3}\right), 3.05\left(2 \mathrm{H}, \mathrm{t},{ }^{3} \mathrm{~J}=6.5 \mathrm{~Hz}\right.$, $\left.\mathrm{CH}_{2}\right), 3.80\left(3 \mathrm{H}, \mathrm{s}, \mathrm{OCH}_{3}\right), 4.38\left(2 \mathrm{H}, \mathrm{t},{ }^{3} J=6.5 \mathrm{~Hz}, \mathrm{CH}_{2}\right), 6.90\left(2 \mathrm{H}, \mathrm{d},{ }^{3} \mathrm{~J}=8.1 \mathrm{~Hz}, \mathrm{Ar} H\right), 7.15(2 \mathrm{H}, \mathrm{d}$, $\left.{ }^{3} J=8.1 \mathrm{~Hz}, \mathrm{Ar} H\right) \cdot \mathrm{C}_{10} \mathrm{H}_{14} \mathrm{O}_{4} \mathrm{~S} ; \mathrm{MW}=230.28 \mathrm{~g} / \mathrm{mol}$.

2-(3,4-dimethoxyphenyl)ethylmethanesulfonate (14b). Yield 76\%, $1.0 \mathrm{~g}$. White solid, mp 42$43^{\circ} \mathrm{C}$ (Lit. ${ }^{51}$ bp $168-169^{\circ} \mathrm{C}$ at $\left.0.2 \mathrm{~mm}\right) .{ }^{1} \mathrm{H}$ NMR $\left(\mathrm{CDCl}_{3}, 300 \mathrm{~Hz}\right): 2.89\left(3 \mathrm{H}, \mathrm{s}, \mathrm{OSO}_{2} \mathrm{CH}_{3}\right), 3.01$ $\left(2 \mathrm{H}, \mathrm{t},{ }^{3} J=6.5 \mathrm{~Hz}, \mathrm{CH}_{2}\right), 3.86\left(3 \mathrm{H}, \mathrm{s}, \mathrm{OCH}_{3}\right), 3.88\left(3 \mathrm{H}, \mathrm{s}, \mathrm{OCH}_{3}\right), 4.41\left(2 \mathrm{H}, \mathrm{t},{ }^{3} J=6.5 \mathrm{~Hz}, \mathrm{CH}_{2}\right)$, $6.76\left(1 \mathrm{H}, \mathrm{dd},{ }^{4} J=1.7 \mathrm{~Hz}\right.$ and $\left.{ }^{3} J=8.0 \mathrm{~Hz}, \operatorname{Ar} H\right), 6.80\left(1 \mathrm{H}, \mathrm{d},{ }^{3} J=1.7 \mathrm{~Hz}, \operatorname{Ar} H\right), 6.84\left(1 \mathrm{H}, \mathrm{d},{ }^{3} J=8.0\right.$ $\mathrm{Hz}, \mathrm{Ar} H) . \mathrm{C}_{11} \mathrm{H}_{16} \mathrm{O}_{5} \mathrm{~S} ; \mathrm{MW}=260.30 \mathrm{~g} / \mathrm{mol}$.

2-(3,4,5-trimethoxyphenyl)ethylmethanesulfonate (14c). Yield 83\%, $1.2 \mathrm{~g}$. White solid, mp 76$77^{\circ} \mathrm{C}\left(\mathrm{Lit}^{10}{ }^{10} 76-77^{\circ} \mathrm{C}\right) .{ }^{1} \mathrm{H}$ NMR $\left(\mathrm{CDCl}_{3}, 300 \mathrm{~Hz}\right): 3.02\left(3 \mathrm{H}, \mathrm{s}, \mathrm{OSO}_{2} \mathrm{CH}_{3}\right), 3.10\left(2 \mathrm{H}, \mathrm{t},{ }^{3} \mathrm{~J}=6.5\right.$ $\mathrm{Hz}), 3.85\left(3 \mathrm{H}, \mathrm{s}, \mathrm{OCH}_{3}\right), 3.88\left(6 \mathrm{H}, \mathrm{s}, \mathrm{OCH}_{3}\right), 4.43\left(2 \mathrm{H}, \mathrm{t},{ }^{3} \mathrm{~J}=6.5 \mathrm{~Hz}, \mathrm{CH}_{2}\right), 6.46(2 \mathrm{H}, \mathrm{s}, \operatorname{Ar} H)$. $\mathrm{C}_{12} \mathrm{H}_{18} \mathrm{O}_{6} \mathrm{~S} ; \mathrm{MW}=290.33 \mathrm{~g} / \mathrm{mol}$.

2-(3-benzyloxy-4-methoxyphenyl)ethylmethanesulfonate (14d). Yield 69\%, $1.2 \mathrm{~g}$. White solid, mp 95-97 ${ }^{\circ} \mathrm{C}\left(\mathrm{Lit}^{52}{ }^{2} 106-107^{\circ} \mathrm{C}\right) .{ }^{1} \mathrm{H} \mathrm{NMR}\left(\mathrm{CDCl}_{3}, 300 \mathrm{~Hz}\right): 2.78\left(3 \mathrm{H}, \mathrm{s}, \mathrm{OSO}_{2} \mathrm{CH}_{3}\right), 2.95(2 \mathrm{H}, \mathrm{t}$, $\left.{ }^{3} J=7.5 \mathrm{~Hz}, \mathrm{CH}_{2}\right), 3.89\left(3 \mathrm{H}, \mathrm{s}, \mathrm{OCH}_{3}\right), 4.34\left(2 \mathrm{H}, \mathrm{t},{ }^{3} J=7.5 \mathrm{~Hz}, \mathrm{CH}_{2}\right), 5.17\left(2 \mathrm{H}, \mathrm{s}, \mathrm{OCH}_{2}\right), 6.75-6.90$ (3H, m, $\mathrm{Ar} H$ ), 7.30-7.50 (5H, m, $\mathrm{Ar} H$ benz). $\mathrm{C}_{17} \mathrm{H}_{20} \mathrm{O}_{5} \mathrm{~S} ; \mathrm{MW}=336.40 \mathrm{~g} / \mathrm{mol}$.

General Procedure for synthesis of compounds 15a-d and 16a-d. A solution of compound 9 or $10(1 \mathrm{mmol})$ in anhydrous DMF $(5 \mathrm{~mL})$ is added dropwise at room temperature under nitrogen 
to a suspension of sodium hydride $(0.06 \mathrm{~g}, 1.5 \mathrm{mmol}, 60 \%$ dispersion in mineral oil) in anhydrous DMF $(5 \mathrm{~mL})$ and then stirred for $1 \mathrm{~h}$ at $60{ }^{\circ} \mathrm{C}$. A solution of synthesized arylalkyl methanesulfonate 14a-d $(1.5 \mathrm{mmol})$ in anhydrous DMF $(5 \mathrm{~mL})$ is added dropwise to the previous solution and stirred for $24 \mathrm{~h}$ at $60{ }^{\circ} \mathrm{C}$. The reaction mixture is cooled in an ice bath and hydrolyzed with water $(85 \mathrm{~mL})$. The resulting precipitate is filtered and recrystallized in EtOH/water (80/20).

N-[2-(4-methoxyphenyl)ethyl]imidazo[2,1-b]quinazolin-5-one (15a). Yield 23\%, $74 \mathrm{mg}$. White solid, mp 133-135 ${ }^{\circ} \mathrm{C} .{ }^{1} \mathrm{H}$ NMR $\left(\mathrm{CDCl}_{3}, 300 \mathrm{~Hz}\right): 3.13\left(2 \mathrm{H}, \mathrm{t},{ }^{3} \mathrm{~J}=7.4 \mathrm{~Hz}, \mathrm{CH}_{2}\right), 3.79(3 \mathrm{H}, \mathrm{s}$, $\left.\mathrm{OCH}_{3}\right), 4.34\left(2 \mathrm{H}, \mathrm{t},{ }^{3} J=7.5 \mathrm{~Hz}, \mathrm{CH}_{2}\right), 6.57\left(1 \mathrm{H}, \mathrm{d},{ }^{3} \mathrm{~J}=2.85 \mathrm{~Hz}, \mathrm{NCH}\right), 6.84\left(2 \mathrm{H}, \mathrm{d},{ }^{3} \mathrm{~J}=8.9 \mathrm{~Hz}\right.$, $\operatorname{Ar} H), 7.07\left(2 \mathrm{H}, \mathrm{d},{ }^{3} J=8.9 \mathrm{~Hz}, \operatorname{Ar} H\right), 7.28\left(1 \mathrm{H}, \mathrm{t},{ }^{3} J=7.6 \mathrm{~Hz}, \mathrm{CH}\right.$ quina), $7.45\left(1 \mathrm{H}, \mathrm{d},{ }^{3} J=2.7 \mathrm{~Hz}\right.$ $\mathrm{CONCH}), 7.65-7.72\left(2 \mathrm{H}, \mathrm{m}, \mathrm{CH}\right.$ quina), $8.37\left(1 \mathrm{H}, \mathrm{d},{ }^{3} \mathrm{~J}=8.15 \mathrm{~Hz}, \mathrm{CH}\right.$ quina) ${ }^{13} \mathrm{C} \mathrm{NMR}\left(\mathrm{CDCl}_{3}, 75\right.$ Hz): 34.4, 46.7, 55.2, 105.0, 114.2, 114.6, 119.2, 122.0, 125.5, 126.9, 129.5, 129.8, 134.0, 144.7, 150.0, 158.0, 158.6. $\mathrm{C}_{19} \mathrm{H}_{17} \mathrm{~N}_{3} \mathrm{O}_{2} ; \mathrm{MW}=319.35 \mathrm{~g} / \mathrm{mol} ; t_{\mathrm{R}, \mathrm{LCMS}}=2.38 \mathrm{~min} ; \mathrm{MS}(\mathrm{ESI}+): \mathrm{m} / \mathrm{z}=320$ $[\mathrm{M}+\mathrm{H}]+$. HPLC purity $98.3 \%$.

N-[2-(3,4-dimethoxyphenyl)ethyl]imidazo[2,1-b]quinazolin-5-one (15b). Yield 20\%, $69 \mathrm{mg}$. White solid, mp 160-162 ${ }^{\circ} \mathrm{C} .{ }^{1} \mathrm{H}$ NMR $\left(\mathrm{CDCl}_{3}, 300 \mathrm{~Hz}\right): 3.12\left(2 \mathrm{H}, \mathrm{t},{ }^{3} \mathrm{~J}=7.2 \mathrm{~Hz}, \mathrm{CH}_{2}\right), 3.82$ $\left(3 \mathrm{H}, \mathrm{s}, \mathrm{OCH}_{3}\right), 3.85\left(3 \mathrm{H}, \mathrm{s}, \mathrm{OCH}_{3}\right), 4.36\left(2 \mathrm{H}, \mathrm{t},{ }^{3} \mathrm{~J}=7.1 \mathrm{~Hz}, \mathrm{CH}\right), 6.59\left(1 \mathrm{H}, \mathrm{d},{ }^{3} J=2.5 \mathrm{~Hz}\right.$, $\mathrm{NCH}), 6.68(2 \mathrm{H}, \mathrm{m}, \mathrm{Ar} H), 6.78\left(1 \mathrm{H}, \mathrm{d},{ }^{3} J=8.75 \mathrm{~Hz}, \operatorname{Ar} H\right), 7.28\left(1 \mathrm{H}, \mathrm{t},{ }^{3} J=7.3 \mathrm{~Hz}, \mathrm{CH}\right.$ quina), $7.45\left(1 \mathrm{H}, \mathrm{d},{ }^{3} J=2.35 \mathrm{~Hz}, \mathrm{CONCH}\right), 7.63-7.73\left(2 \mathrm{H}, \mathrm{m}, \mathrm{CH}\right.$ quina), $8.36\left(1 \mathrm{H}, \mathrm{d},{ }^{3} J=8.0 \mathrm{~Hz}, \mathrm{CH}\right.$ quina). ${ }^{13} \mathrm{C} \mathrm{NMR}\left(\mathrm{CDCl}_{3}, 75 \mathrm{~Hz}\right): 34.8,46.5,55.9,105.0,111.3,111.8,114.6,119.2,120.9$, $122.0,125.5,126.9,129.9,134.0,144.7,147.9,149.1,150.0,157.9 . \mathrm{C}_{20} \mathrm{H}_{19} \mathrm{~N}_{3} \mathrm{O}_{3} ; \mathrm{MW}=349.38$ $\mathrm{g} / \mathrm{mol} ; t_{\mathrm{R}, \mathrm{LCMS}}=2.17 \mathrm{~min} ; \mathrm{MS}(\mathrm{ESI}+): \mathrm{m} / \mathrm{z}=350[\mathrm{M}+\mathrm{H}]+$. HPLC purity $99.4 \%$.

$N$-[2-(3,4,5-trimethoxyphenyl)ethyl]imidazo[2,1-b]quinazolin-5-one (15c). Yield 22\%, $83 \mathrm{mg}$. Off-white solid, mp 172-174 ${ }^{\circ} \mathrm{C} .{ }^{1} \mathrm{H}$ NMR $\left(\mathrm{CDCl}_{3}, 300 \mathrm{~Hz}\right): 3.12\left(2 \mathrm{H}, \mathrm{t},{ }^{3} J=7.2 \mathrm{~Hz}, \mathrm{CH}_{2}\right), 3.80$ 
$\left(9 \mathrm{H}, \mathrm{s}, \mathrm{OCH}_{3}\right), 4.39\left(2 \mathrm{H}, \mathrm{t},{ }^{3} J=7.1 \mathrm{~Hz}, \mathrm{CH}_{2}\right), 6.38(2 \mathrm{H}, \mathrm{s}, \mathrm{Ar} H), 6.67\left(1 \mathrm{H}, \mathrm{d},{ }^{3} J=2.6 \mathrm{~Hz}, \mathrm{NCH}\right)$ $7.29\left(1 \mathrm{H}, \mathrm{t},{ }^{3} J=7.5 \mathrm{~Hz}, \mathrm{CH}\right.$ quina), $7.50\left(1 \mathrm{H}, \mathrm{d},{ }^{3} J=2.6 \mathrm{~Hz}, \mathrm{CONCH}\right), 7.63-7.74(2 \mathrm{H}, \mathrm{m}, \mathrm{CH}$ quina), $8.36\left(1 \mathrm{H}, \mathrm{d},{ }^{3} J=7.5 \mathrm{~Hz}, \mathrm{CH}\right.$ quina). ${ }^{13} \mathrm{C} \mathrm{NMR}\left(\mathrm{CDCl}_{3}, 75 \mathrm{~Hz}\right): 35.7,46.2,56.1,60.9$, 105.2, 105.7, 114.6, 119.1, 122.1, 125.4, 127.0, 133.2, 134.1, 136.9, 144.8, 149.9, 153.4, 157.9. $\mathrm{C}_{21} \mathrm{H}_{21} \mathrm{~N}_{3} \mathrm{O}_{4} ; \mathrm{MW}=379.41 \mathrm{~g} / \mathrm{mol} ; t_{\mathrm{R}, \mathrm{LCMS}}=2.07 \mathrm{~min} ; \mathrm{MS}(\mathrm{ESI}+): \mathrm{m} / \mathrm{z}=380[\mathrm{M}+\mathrm{H}]+$ HPLC purity $99.1 \%$.

N-[2-(3-benzyloxy-4-methoxyphenyl)ethyl]imidazo[2,1-b]quinazolin-5-one (15d). Yield 26\%, 238 mg. Off-white solid, mp 104-106 ${ }^{\circ} \mathrm{C} .{ }^{1} \mathrm{H}$ NMR $\left(\mathrm{CDCl}_{3}, 300 \mathrm{~Hz}\right): 3.07\left(2 \mathrm{H}, \mathrm{t},{ }^{3} \mathrm{~J}=7.2 \mathrm{~Hz}\right.$, $\left.\mathrm{CH}_{2}\right), 3.87\left(3 \mathrm{H}, \mathrm{s}, \mathrm{OCH}_{3}\right), 4.28\left(2 \mathrm{H}, \mathrm{t},{ }^{3} J=7.2 \mathrm{~Hz}, \mathrm{CH}_{2}\right), 5.12\left(2 \mathrm{H}, \mathrm{s}, \mathrm{OCH}_{2}\right), 6.36\left(1 \mathrm{H}, \mathrm{d},{ }^{3} J=\right.$ $2.9 \mathrm{~Hz}, \mathrm{NCH}), 6.65\left(1 \mathrm{H}, \mathrm{dd},{ }^{4} J=1.8 \mathrm{~Hz}\right.$ and $\left.{ }^{3} J=8.1 \mathrm{~Hz}, \operatorname{Ar} H\right), 6.71\left(1 \mathrm{H}, \mathrm{d},{ }^{4} J=1.8 \mathrm{~Hz}, \operatorname{Ar} H\right)$, $6.79\left(1 \mathrm{H}, \mathrm{d},{ }^{3} J=8.12 \mathrm{~Hz}, \mathrm{Ar} H\right), 7.26-7.42(7 \mathrm{H}, \mathrm{m}, \mathrm{CONCH}, \mathrm{CH}$ quina, $\operatorname{Ar} H$ benz), $7.65(1 \mathrm{H}, \mathrm{d}$, ${ }^{3} J=7.4 \mathrm{~Hz}, \mathrm{CH}$ quina), $7.71\left(1 \mathrm{H}, \mathrm{td},{ }^{4} J=1.6 \mathrm{~Hz}\right.$ and ${ }^{3} J=6.8 \mathrm{~Hz}, \mathrm{CH}$ quina), $8.37\left(1 \mathrm{H}, \mathrm{dd},{ }^{4} J=\right.$ $1.3 \mathrm{~Hz}$ and ${ }^{3} \mathrm{~J}=8.4 \mathrm{~Hz}, \mathrm{CH}$ quina); ${ }^{13} \mathrm{C} \mathrm{NMR}\left(\mathrm{CDCl}_{3}, 75 \mathrm{~Hz}\right): 34.6,46.4,56.0,71.0,104.9$, 112.0, 114.6, 114.8, 119.2, 121.6, 122.0, 125.5, 126.9, 127.2, 127.9, 128.5, 129.8, 134.0, 137.0, 144.7, 148.0, 148.7, 150.0, 157.9. $\mathrm{C}_{26} \mathrm{H}_{23} \mathrm{~N}_{3} \mathrm{O}_{3} ; \mathrm{MW}=425.48 \mathrm{~g} / \mathrm{mol} ; t_{\mathrm{R}, \mathrm{LCMS}}=2.69 \mathrm{~min} ; \mathrm{MS}$ $(\mathrm{ESI}+): \mathrm{m} / \mathrm{z}=426[\mathrm{M}+\mathrm{H}]+$.

N-[2-(4-methoxyphenyl)ethyl]-1,2-dihydro-pyrimidino[2,1-b]quinazolin-6-one (16a). Yield 23\%, $77 \mathrm{mg}$. White solid, mp 114-116 ${ }^{\circ} \mathrm{C} .{ }^{1} \mathrm{H}$ NMR $\left(\mathrm{CDCl}_{3}, 300 \mathrm{~Hz}\right): 3.00\left(2 \mathrm{H}, \mathrm{t},{ }^{3} \mathrm{~J}=7.6 \mathrm{~Hz}\right.$, $\left.\mathrm{CH}_{2}\right), 3.80\left(5 \mathrm{H}, \mathrm{m}, \mathrm{CH}_{2}, \mathrm{OCH}_{3}\right), 4.01\left(2 \mathrm{H}, \mathrm{dd},{ }^{3} J=2.1 \mathrm{~Hz}\right.$ and $\left.{ }^{3} J=3.5 \mathrm{~Hz}, \mathrm{NCH}_{2}\right), 5.34(1 \mathrm{H}, \mathrm{td}$, ${ }^{3} J=3.5 \mathrm{~Hz}$ and $\left.{ }^{3} J=8.5 \mathrm{~Hz}, \mathrm{CH}_{2} \mathrm{CH}\right), 6.87\left(2 \mathrm{H}, \mathrm{d},{ }^{3} J=8.6 \mathrm{~Hz}, \mathrm{Ar} H\right), 7.13\left(1 \mathrm{H}, \mathrm{td},{ }^{4} J=1.05 \mathrm{~Hz}\right.$ and ${ }^{3} J=7.15 \mathrm{~Hz}, \mathrm{CH}$ quina), $7.22\left(2 \mathrm{H}, \mathrm{d},{ }^{3} J=8.6 \mathrm{~Hz}, \mathrm{Ar} H\right), 7.36\left(1 \mathrm{H}, \mathrm{d},{ }^{3} J=8.5 \mathrm{~Hz}, \mathrm{CONCH}\right)$, 7.49-7.59 (2H, m, CH quina), $8.07\left(1 \mathrm{H}, \mathrm{dd},{ }^{4} J=1.2 \mathrm{~Hz}\right.$ and ${ }^{3} J=7.9 \mathrm{~Hz}, \mathrm{CH}$ quina). ${ }^{13} \mathrm{C}$ NMR $\left(\mathrm{CDCl}_{3}, 75 \mathrm{~Hz}\right): 31.5,46.9,51.3,55.3,107.2,114.0,116.5,120.2,122.4,125.2,127.2,129.8$ 
131.2, 134.6, 146.2, $149.5,158.2,159.5 . \mathrm{C}_{20} \mathrm{H}_{19} \mathrm{~N}_{3} \mathrm{O}_{2}, \mathrm{MW}=333.38 \mathrm{~g} / \mathrm{mol} ; t_{\mathrm{R}, \mathrm{LCMS}}=2.93 \mathrm{~min}$ MS (ESI+): $\mathrm{m} / \mathrm{z}=334[\mathrm{M}+\mathrm{H}]+$. HPLC purity $97.9 \%$.

Yield 20\%, $72 \mathrm{mg}$. White solid, mp 144-146 ${ }^{\circ} \mathrm{C} .{ }^{1} \mathrm{H}$ NMR $\left(\mathrm{CDCl}_{3}, 300 \mathrm{~Hz}\right): 3.01\left(2 \mathrm{H}, \mathrm{t},{ }^{3} \mathrm{~J}=7.6\right.$ $\left.\mathrm{Hz}, \mathrm{CH}_{2}\right), 3.80-3.90\left(8 \mathrm{H}, \mathrm{m}, \mathrm{CH}_{2}, \mathrm{OCH}_{3}\right), 4.01\left(2 \mathrm{H}, \mathrm{dd},{ }^{3} \mathrm{~J}=2.0 \mathrm{~Hz}\right.$ and $\left.{ }^{3} J=3.3 \mathrm{~Hz}, \mathrm{NCH}_{2}\right)$, $5.35\left(1 \mathrm{H}, \mathrm{td},{ }^{3} J=3.5 \mathrm{~Hz}\right.$ and $\left.{ }^{3} J=7.7 \mathrm{~Hz}, \mathrm{CH}_{2} \mathrm{CH}\right), 6.82(3 \mathrm{H}, \mathrm{m}, \mathrm{Ar} H), 7.14\left(1 \mathrm{H}, \mathrm{t},{ }^{3} J=7.3 \mathrm{~Hz}\right.$, $\mathrm{CH}$ quina), $7.33\left(1 \mathrm{H}, \mathrm{d},{ }^{3} J=8.15 \mathrm{~Hz}, \mathrm{CH}\right.$ quina), 7.51-7.59 (2H, m, $\mathrm{CONCH}, \mathrm{CH}$ quina), 8.09 $\left(1 \mathrm{H}, \mathrm{d},{ }^{3} J=7.95 \mathrm{~Hz}, \mathrm{CH}\right.$ quina). ${ }^{13} \mathrm{C} \mathrm{NMR}\left(\mathrm{CDCl}_{3}, 75 \mathrm{~Hz}\right): 32.1,46.9,51.1,55.9,55.9,107.1$, $111.3,112.0,116.5,120.3,120.7,122.5,125.1,127.3,131.8,134.6,146.2,147.6,149.0,149.4$ $159.5 . \mathrm{C}_{21} \mathrm{H}_{21} \mathrm{~N}_{3} \mathrm{O}_{3}, \mathrm{MW}=363.41 \mathrm{~g} / \mathrm{mol} ; t_{\mathrm{R}, \mathrm{LCMS}}=2.65 \mathrm{~min} ; \mathrm{MS}(\mathrm{ESI}+): \mathrm{m} / \mathrm{z}=364[\mathrm{M}+\mathrm{H}]+$. HPLC purity $97.4 \%$.

$N$-[2-(3,4,5-trimethoxyphenyl)ethyl]-1,2-dihydro-pyrimidino[2,1-b] quinazolin-6-one (16c).

Yield 22\%, $86 \mathrm{mg}$. White solid, mp 156-158 ${ }^{\circ} \mathrm{C} .{ }^{1} \mathrm{H}$ NMR $\left(\mathrm{CDCl}_{3}, 300 \mathrm{~Hz}\right): 3.00\left(2 \mathrm{H}, \mathrm{t},{ }^{3} J=7.4\right.$ $\left.\mathrm{Hz}, \mathrm{CH}_{2}\right), 3.84\left(5 \mathrm{H}, \mathrm{m}, \mathrm{CH}_{2}, \mathrm{OCH}_{3}\right), 3.88\left(6 \mathrm{H}, \mathrm{s}, \mathrm{OCH}_{3}\right), 4.04\left(2 \mathrm{H}, \mathrm{dd},{ }^{3} J=1.95 \mathrm{~Hz}\right.$ and ${ }^{3} J=$ $\left.3.25 \mathrm{~Hz}, \mathrm{NCH}_{2}\right), 5.37\left(1 \mathrm{H}, \mathrm{td},{ }^{3} J=3.55 \mathrm{~Hz}\right.$ and $\left.{ }^{3} J=8.3 \mathrm{~Hz}, \mathrm{CH}_{2} \mathrm{CH}\right), 6.53(2 \mathrm{H}, \mathrm{s}, \mathrm{ArH}), 7.14$ $\left(1 \mathrm{H}, \mathrm{td},{ }^{4} J=1.0 \mathrm{~Hz}\right.$ and ${ }^{3} J=8.1 \mathrm{~Hz}, \mathrm{C} H$ quina), $7.32\left(1 \mathrm{H}, \mathrm{d},{ }^{3} J=8.1 \mathrm{~Hz}, \mathrm{C} H\right.$ quina), 7.51-7.60 (2H, m, CONCH, CH quina), $8.08\left(1 \mathrm{H}, \mathrm{dd},{ }^{4} J=1.15 \mathrm{~Hz}\right.$ and ${ }^{3} J=7.8 \mathrm{~Hz}, \mathrm{CH}$ quina). ${ }^{13} \mathrm{C}$ NMR $\left(\mathrm{CDCl}_{3}, 75 \mathrm{~Hz}\right): 32.9,46.9,50.9,56.1,60.9,105.6,107.1,116.5,120.3,122.5,125.0,127.3$, 134.7, 135.0, 136.5, 146.2, 149.4, 153.3, 159.5. $\mathrm{C}_{22} \mathrm{H}_{23} \mathrm{~N}_{3} \mathrm{O}_{4}, \mathrm{MW}=393.43 \mathrm{~g} / \mathrm{mol} ; t_{\mathrm{R}, \mathrm{LCMS}}=2.67$ $\min ;$ MS (ESI+): $\mathrm{m} / \mathrm{z}=394[\mathrm{M}+\mathrm{H}]+$. HPLC purity $97.7 \%$.

N-[2-(3-benzyloxy-4-methoxyphenyl)ethyl]-1,2-dihydro-pyrimidino[2,1-b]quinazolin-6-one (16d). Yield 26\%, $114 \mathrm{mg}$. White solid, mp 139-141 ${ }^{\circ} \mathrm{C} .{ }^{1} \mathrm{H}$ NMR $\left(\mathrm{CDCl}_{3}, 300 \mathrm{~Hz}\right): 2.94$ (2H, t, $\left.{ }^{3} J=7.6 \mathrm{~Hz}, \mathrm{CH}_{2}\right), 3.74\left(2 \mathrm{H}, \mathrm{t},{ }^{3} \mathrm{~J}=7.15 \mathrm{~Hz}, \mathrm{CH}_{2}\right), 3.88\left(5 \mathrm{H}, \mathrm{m}, \mathrm{NCH}_{2}, \mathrm{OCH}_{3}\right), 5.16(2 \mathrm{H}, \mathrm{s}$, 
$\left.\mathrm{OCH}_{2}\right), 5.29\left(1 \mathrm{H}, \mathrm{td},{ }^{3} J=3.5 \mathrm{~Hz}\right.$ and $\left.{ }^{3} J=7.15 \mathrm{~Hz}, \mathrm{CH}_{2} \mathrm{CH}\right), 6.84(3 \mathrm{H}, \mathrm{m}, \mathrm{Ar} H), 7.13\left(1 \mathrm{H}, \mathrm{t},{ }^{3} J=\right.$ 7.5 Hz, $\mathrm{CH}$ quina), 7.29-7.38 (4H, m, $\mathrm{CH}$ quina, $\mathrm{Ar} H$ benz), 7.42-7.50 (3H, m, $\mathrm{CONCH}, \operatorname{Ar} H$ benz), $7.56\left(1 \mathrm{H}, \mathrm{td},{ }^{4} J=1.45 \mathrm{~Hz}\right.$ and ${ }^{3} J=8.5 \mathrm{~Hz}, \mathrm{CH}$ quina $), 8.08\left(1 \mathrm{H}, \mathrm{dd},{ }^{4} J=1.25 \mathrm{~Hz}\right.$ and ${ }^{3} J=$ $7.9 \mathrm{~Hz}, \mathrm{CH}$ quina); ${ }^{13} \mathrm{C} \mathrm{NMR}\left(\mathrm{CDCl}_{3}, 75 \mathrm{~Hz}\right): 20.3,32.7,40.4,46.3,51.4,55.9,70.4,113.3$, 114.4, 116.2, 121.1, 121.6, 124.8, 126.6, 128.2, 128.8, 132.8, 134.4, 137.7, 146.6, 148.9, 149.5, 149.8, 161.9. $\mathrm{C}_{27} \mathrm{H}_{25} \mathrm{~N}_{3} \mathrm{O}_{3}, \mathrm{MW}=439.50 \mathrm{~g} / \mathrm{mol} ; t_{\mathrm{R}, \mathrm{LCMS}}=2.95 \mathrm{~min} ; \mathrm{MS}(\mathrm{ESI}+): \mathrm{m} / \mathrm{z}=440$ $[\mathrm{M}+\mathrm{H}]+$.

General Procedure for synthesis of compounds 15e and 16e. A solution of $15 \mathrm{~d}$ or $16 \mathrm{~d}(0.5$ $\mathrm{mmol})$ in a $33 \%$ solution of hydrobromic acid $(3 \mathrm{~mL})$ and glacial acetic acid $(5 \mathrm{~mL})$ is stirred at room temperature until starting material disappeared (followed by TLC). After cooling, the reaction mixture was diluted with water $(50 \mathrm{~mL})$ and the resulting precipitate was extracted with EtOAc $(3 \times 20 \mathrm{~mL})$. The organic layers were combined, washed with an aqueous $10 \% \mathrm{NaHCO}_{3}$ solution, dried $\left(\mathrm{MgSO}_{4}\right)$, and evaporated to give a white solid purified by recrystallization from ethanol.

N-[2-(3-hydroxy-4-methoxy-phenyl)ethyl] imidazo[2,1-b]quinazoline-5-one (15e). Yield 63\%, $105 \mathrm{mg}$. White solid, mp 133-135 ${ }^{\circ} \mathrm{C} .{ }^{1} \mathrm{H} \mathrm{NMR}\left(\mathrm{CDCl}_{3}, 300 \mathrm{~Hz}\right): 3.07\left(2 \mathrm{H}, \mathrm{t},{ }^{3} J=6.9 \mathrm{~Hz}, \mathrm{CH}_{2}\right)$, $3.84\left(3 \mathrm{H}, \mathrm{s}, \mathrm{OCH}_{3}\right), 4.32\left(2 \mathrm{H}, \mathrm{t},{ }^{3} J=6.95 \mathrm{~Hz}, \mathrm{CH}_{2}\right), 6.55\left(1 \mathrm{H}, \mathrm{dd},{ }^{4} J=2.05 \mathrm{~Hz}\right.$ and ${ }^{3} J=8.2 \mathrm{~Hz}$, $\operatorname{Ar} H), 6.59\left(1 \mathrm{H}, \mathrm{d},{ }^{4} J=2.7 \mathrm{~Hz}, \operatorname{Ar} H\right), 6.73\left(1 \mathrm{H}, \mathrm{d},{ }^{3} J=8.2 \mathrm{~Hz}, \operatorname{Ar} H\right), 6.79\left(1 \mathrm{H}, \mathrm{d},{ }^{3} J=2.05 \mathrm{~Hz}\right.$ $\mathrm{NCH}), 7.27\left(1 \mathrm{H}, \mathrm{m}, \mathrm{CH}\right.$ quina), $7.44\left(1 \mathrm{H}, \mathrm{d},{ }^{3} \mathrm{~J}=2.75 \mathrm{~Hz}, \mathrm{CONCH}\right), 7.63-7.72(2 \mathrm{H}, \mathrm{m}, \mathrm{CH}$ quina), $8.34\left(1 \mathrm{H}, \mathrm{dd},{ }^{4} J=1.15 \mathrm{~Hz}\right.$ and ${ }^{3} J=8.4 \mathrm{~Hz}, \mathrm{CH}$ quina) ${ }^{13} \mathrm{C} \mathrm{NMR}\left(\mathrm{CDCl}_{3}, 75 \mathrm{~Hz}\right): 34.6$, $46.5,55.9,105.0,110.9,114.6,114.9,119.2,120.3,121.9,125.6,126.9,130.6,133.9,144.7$, 145.7, $145.9,150.0,157.9 . \mathrm{C}_{19} \mathrm{H}_{17} \mathrm{~N}_{3} \mathrm{O}_{3}, \mathrm{MW}=335.35 \mathrm{~g} / \mathrm{mol} ; t_{\mathrm{R}, \mathrm{LCMS}}=2.01 \mathrm{~min} ; \mathrm{MS}(\mathrm{ESI}+)$ : $\mathrm{m} / \mathrm{z}=336[\mathrm{M}+\mathrm{H}]+$. HPLC purity $98.6 \%$. 
N-[2-(3-hydroxy,4-methoxyphenyl)ethyl]-1,2-dihydro-pyrimidino[2,1-b]quinazolin-6-one

(16e). Yield 56\%, $98 \mathrm{mg}$. White solid, mp 140-142 ${ }^{\circ} \mathrm{C} .{ }^{1} \mathrm{H}$ NMR $\left(\mathrm{CDCl}_{3}, 300 \mathrm{~Hz}\right): 2.96\left(2 \mathrm{H}, \mathrm{t},{ }^{3} \mathrm{~J}\right.$ $\left.\left.=7.7 \mathrm{~Hz}, \mathrm{CH}_{2}\right), 3.79\left(2 \mathrm{H}, \mathrm{t},{ }^{3} \mathrm{~J}=7.7 \mathrm{~Hz}, \mathrm{CH}_{2}\right), 3.89(3 \mathrm{H}, \mathrm{s}, \mathrm{OCH})_{3}\right), 4.03\left(2 \mathrm{H}, \mathrm{dd},{ }^{3} J=2.1 \mathrm{~Hz}\right.$ and ${ }^{3} \mathrm{~J}$ $\left.=3.4 \mathrm{~Hz}, \mathrm{NCH}_{2}\right), 5.35\left(1 \mathrm{H}, \mathrm{td},{ }^{3} J=3.4 \mathrm{~Hz}\right.$ and $\left.{ }^{3} J=8.4 \mathrm{~Hz}, \mathrm{CH}_{2} \mathrm{CH}\right), 5.63(1 \mathrm{H}, \mathrm{s}, \mathrm{OH}), 6.78(2 \mathrm{H}, \mathrm{m}$, $\operatorname{Ar} H), 6.91\left(1 \mathrm{H}, \mathrm{d},{ }^{3} J=1.8 \mathrm{~Hz}, \operatorname{Ar} H\right), 7.12\left(1 \mathrm{H}, \mathrm{td},{ }^{4} J=1.2 \mathrm{~Hz}\right.$ and ${ }^{3} J=8.15 \mathrm{~Hz}, \mathrm{CH}$ quina $), 7.36$ $\left(1 \mathrm{H}, \mathrm{dd},{ }^{4} J=1.2 \mathrm{~Hz}\right.$ and ${ }^{3} J=8.2 \mathrm{~Hz}, \mathrm{CH}$ quina), 7.49-7.59 (2H, m, CONCH, CH quina), 8.07 (1H, dd, ${ }^{4} J=1.6 \mathrm{~Hz}$ and ${ }^{3} J=8.25 \mathrm{~Hz}, \mathrm{CH}$ quina); ${ }^{13} \mathrm{C} \mathrm{NMR}\left(\mathrm{CDCl}_{3}, 75 \mathrm{~Hz}\right): 20.3,32.6,40.4,46.3,51.6$, 55.9, 113.3, 115.8, 116.1, 121.4, 121.6, 124.8, 126.6, 130.6, 134.4, 145.3, 147.9, 148.9, 149.8, 161.9. $\mathrm{C}_{20} \mathrm{H}_{19} \mathrm{~N}_{3} \mathrm{O}_{3}, \mathrm{MW}=349.38 \mathrm{~g} / \mathrm{mol} ; t_{\mathrm{R}, \mathrm{LCMS}}=2.17 \mathrm{~min} ; \mathrm{MS}(\mathrm{ESI}+): \mathrm{m} / \mathrm{z}=350[\mathrm{M}+\mathrm{H}]+$ HPLC purity $98.5 \%$.

General Procedure for synthesis of compounds 17a-d and 18a-d. A solution of 15a-d or 16ad $(0.5 \mathrm{mmol})$ in EtOH $(100 \mathrm{~mL})$ is stirred with $10 \% \mathrm{Pd} / \mathrm{C}$ catalyst and ammonium formate $(15$ $\mathrm{mmol}$ ) at $60^{\circ} \mathrm{C}$ until starting material disappeared (followed by TLC). The warm solution was filtered on a pad of celite and the filtrate was evaporated. The residue was recrystallized from methanol.

N-[2-(4-methoxyphenyl)ethyl]-2,3-dihydro-imidazo-[2,1-b]quinazolin-5-one (17a). Yield 65\%, $104 \mathrm{mg}$. White solid, mp 98-100 ${ }^{\circ} \mathrm{C} .{ }^{1} \mathrm{H}$ NMR (DMSO- $\left.d_{6}, 300 \mathrm{~Hz}\right): 2.85\left(2 \mathrm{H}, \mathrm{t},{ }^{3} \mathrm{~J}=7.45 \mathrm{~Hz}\right.$, $\left.\mathrm{CH}_{2}\right), 3.60\left(4 \mathrm{H}, \mathrm{m}, \mathrm{NCH}_{2}\right), 3.71\left(3 \mathrm{H}, \mathrm{s}, \mathrm{OCH}_{3}\right), 4.02\left(2 \mathrm{H}, \mathrm{t},{ }^{3} J=7.9 \mathrm{~Hz}, \mathrm{CH}_{2}\right), 6.87\left(2 \mathrm{H}, \mathrm{d},{ }^{3} J=8.9\right.$ $\mathrm{Hz}, \operatorname{Ar} H), 7.12\left(1 \mathrm{H}, \mathrm{t},{ }^{3} J=7.45, \mathrm{CH}\right.$ quina), $7.22\left(2 \mathrm{H}, \mathrm{d},{ }^{3} J=8.9 \mathrm{~Hz}, \operatorname{Ar} H\right), 7.29\left(1 \mathrm{H}, \mathrm{d},{ }^{3} J=7.9 \mathrm{~Hz}\right.$, $\mathrm{C} H$ quina), $7.57\left(1 \mathrm{H}, \mathrm{t},{ }^{3} J=8.4 \mathrm{~Hz}, \mathrm{C} H\right.$ quina), $7.92\left(1 \mathrm{H}, \mathrm{d},{ }^{3} J=7.95 \mathrm{~Hz}, \mathrm{CH}\right.$ quina). ${ }^{13} \mathrm{C}$ NMR (DMSO- $d_{6}, 75$ Hz): $32.2,44.8,46.1,55.4,114.3,117.8,122.3,125.0,126.2,130.1,131.2,134.4$, 151.3, 153.0, 158.2, 160.6. $\mathrm{C}_{19} \mathrm{H}_{19} \mathrm{~N}_{3} \mathrm{O}_{2}, \mathrm{MW}=321.37 \mathrm{~g} / \mathrm{mol} ; t_{\mathrm{R}, \mathrm{LCMS}}=2.21 \mathrm{~min} ; \mathrm{MS}(\mathrm{ESI}+$ ): $\mathrm{m} / \mathrm{z}=322[\mathrm{M}+\mathrm{H}]+$. HPLC purity $99.0 \%$. 
N-[2-(3,4-dimethoxyphenyl)ethyl]-2,3-dihydro-imidazo-[2,1-b]quinazolin-5-one (17b). Yield 53\%, $93 \mathrm{mg}$. White solid, mp $84-86{ }^{\circ} \mathrm{C} .{ }^{1} \mathrm{H}$ NMR $\left(\mathrm{CDCl}_{3}, 300 \mathrm{~Hz}\right): 2.95\left(2 \mathrm{H}, \mathrm{t},{ }^{3} \mathrm{~J}=7.45 \mathrm{~Hz}\right.$, $\left.\mathrm{CH}_{2}\right), 3.53\left(2 \mathrm{H}, \mathrm{t},{ }^{3} J=8.6 \mathrm{~Hz}, \mathrm{NC} H_{2}\right), 3.75\left(2 \mathrm{H}, \mathrm{t},{ }^{3} J=6.85 \mathrm{~Hz}, \mathrm{NCH} H_{2}\right), 3.86\left(3 \mathrm{H}, \mathrm{s}, \mathrm{OCH}_{3}\right), 3.87$ $\left(3 \mathrm{H}, \mathrm{s}, \mathrm{OCH} \mathrm{O}_{3}\right), 4.10\left(2 \mathrm{H}, \mathrm{t},{ }^{3} J=8.05 \mathrm{~Hz}, \mathrm{CH}_{2}\right), 6.81(3 \mathrm{H}, \mathrm{m}, \mathrm{Ar} H), 7.16\left(1 \mathrm{H}, \mathrm{td},{ }^{4} J=1.15 \mathrm{~Hz}\right.$ and ${ }^{3} J$ $=8.05 \mathrm{~Hz}, \mathrm{C} H$ quina), $7.39\left(1 \mathrm{H}, \mathrm{dd},{ }^{4} J=0.65 \mathrm{~Hz}\right.$ and ${ }^{3} J=8.2 \mathrm{~Hz}, \mathrm{CH}$ quina), $7.57\left(1 \mathrm{H}, \mathrm{td},{ }^{4} J=1.6\right.$ $\mathrm{Hz}$ and ${ }^{3} J=8.45 \mathrm{~Hz}, \mathrm{CH}$ quina), $8.11\left(1 \mathrm{H}, \mathrm{dd},{ }^{4} J=1.25 \mathrm{~Hz}\right.$ and ${ }^{3} J=7.9 \mathrm{~Hz}, \mathrm{C} H$ quina $) .{ }^{13} \mathrm{C}$ NMR $\left(\mathrm{CDCl}_{3}, 75 \mathrm{~Hz}\right): 33.2,40.4,45.1,46.0,55.9,111.3,111.8,117.7,120.7,122.5,124.8,126.5$, 131.1, 134.3, 147.7, 149.1, 150.9, 152.4, 161.3. $\mathrm{C}_{20} \mathrm{H}_{21} \mathrm{~N}_{3} \mathrm{O}_{3}, \mathrm{MW}=351.40 \mathrm{~g} / \mathrm{mol} ; t_{\mathrm{R}, \mathrm{LCMS}}=2.05$ $\min (98.9 \%) ; \mathrm{MS}(\mathrm{ESI}+): \mathrm{m} / \mathrm{z}=352[\mathrm{M}+\mathrm{H}]+$. HPLC purity $97.9 \%$.

$N$-[2-(3,4,5-trimethoxyphenyl)ethyl]-2,3-dihydro-imidazo-[2,1-b]quinazolin-5-one (17c). Yield 52\%, 93 mg. White solid, mp 144-146 ${ }^{\circ} \mathrm{C} .{ }^{1} \mathrm{H}$ NMR $\left(\mathrm{CDCl}_{3}, 300 \mathrm{~Hz}\right): 2.96\left(2 \mathrm{H}, \mathrm{t},{ }^{3} \mathrm{~J}=7.4 \mathrm{~Hz}\right.$, $\left.\mathrm{CH}_{2}\right), 3.59\left(2 \mathrm{H}, \mathrm{t},{ }^{3} \mathrm{~J}=8.2 \mathrm{~Hz}, \mathrm{NCH} \mathrm{N}_{2}\right), 3.78\left(2 \mathrm{H}, \mathrm{t},{ }^{3} \mathrm{~J}=7.4 \mathrm{~Hz}, \mathrm{NCH} \mathrm{N}_{2}\right), 3.82\left(3 \mathrm{H}, \mathrm{s}, \mathrm{OCH}_{3}\right), 3.85$ $\left(6 \mathrm{H}, \mathrm{s}, \mathrm{OCH}_{3}\right), 4.14\left(2 \mathrm{H}, \mathrm{t},{ }^{3} J=8.2 \mathrm{~Hz}, \mathrm{CH}_{2}\right), 6.52(2 \mathrm{H}, \mathrm{s}, \mathrm{Ar} H), 7.18\left(1 \mathrm{H}, \mathrm{t},{ }^{3} J=7.75 \mathrm{~Hz}, \mathrm{CH}\right.$ quina), $7.40\left(1 \mathrm{H}, \mathrm{d},{ }^{3} J=8.1 \mathrm{~Hz}, \mathrm{CH}\right.$ quina), $7.58\left(1 \mathrm{H}, \mathrm{t},{ }^{3} J=7.1 \mathrm{~Hz}, \mathrm{C} H\right.$ quina $), 8.13\left(1 \mathrm{H}, \mathrm{d},{ }^{3} J=\right.$ $7.75 \mathrm{~Hz}, \mathrm{CH}$ quina). ${ }^{13} \mathrm{C} \mathrm{NMR}\left(\mathrm{CDCl}_{3}, 75 \mathrm{~Hz}\right): 33.9,40.4,45.0,45.7,56.2,60.9,105.5,117.7$, $122.6,124.8,126.5,134.2,134.3,150.9,152.4,153.3,161.3 . \mathrm{C}_{21} \mathrm{H}_{23} \mathrm{~N}_{3} \mathrm{O}_{4}, \mathrm{MW}=381.42 \mathrm{~g} / \mathrm{mol}$; $t_{\mathrm{R}, \mathrm{LCMS}}=2.05 \min (95.6 \%) ; \mathrm{MS}(\mathrm{ESI}+): \mathrm{m} / \mathrm{z}=382[\mathrm{M}+\mathrm{H}]+$. HPLC purity $95.9 \%$.

N-[2-(3-hydroxy-4-méthoxy-phényl)éthyl]-2,3-dihydro-imidazo[2,1-b]quinazoline-5-one (17d). Yield 45\%, $151 \mathrm{mg}$. White solid, mp 210-212 ${ }^{\circ} \mathrm{C} .{ }^{1} \mathrm{H} \mathrm{NMR}\left(\mathrm{CDCl}_{3}, 300 \mathrm{~Hz}\right): 2.92\left(2 \mathrm{H}, \mathrm{t},{ }^{3} \mathrm{~J}=\right.$ $\left.7.05 \mathrm{~Hz}, \mathrm{CH}_{2}\right), 3.53\left(2 \mathrm{H}, \mathrm{t},{ }^{3} J=8.5 \mathrm{~Hz}, \mathrm{NCH}_{2}\right), 3.72\left(2 \mathrm{H}, \mathrm{t},{ }^{3} J=7.05 \mathrm{~Hz}, \mathrm{NCH}_{2}\right), 3.87(3 \mathrm{H}, \mathrm{s}$, $\left.\mathrm{OCH}_{3}\right), 4.11\left(2 \mathrm{H}, \mathrm{t},{ }^{3} J=7.5 \mathrm{~Hz}, \mathrm{CH}_{2}\right), 5.77(1 \mathrm{H}, \mathrm{s}, \mathrm{OH}), 6.74\left(1 \mathrm{H}, \mathrm{dd},{ }^{4} J=2.05 \mathrm{~Hz}\right.$ and ${ }^{3} J=8.2$ $\mathrm{Hz}, \operatorname{Ar} H), 6.80\left(1 \mathrm{H}, \mathrm{d},{ }^{3} J=8.2 \mathrm{~Hz}, \operatorname{Ar} H\right), 6.88\left(1 \mathrm{H}, \mathrm{d},{ }^{4} J=2.05 \mathrm{~Hz}, \operatorname{Ar} H\right), 7.17\left(1 \mathrm{H}, \mathrm{td},{ }^{4} J=1.15\right.$ $\mathrm{Hz}$ and ${ }^{3} J=7.15 \mathrm{~Hz}, \mathrm{CH}$ quina), $7.41\left(1 \mathrm{H}, \mathrm{dd},{ }^{4} J=0.6 \mathrm{~Hz}\right.$ and ${ }^{3} J=8.3 \mathrm{~Hz}, \mathrm{CH}$ quina), $7.58(1 \mathrm{H}$, td, ${ }^{4} J=1.5 \mathrm{~Hz}$ and ${ }^{3} J=7.1 \mathrm{~Hz}, \mathrm{C} H$ quina $), 8.12\left(1 \mathrm{H}, \mathrm{dd},{ }^{4} J=1.15 \mathrm{~Hz}\right.$ and ${ }^{3} J=7.95 \mathrm{~Hz}, \mathrm{CH}$ quina $) .{ }^{13} \mathrm{C}$ 
NMR $\left(\mathrm{CDCl}_{3}, 75 \mathrm{~Hz}\right): 33.1,40.4,45.2,46.2,55.9,110.8,114.9,117.8,120.1,122.4,124.9$,

$126.4,131.9,134.2,145.4,145.7,151.0,152.4,161.3 . \mathrm{C}_{15} \mathrm{H}_{19} \mathrm{~N}_{3} \mathrm{O}_{3} ; \mathrm{MW}=337.37 \mathrm{~g} / \mathrm{mol} ; t_{\mathrm{R}, \mathrm{LCMS}}$ $=1.87 \mathrm{~min}(96.6 \%) ; \mathrm{MS}(\mathrm{ESI}+): \mathrm{m} / \mathrm{z}=338[\mathrm{M}+\mathrm{H}]+$. HPLC purity $98.4 \%$.

N-[2-(4-methoxyphenyl)ethyl]-1,2,3,4-tetrahydro-pyrimidino[2,1-b]quinazolin-6-one

$(18 a)$.

Yield 69\%, $115 \mathrm{mg}$. White solid, mp 242-244 ${ }^{\circ} \mathrm{C} .{ }^{1} \mathrm{H} \mathrm{NMR}\left(\mathrm{CDCl}_{3}, 300 \mathrm{~Hz}\right): 1.97\left(2 \mathrm{H}, \mathrm{m}, \mathrm{CH}_{2}\right)$, $2.99\left(2 \mathrm{H}, \mathrm{t},{ }^{3} J=7.5 \mathrm{~Hz}, \mathrm{NCH}\right)_{2}, 3.26\left(2 \mathrm{H}, \mathrm{t},{ }^{3} J=6.9 \mathrm{~Hz}, \mathrm{NCH}\right), 3.80\left(3 \mathrm{H}, \mathrm{s}, \mathrm{OCH}_{3}\right), 3.86\left(2 \mathrm{H}, \mathrm{t},{ }^{3} J\right.$ $\left.=7.1 \mathrm{~Hz}, \mathrm{CH}_{2}\right), 4.05\left(2 \mathrm{H}, \mathrm{t},{ }^{2} J=6.8 \mathrm{~Hz}, \mathrm{CH}_{2}\right), 6.85\left(2 \mathrm{H}, \mathrm{d},{ }^{3} J=8.65 \mathrm{~Hz}, \mathrm{Ar} H\right), 7.11\left(1 \mathrm{H}, \mathrm{td},{ }^{4} J=1.3\right.$ $\mathrm{Hz}$ and ${ }^{3} J=7.1 \mathrm{~Hz}, \mathrm{C} H$ quina), $7.18\left(2 \mathrm{H}, \mathrm{d},{ }^{3} J=8.4 \mathrm{~Hz}, \mathrm{Ar} H\right), 7.36\left(1 \mathrm{H}, \mathrm{dd},{ }^{4} J=0.5 \mathrm{~Hz}\right.$ and ${ }^{3} J=8.3$ $\mathrm{Hz}, \mathrm{C} H$ quina), $7.57\left(1 \mathrm{H}, \mathrm{td},{ }^{4} J=1.6 \mathrm{~Hz}\right.$ and ${ }^{3} J=7.0 \mathrm{~Hz}, \mathrm{CH}$ quina), $8.09\left(1 \mathrm{H}, \mathrm{dd},{ }^{4} J=1.15 \mathrm{~Hz}\right.$ and ${ }^{3} J=8.0 \mathrm{~Hz}, \mathrm{CH}$ quina). ${ }^{13} \mathrm{C} \mathrm{NMR}\left(\mathrm{CDCl}_{3}, 75 \mathrm{~Hz}\right): 20.7,32.5,40.0,47.0,52.2,55.3,113.9,116.3$, $121.7,124.7,126.8,129.9,131.4,134.1,148.3,149.6,158.2,162.7 . \mathrm{C}_{20} \mathrm{H}_{21} \mathrm{~N}_{3} \mathrm{O}_{2} ; \mathrm{MW}=335.39$ $\mathrm{g} / \mathrm{mol} ; t_{\mathrm{R}, \mathrm{LCMS}}=2.59 \mathrm{~min}(96.7 \%) ; \mathrm{MS}(\mathrm{ESI}+): \mathrm{m} / \mathrm{z}=336[\mathrm{M}+\mathrm{H}]+$. HPLC purity $99.1 \%$.

N-[2-(3,4-dimethoxyphenyl)ethyl]-1,2,3,4-tetrahydro-pyrimidino[2,1-b]quinazolin-6-one

(18b). Yield 52\%, $95 \mathrm{mg}$. White solid, mp 132-134 ${ }^{\circ} \mathrm{C} .{ }^{1} \mathrm{H}$ NMR $\left(\mathrm{CDCl}_{3}, 300 \mathrm{~Hz}\right): 1.98(2 \mathrm{H}, \mathrm{m}$, $\left.\mathrm{CH}_{2}\right), 2.99\left(2 \mathrm{H}, \mathrm{t},{ }^{3} \mathrm{~J}=7.5 \mathrm{~Hz}, \mathrm{NCH}_{2}\right), 3.26\left(2 \mathrm{H}, \mathrm{t},{ }^{3} \mathrm{~J}=5.8 \mathrm{~Hz}, \mathrm{NCH}_{2}\right), 3.87-3.91\left(8 \mathrm{H}, \mathrm{m}, \mathrm{CH}_{2}\right.$, $\left.O C \mathrm{H}_{3}\right), 4.04\left(2 \mathrm{H}, \mathrm{t},{ }^{2} J=5.85 \mathrm{~Hz}, \mathrm{CH}_{2}\right), 6.68(3 \mathrm{H}, \mathrm{m}, \mathrm{Ar} H), 7.11\left(1 \mathrm{H}, \mathrm{td},{ }^{4} J=1.1 \mathrm{~Hz}\right.$ and ${ }^{3} J=8.0$ $\mathrm{Hz}, \mathrm{C} H$ quina), $7.34\left(1 \mathrm{H}, \mathrm{d},{ }^{3} J=8.15 \mathrm{~Hz}, \mathrm{CH}\right.$ quina), $7.56\left(1 \mathrm{H}, \mathrm{td},{ }^{4} J=1.6 \mathrm{~Hz}\right.$ and ${ }^{3} J=8.3 \mathrm{~Hz}$, $\mathrm{CH}$ quina), 8.09 (1H, dd, ${ }^{4} J=1.5 \mathrm{~Hz}$ and ${ }^{3} J=8.0 \mathrm{~Hz}, \mathrm{CH}$ quina). ${ }^{13} \mathrm{C} \mathrm{NMR}\left(\mathrm{CDCl}_{3}, 75 \mathrm{~Hz}\right): 20.7$, 33.0, 40.0, 46.9, 51.9, 55.8, 55.9, 111.2, 112.1, 116.3, 120.9, 121.7, 124.6, 126.8, 132.0, 134.1, $147.6,148.3,148.9,149.6,162.6 . \mathrm{C}_{21} \mathrm{H}_{23} \mathrm{~N}_{3} \mathrm{O}_{3} ; \mathrm{MW}=365.42 \mathrm{~g} / \mathrm{mol} ; t_{\mathrm{R}, \mathrm{LCMS}}=2.38 \mathrm{~min}(98.2 \%)$; MS (ESI+): $\mathrm{m} / \mathrm{z}=366[\mathrm{M}+\mathrm{H}]+$. HPLC purity $98.5 \%$.

N-[2-(3,4,5-trimethoxyphenyl)ethyl]-1,2,3,4-tetrahydro-pyrimidino[2,1-b]quinazolin-6-one (18c). Yield 43\%, $85 \mathrm{mg}$. White solid, mp 136-138 ${ }^{\circ} \mathrm{C} .{ }^{1} \mathrm{H}$ NMR $\left(\mathrm{CDCl}_{3}, 300 \mathrm{~Hz}\right): 2.01(2 \mathrm{H}, \mathrm{m}$, $\left.\mathrm{CH}_{2}\right), 2.99\left(2 \mathrm{H}, \mathrm{t},{ }^{3} \mathrm{~J}=7.45 \mathrm{~Hz}, \mathrm{NCH} \mathrm{N}_{2}\right), 3.31\left(2 \mathrm{H}, \mathrm{t},{ }^{3} \mathrm{~J}=5.8 \mathrm{~Hz}, \mathrm{NCH} \mathrm{N}_{2}\right), 3.82\left(3 \mathrm{H}, \mathrm{s}, \mathrm{OCH}_{3}\right), 3.84$ 
$\left(6 \mathrm{H}, \mathrm{s}, \mathrm{OCH}_{3}\right), 3.91\left(2 \mathrm{H}, \mathrm{t},{ }^{3} \mathrm{~J}=7.0 \mathrm{~Hz}, \mathrm{CH}_{2}\right), 4.06\left(2 \mathrm{H}, \mathrm{t},{ }^{3} \mathrm{~J}=5.95 \mathrm{~Hz}, \mathrm{CH}_{2}\right), 6.49(2 \mathrm{H}, \mathrm{s}, \mathrm{Ar} H)$, $7.11\left(1 \mathrm{H}, \mathrm{td},{ }^{4} J=1.15 \mathrm{~Hz}\right.$ and ${ }^{3} J=8.0 \mathrm{~Hz}, \mathrm{CH}$ quina $), 7.33\left(1 \mathrm{H}, \mathrm{d},{ }^{3} J=8.2 \mathrm{~Hz}, \mathrm{CH}\right.$ quina $), 7.56$ $\left(1 \mathrm{H}, \mathrm{td},{ }^{4} J=1.7 \mathrm{~Hz}\right.$ and ${ }^{3} J=8.45 \mathrm{~Hz}, \mathrm{CH}$ quina $), 8.09\left(1 \mathrm{H}, \mathrm{dd},{ }^{4} J=1.25 \mathrm{~Hz}\right.$ and ${ }^{3} J=8.0 \mathrm{~Hz}, \mathrm{CH}$ quina). ${ }^{13} \mathrm{C} \mathrm{NMR}\left(\mathrm{CDCl}_{3}, 75 \mathrm{~Hz}\right): 20.7,33.8,40.1,46.8,51.7,56.1,60.9,105.7,116.3,121.8$, $124.6,126.9,134.1,135.2,136.5,148.3,149.5,153.3,162.6 . \mathrm{C}_{22} \mathrm{H}_{25} \mathrm{~N}_{3} \mathrm{O}_{4} ; \mathrm{MW}=395.45 \mathrm{~g} / \mathrm{mol}$; $t_{\mathrm{R}, \mathrm{LCMS}}=2.38 \min (97.3 \%) ; \mathrm{MS}(\mathrm{ESI}+): \mathrm{m} / \mathrm{z}=396[\mathrm{M}+\mathrm{H}]+$. HPLC purity $98.1 \%$.

N-[2-(3-hydroxy-4-methoxyphenyl)ethyl]-1,2,3,4-tetrahydropyrimidino[2,1-b]quinazolin-6-one (18d). Yield 51\%, $89 \mathrm{mg}$. White solid, mp 153-155 ${ }^{\circ} \mathrm{C} .{ }^{1} \mathrm{H}$ NMR (DMSO- $\left.d_{6}, 300 \mathrm{~Hz}\right): 1.93$ (2H, m, $\left.\mathrm{CH}_{2}\right), 2.81\left(2 \mathrm{H}, \mathrm{t},{ }^{3} \mathrm{~J}=7.7 \mathrm{~Hz}, \mathrm{NCH}_{2}\right), 3.31\left(2 \mathrm{H}, \mathrm{t},{ }^{3} \mathrm{~J}=5.3 \mathrm{~Hz}, \mathrm{NCH}_{2}\right), 3.73\left(5 \mathrm{H}, \mathrm{m}, \mathrm{CH}_{2}\right.$, $\left.\mathrm{OCH}_{3}\right), 3.93\left(2 \mathrm{H}, \mathrm{t},{ }^{3} J=5.8 \mathrm{~Hz}, \mathrm{CH}_{2}\right), 6.65\left(1 \mathrm{H}, \mathrm{dd},{ }^{4} J=1.9 \mathrm{~Hz}\right.$ and $\left.{ }^{3} J=8.1 \mathrm{~Hz}, \mathrm{Ar} H\right), 6.73(1 \mathrm{H}$, $\left.\mathrm{d},{ }^{4} J=1.9 \mathrm{~Hz}, \operatorname{Ar} H\right), 6.84\left(1 \mathrm{H}, \mathrm{d},{ }^{3} J=8.3 \mathrm{~Hz}, \operatorname{Ar} H\right), 7.08\left(1 \mathrm{H}, \mathrm{t},{ }^{4} J=1.1 \mathrm{~Hz}\right.$ and ${ }^{3} J=8.1 \mathrm{~Hz}, \mathrm{CH}$ quina), $7.27\left(1 \mathrm{H}, \mathrm{dd},{ }^{4} J=1.1 \mathrm{~Hz}\right.$ and ${ }^{3} J=7.75 \mathrm{~Hz}, \mathrm{CH}$ quina), $7.57\left(1 \mathrm{H}, \mathrm{t},{ }^{4} J=1.6 \mathrm{~Hz}\right.$ and ${ }^{3} J=8.4$ $\mathrm{Hz}, \mathrm{CH}$ quina), $7.89\left(1 \mathrm{H}, \mathrm{dd},{ }^{4} J=1.15 \mathrm{~Hz}\right.$ and ${ }^{3} J=7.95 \mathrm{~Hz}, \mathrm{CH}$ quina $), 8.90(1 \mathrm{H}, \mathrm{s}, \mathrm{OH}) ;{ }^{13} \mathrm{C}$ NMR $\left(\mathrm{CDCl}_{3}, 75 \mathrm{~Hz}\right): 20.3,32.3,40.3,46.4,51.8,56.1,112.8,116.2,116.5,119.7,121.6$, $124.9,126.6,132.4,134.4,146.5,146.9,148.9,149.8,161.9 . \mathrm{C}_{20} \mathrm{H}_{21} \mathrm{~N}_{3} \mathrm{O}_{3} ; \mathrm{MW}=351.39 \mathrm{~g} / \mathrm{mol}$; $t_{\mathrm{R}, \mathrm{LCMS}}=2.10 \mathrm{~min}(99.2 \%) ; \mathrm{MS}(\mathrm{ESI}+): \mathrm{m} / \mathrm{z}=352[\mathrm{M}+\mathrm{H}]+$. HPLC purity $96.6 \%$.

General Procedure for synthesis of compounds 22 and 23. To a mixture of compound 20 or $21(0.02 \mathrm{~mol})$ and triethylamine $(5.6 \mathrm{~mL}, 0.04 \mathrm{~mol})$ in DCM $(200 \mathrm{~mL})$ is added under ice cooling and dropwise 2-nitrobenzenesulfonyl chloride 19 (3.5 g, $0.016 \mathrm{~mol})$ dissolved in DCM (50 mL) and the mixture is allowed to stir at room temperature for $2 \mathrm{~h}$. The reaction mixture is hydrolyzed, extracted with DCM (2 x $50 \mathrm{~mL})$ and washed with $10 \%$ aqueous sodium thiosulfate solution. The organic layers were combined, dried $\left(\mathrm{MgSO}_{4}\right)$, and evaporated to give a colorless solid purified by recrystallization from methanol. 
N-(2-nitrophenylsulfonyl)-2-methylsulfanyl-4,5-dihydro-imidazole (22). Yield 62\%, 3.0 g. Colorless solid, mp 184-185 ${ }^{\circ} \mathrm{C}\left(\mathrm{Lit}^{53}{ }^{53} 185-186{ }^{\circ} \mathrm{C}\right) .{ }^{1} \mathrm{H}$ NMR $\left(\mathrm{CDCl}_{3}, 300 \mathrm{~Hz}\right): 2.47(3 \mathrm{H}, \mathrm{s}$, $\left.\mathrm{SCH}_{3}\right), 3.91\left(2 \mathrm{H}, \mathrm{t},{ }^{3} J=7.5 \mathrm{~Hz}, \mathrm{NCH}_{2}\right), 4.10\left(2 \mathrm{H}, \mathrm{t},{ }^{3} J=7.5 \mathrm{~Hz}, \mathrm{NCH}_{2}\right), 7.68-7.82(3 \mathrm{H}, \mathrm{m}$, $\operatorname{Ar} H), 8.28\left(1 \mathrm{H}, \mathrm{dd},{ }^{4} J=2.4 \mathrm{~Hz}\right.$ and $\left.{ }^{3} J=7.3 \mathrm{~Hz}, \mathrm{Ar} H\right) . \mathrm{C}_{10} \mathrm{H}_{11} \mathrm{~N}_{3} \mathrm{O}_{4} \mathrm{~S}_{2} ; \mathrm{MW}=301.34 \mathrm{~g} / \mathrm{mol}$.

N-(2-nitrophenylsulfonyl)-2-benzylsulfanyl-1,4,5,6-tetrahydropyrimidine (23). Yield 91\%, 5.7

g. Colorless solid, mp $68-70{ }^{\circ} \mathrm{C}\left(\mathrm{Lit}^{27}{ }^{27} 8{ }^{\circ} \mathrm{C}\right) .{ }^{1} \mathrm{H} \mathrm{NMR}\left(\mathrm{CDCl}_{3}, 300 \mathrm{~Hz}\right): 1.99\left(2 \mathrm{H}, \mathrm{m}, \mathrm{CH}_{2}\right)$, $\left.3.63\left(2 \mathrm{H}, \mathrm{m}, \mathrm{NCH}_{2}\right), 3.89\left(2 \mathrm{H}, \mathrm{m}, \mathrm{NCH}_{2}\right), 4.12(2 \mathrm{H}, \mathrm{s}, \mathrm{SCH})_{2}\right), 7.16-7.31(5 \mathrm{H}, \mathrm{m}, \mathrm{ArH}$ benz), 7.59-7.71 (3H, m, $\mathrm{Ar} H), 8.27\left(1 \mathrm{H}, \mathrm{dd},{ }^{4} J=2.4 \mathrm{~Hz}\right.$ and $\left.{ }^{3} J=7.65 \mathrm{~Hz}, \mathrm{Ar} H\right) . \mathrm{C}_{17} \mathrm{H}_{17} \mathrm{~N}_{3} \mathrm{O}_{4} \mathrm{~S}_{2} ; \mathrm{MW}=$ $391.47 \mathrm{~g} / \mathrm{mol}$.

General Procedure for synthesis of compounds 24 and 25. A mixture of compound 22 or 23 (0.01 mol), tin(II) chloride $(0.05 \mathrm{~mol})$ and a few drops of concentrated hydrochloric acid is refluxed for 12 in EtOH $(100 \mathrm{~mL})$. After cooling, the reaction mixture is alkalinized with $20 \%$ aqueous ammonia solution and evaporated under vacuum. The brown solid is then extracted with EtOAc $(250 \mathrm{~mL})$ using a soxhlet apparatus for 2 days. The organic layer is evaporated under vacuum to provide a yellow solid which is washed with diethyl ether.

2,3-dihydroimidazo[1,2-b]1,2,4-benzothiadiazine 5,5-dioxyde (24). Yield 47\%, 1.05 g. Yellow solid, mp 244-246 ${ }^{\circ} \mathrm{C}$ (Lit. $\left.{ }^{27} 267^{\circ} \mathrm{C}\right) .{ }^{1} \mathrm{H}$ NMR (DMSO- $\left.d_{6}, 300 \mathrm{~Hz}\right): 3.57\left(2 \mathrm{H}, \mathrm{m}, \mathrm{NHCH}_{2}\right.$ ), 4.03 (2H, m, NCH$), 7.10-7.20\left(2 \mathrm{H}, \mathrm{m}, \mathrm{CH}\right.$ thiadia), $7.58\left(1 \mathrm{H}, \mathrm{td},{ }^{4} J=1.55 \mathrm{~Hz}\right.$ and ${ }^{3} J=7.15 \mathrm{~Hz}, \mathrm{CH}$ thiadia), $7.78\left(1 \mathrm{H}, \mathrm{dd},{ }^{4} J=1.55 \mathrm{~Hz}\right.$ and ${ }^{3} J=7.9 \mathrm{~Hz}, \mathrm{C} H$ thiadia $), 8.24(1 \mathrm{H}, \mathrm{s}, \mathrm{N} H) ;{ }^{13} \mathrm{C}$ NMR (DMSO- $d_{6}, 75 \mathrm{~Hz}$ ): 39.0, 41.3, 122.2, 122.7, 123.0, 125.3, 134.7, 146.2, 154.9. $\mathrm{C}_{9} \mathrm{H}_{9} \mathrm{~N}_{3} \mathrm{O}_{2} \mathrm{~S}$; $\mathrm{MW}=223.25 \mathrm{~g} / \mathrm{mol} ; t_{\mathrm{R}, \mathrm{LCMS}}=1.53 \mathrm{~min} ; \mathrm{MS}(\mathrm{ESI}-): \mathrm{m} / \mathrm{z}=222[\mathrm{M}-\mathrm{H}]+$.

1,2,3,4-tetrahydropyrimido[1,2-b]1,2,4-benzothiadiazine-6,6-dioxyde (25). Yield 42\%, 1.0 g. Yellow solid, mp 246-247 ${ }^{\circ} \mathrm{C}$ (Lit. ${ }^{27} 245-248{ }^{\circ} \mathrm{C}$ ). ${ }^{1} \mathrm{H}$ NMR (DMSO- $\left.d_{6}, 300 \mathrm{~Hz}\right): 1.97(2 \mathrm{H}, \mathrm{m}$, 
$\left.\mathrm{CH}_{2}\right), 3.28\left(2 \mathrm{H}, \mathrm{t},{ }^{3} \mathrm{~J}=5.8 \mathrm{~Hz}, \mathrm{NHCH}_{2}\right), 3.80\left(2 \mathrm{H}, \mathrm{t},{ }^{3} \mathrm{~J}=5.4 \mathrm{~Hz}, \mathrm{NCH}_{2}\right), 7.06-7.11(2 \mathrm{H}, \mathrm{m}, \mathrm{CH}$ thidia), $7.53\left(1 \mathrm{H}, \mathrm{td}, 1 \mathrm{H},{ }^{4} J=1.55 \mathrm{~Hz}\right.$ and ${ }^{3} J=7.95 \mathrm{~Hz}, \mathrm{CH}$ thiadia $), 7.66\left(1 \mathrm{H}, \mathrm{dd},{ }^{4} J=1.55 \mathrm{~Hz}\right.$ and ${ }^{3} J=7.95 \mathrm{~Hz}, \mathrm{C} H$ thiadia $), 8.09(1 \mathrm{H}, \mathrm{s}, \mathrm{N} H) . \mathrm{C}_{10} \mathrm{H}_{11} \mathrm{~N}_{3} \mathrm{O}_{2} \mathrm{~S} ; \mathrm{MW}=237.27 \mathrm{~g} / \mathrm{mol} ; t_{\mathrm{R}, \mathrm{LCMS}}=$ $1.57 \mathrm{~min} ; \mathrm{MS}$ (ESI-): $\mathrm{m} / \mathrm{z}=236[\mathrm{M}-\mathrm{H}]+$.

General Procedure for synthesis of compounds 26a,d and 27a-d. A solution of benzothiadiazine 24 or $25(1 \mathrm{mmol})$ in anhydrous DMF $(10 \mathrm{~mL})$ is added dropwise at room temperature under nitrogen to a suspension of sodium hydride $(0.06 \mathrm{~g}, 1.5 \mathrm{mmol}, 60 \%$ dispersion in mineral oil) in anhydrous DMF (5 mL) and then stirred for $1 \mathrm{~h}$ at $60{ }^{\circ} \mathrm{C}$. A solution of synthesized arylalkyl methanesulfonate 14a-d $(1.5 \mathrm{mmol})$ in anhydrous DMF $(5 \mathrm{~mL})$ is added dropwise to the previous solution and stirred for $24 \mathrm{~h}$ at $60{ }^{\circ} \mathrm{C}$. The reaction mixture is cooled in an ice bath and hydrolyzed with water $(85 \mathrm{~mL})$. The resulting precipitate is filtered and recrystallized from methanol.

1-[2-(4-Methoxyphenyl)-ethyl]-2,3-dihydroimidazo[1,2-b] 1,2,4-benzothiadiazine 5,5-dioxide (26a). Yield 69\%, $246 \mathrm{mg}$. White solid, mp 76-78 ${ }^{\circ} \mathrm{C} .{ }^{1} \mathrm{H}$ NMR (300 MHz, $\left.\mathrm{CDCl}_{3}\right): 2.96(2 \mathrm{H}, \mathrm{t}$, $\left.{ }^{3} J=7.3 \mathrm{~Hz}, \mathrm{PhCH}_{2}\right), 3.42\left(2 \mathrm{H}, \mathrm{t},{ }^{3} J=7.2 \mathrm{~Hz}, \mathrm{PhCH}_{2} \mathrm{CH}_{2} \mathrm{~N}\right), 3.69\left(2 \mathrm{H}, \mathrm{m},{ }^{3} J=7.3 \mathrm{~Hz}, \mathrm{NCH}_{2}\right)$, $3.88\left(3 \mathrm{H}, \mathrm{s}, \mathrm{OCH}_{3}\right), 4.00\left(2 \mathrm{H}, \mathrm{m}, \mathrm{SO}_{2} \mathrm{NCH}_{2}\right), 6.87\left(2 \mathrm{H}, \mathrm{d},{ }^{3} \mathrm{~J}=8.6 \mathrm{~Hz}, \mathrm{Ar} H\right), 7.18(3 \mathrm{H}, \mathrm{m}, \mathrm{ArH}$, $\mathrm{CH}$ thiadia), $7.37\left(1 \mathrm{H}, \mathrm{dd},{ }^{4} J=2.0 \mathrm{~Hz}\right.$ and ${ }^{3} J=7.8 \mathrm{~Hz}, \mathrm{CH}$ thiadia), $7.55\left(1 \mathrm{H}, \mathrm{td},{ }^{4} J=2.0 \mathrm{~Hz}\right.$ and ${ }^{3} J=7.8 \mathrm{~Hz}, \mathrm{C} H$ thiadia), $7.84\left(1 \mathrm{H}, \mathrm{dd},{ }^{4} J=0.8 \mathrm{~Hz}\right.$ and ${ }^{3} J=7.5 \mathrm{~Hz}, \mathrm{C} H$ thiadia). ${ }^{13} \mathrm{C}$ NMR $(75$ $\left.\mathrm{MHz}, \mathrm{CDCl}_{3}\right)$ 32.6, 38.9, 44.5, 46.6, 55.3, 114.1, 122.1, 122.5, 122.9, 125.8, 129.7, 130.5, 134.1, 145.7, 152.0, 158.4. $\mathrm{C}_{18} \mathrm{H}_{19} \mathrm{~N}_{3} \mathrm{O}_{3} \mathrm{~S} ; \mathrm{MW}=357.42 \mathrm{~g} / \mathrm{mol} ; t_{\mathrm{R}, \mathrm{LCMS}}=2.61 \mathrm{~min}(98.6 \%) ; \mathrm{MS}(\mathrm{ESI}+)$ : $\mathrm{m} / \mathrm{z}=358[\mathrm{M}+\mathrm{H}]+$. HPLC purity $99.3 \%$.

1-[2-(3-benzyloxy-4-Methoxyphenyl)-ethyl]-2,3-dihydroimidazo[1,2-b] 1,2,4-benzothiadiazine 5,5-dioxide (26d). Yield 54\%, $250 \mathrm{mg}$. White solid, mp 75-77 ${ }^{\circ} \mathrm{C} .{ }^{1} \mathrm{H}$ NMR $\left(300 \mathrm{MHz}, \mathrm{CDCl}_{3}\right)$ : 
$2.88\left(2 \mathrm{H}, \mathrm{t},{ }^{3} J=7.15 \mathrm{~Hz}, \mathrm{PhCH}_{2}\right), 3.23\left(2 \mathrm{H}, \mathrm{t},{ }^{3} J=6.3 \mathrm{~Hz}, \mathrm{PhCH}_{2} \mathrm{CH}_{2}\right), 3.64\left(2 \mathrm{H}, \mathrm{m},{ }^{3} J=7.15\right.$ $\left.\mathrm{Hz}, \mathrm{NCH}_{2}\right), 3.88-3.94\left(5 \mathrm{H}, \mathrm{m}, \mathrm{OCH}_{3}, \mathrm{SO}_{2} \mathrm{NCH}_{2}\right), 6.77-6.86(3 \mathrm{H}, \mathrm{m}, \mathrm{Ar} H), 7.16\left(1 \mathrm{H}, \mathrm{td},{ }^{4} J=\right.$ $1.15 \mathrm{~Hz}$ and ${ }^{3} J=8.05 \mathrm{~Hz}, \mathrm{CH}$ thiadia), 7.29-7.43 (6H, m, CH thiadia, $\mathrm{Ar} H$ benz), $7.53\left(1 \mathrm{H}, \mathrm{td},{ }^{4} J\right.$ $=1.5 \mathrm{~Hz}$ and ${ }^{3} J=8.3 \mathrm{~Hz}, \mathrm{C} H$ thiadia $), 7.83\left(1 \mathrm{H}, \mathrm{dd},{ }^{4} J=1.25 \mathrm{~Hz}\right.$ and ${ }^{3} J=8.0 \mathrm{~Hz}, \mathrm{CH}$ thiadia $)$. ${ }^{13} \mathrm{C} \mathrm{NMR}\left(75 \mathrm{MHz}, \mathrm{CDCl}_{3}\right): 33.0,38.9,44.6,46.3,56.1,70.9,112.0,114.7,121.4,122.1,122.5$, $122.9,125.7,127.3,127.8,128.5,130.9,134.0,137.1,145.7,148.1,148.5,152.0 . \mathrm{C}_{25} \mathrm{H}_{25} \mathrm{~N}_{3} \mathrm{O}_{4} \mathrm{~S}$ $\mathrm{MW}=463.54 \mathrm{~g} / \mathrm{mol} ; t_{\mathrm{R}, \mathrm{LCMS}}=2.93 \mathrm{~min}(100 \%) ; \mathrm{MS}(\mathrm{ESI}+): \mathrm{m} / \mathrm{z}=464[\mathrm{M}+\mathrm{H}]+$.

1-[2-(4-methoxyphenyl)-ethyl]-1,2,3,4-tetrahydropyrimidino[1,2-b] 1,2,4-benzothiadiazine 6,6dioxyde (27a). Yield 63\%, $234 \mathrm{mg}$. Off-white solid, mp 105-107 ${ }^{\circ} \mathrm{C} .{ }^{1} \mathrm{H}$ NMR (300 MHz, $\left.\mathrm{CDCl}_{3}\right): 2.02\left(2 \mathrm{H}, \mathrm{m}, \mathrm{CH}_{2}\right), 3.00\left(2 \mathrm{H}, \mathrm{t},{ }^{3} J=7.3 \mathrm{~Hz}, \mathrm{PhCH}_{2}\right), 3.19\left(2 \mathrm{H}, \mathrm{t},{ }^{3} J=6.25 \mathrm{~Hz}\right.$, $\left.\mathrm{PhCH}_{2} \mathrm{CH}_{2}\right), 3.80\left(3 \mathrm{H}, \mathrm{s}, \mathrm{OCH}_{3}\right), 3.84\left(4 \mathrm{H}, \mathrm{m}, \mathrm{SO}_{2} \mathrm{NCH}_{2}, \mathrm{NCH}_{2}\right), 6.86\left(2 \mathrm{H}, \mathrm{d},{ }^{3} \mathrm{~J}=8.75 \mathrm{~Hz}\right.$, $\operatorname{Ar} H), 7.11\left(1 \mathrm{H}, \mathrm{t},{ }^{3} J=8.05 \mathrm{~Hz}, \mathrm{C} H\right.$ thiadia $), 7.17\left(2 \mathrm{H}, \mathrm{d},{ }^{3} J=8.75 \mathrm{~Hz}, \mathrm{Ar} H\right), 7.29\left(1 \mathrm{H}, \mathrm{d},{ }^{3} J=\right.$ $8.5 \mathrm{~Hz}, \mathrm{CH}$ thiadia), $7.52\left(1 \mathrm{H}, \mathrm{td},{ }^{4} J=1.5 \mathrm{~Hz}\right.$ and ${ }^{3} J=8.5 \mathrm{~Hz}, \mathrm{CH}$ thiadia $), 7.74\left(1 \mathrm{H}, \mathrm{dd},{ }^{4} J=1.5\right.$ $\mathrm{Hz}$ and ${ }^{3} J=7.95 \mathrm{~Hz}, \mathrm{CH}$ thiadia). ${ }^{1} \mathrm{H}$ NMR $\left(75 \mathrm{MHz}, \mathrm{CDCl}_{3}\right): 22.7,32.5,39.1,47.3,52.3,55.3$, $113.9,121.1,121.5,123.8,125.7,129.9,131.2,133.5,144.8,146.9,158.0 . \mathrm{C}_{19} \mathrm{H}_{21} \mathrm{~N}_{3} \mathrm{O}_{3} \mathrm{~S} ; \mathrm{MW}=$ $371.45 \mathrm{~g} / \mathrm{mol} ; t_{\mathrm{R}, \mathrm{LCMS}}=2.83 \mathrm{~min}(98.6 \%) ; \mathrm{MS}(\mathrm{ESI}+): \mathrm{m} / \mathrm{z}=372[\mathrm{M}+\mathrm{H}]+$. HPLC purity $99.4 \%$. 1-[2-(3,4-dimethoxyphenyl)-ethyl]-1,2,3,4-tetrahydropyrimidino[1,2-b] 1,2,4-benzothiadiazine 6,6-dioxyde (27b). Yield 66\%, $265 \mathrm{mg}$. White solid, mp 109-111 ${ }^{\circ} \mathrm{C} .{ }^{1} \mathrm{H}$ NMR (300 MHz, $\left.\mathrm{CDCl}_{3}\right): 2.00\left(2 \mathrm{H}, \mathrm{m}, \mathrm{CH}_{2}\right), 3.01\left(2 \mathrm{H}, \mathrm{t},{ }^{3} J=7.05 \mathrm{~Hz}, \mathrm{PhCH}_{2}\right), 3.15\left(2 \mathrm{H}, \mathrm{t},{ }^{3} J=6.1 \mathrm{~Hz}\right.$, $\left.\mathrm{PhCH}_{2} \mathrm{CH}_{2}\right), 3.83\left(4 \mathrm{H}, \mathrm{m}, \mathrm{SO}_{2} \mathrm{NCH}_{2}, \mathrm{NCH}_{2}\right), 3.87\left(3 \mathrm{H}, \mathrm{s}, \mathrm{OCH}_{3}\right), 3.88\left(3 \mathrm{H}, \mathrm{s}, \mathrm{OCH}_{3}\right), 6.77-6.84$ (3H, m, ArH), $7.12\left(1 \mathrm{H}, \mathrm{t},{ }^{3} J=8.0 \mathrm{~Hz}, \mathrm{C} H\right.$ thiadia), $7.30\left(1 \mathrm{H}, \mathrm{d},{ }^{3} J=8.5 \mathrm{~Hz}, \mathrm{C} H\right.$ thiadia), 7.52 $\left(1 \mathrm{H}, \mathrm{td},{ }^{4} J=1.5 \mathrm{~Hz}\right.$ and ${ }^{3} J=8.45 \mathrm{~Hz}, \mathrm{CH}$ thiadia), $7.73\left(1 \mathrm{H}, \mathrm{dd},{ }^{4} J=1.4 \mathrm{~Hz}\right.$ and ${ }^{3} J=7.95 \mathrm{~Hz}$, $\mathrm{C} H$ thiadia). ${ }^{1} \mathrm{H}$ NMR (75 MHz, $\left.\mathrm{CDCl}_{3}\right): 22.7,33.1,39.2,47.5,52.4,55.9,111.3,112.1,120.8$, 
121.2, 121.6, 123.9, 125.5, 131.7, 133.5, 147.0, 147.6, 149.0. $\mathrm{C}_{20} \mathrm{H}_{23} \mathrm{~N}_{3} \mathrm{O}_{4} \mathrm{~S} ; \mathrm{MW}=401.48 \mathrm{~g} / \mathrm{mol}$ $t_{\mathrm{R}, \mathrm{LCMS}}=2.60 \mathrm{~min}(97.7 \%) ; \mathrm{MS}(\mathrm{ESI}+): \mathrm{m} / \mathrm{z}=402[\mathrm{M}+\mathrm{H}]+$. HPLC purity $98.2 \%$.

1-[2-(3,4,5-trimethoxyphenyl)-ethyl]-1,2,3,4-tetrahydropyrimidino[1,2-b] 1,2,4-

benzothiadiazine 6,6-dioxyde (27c). Yield 72\%, $310 \mathrm{mg}$. White solid, mp 144-146 ${ }^{\circ} \mathrm{C} .{ }^{1} \mathrm{H}$ NMR (300 MHz, $\left.\mathrm{CDCl}_{3}\right): 2.01\left(2 \mathrm{H}, \mathrm{m}, \mathrm{CH}_{2}\right), 3.01\left(2 \mathrm{H}, \mathrm{t},{ }^{3} \mathrm{~J}=6.95 \mathrm{~Hz}, \mathrm{PhCH}_{2}\right), 3.16\left(2 \mathrm{H}, \mathrm{t},{ }^{3} \mathrm{~J}=6.15\right.$ $\left.\mathrm{Hz}, \mathrm{PhCH}_{2} \mathrm{CH}_{2}\right), 3.82\left(5 \mathrm{H}, \mathrm{m}, \mathrm{NCH}_{2}, \mathrm{OCH}_{3}\right), 3.85\left(8 \mathrm{H}, \mathrm{m}, \mathrm{NCH}_{2}, \mathrm{OCH}_{3}\right), 6.47(2 \mathrm{H}, \mathrm{s}, \mathrm{ArH})$, $7.11\left(1 \mathrm{H}, \mathrm{t},{ }^{3} J=7.95 \mathrm{~Hz}, \mathrm{CH}\right.$ thiadia), $7.27(1 \mathrm{H}, \mathrm{m}, \mathrm{C} H$ thiadia $), 7.52\left(1 \mathrm{H}, \mathrm{td},{ }^{4} J=1.35 \mathrm{~Hz}\right.$ and ${ }^{3} J=8.5 \mathrm{~Hz}, \mathrm{C} H$ thiadia), $7.73\left(1 \mathrm{H}, \mathrm{dd},{ }^{4} J=1.3 \mathrm{~Hz}\right.$ and ${ }^{3} J=7.85 \mathrm{~Hz}, \mathrm{C} H$ thiadia). ${ }^{1} \mathrm{H}$ NMR $(75$ $\left.\mathrm{MHz}, \mathrm{CDCl}_{3}\right): 22.7,33.9,39.1,47.5,52.2,56.1,60.9,105.7,121.2,121.6,123.9,125.5,133.5$, 135.0, 136.5, 144.6, 146.9, 153.3. $\mathrm{C}_{21} \mathrm{H}_{25} \mathrm{~N}_{3} \mathrm{O}_{5} \mathrm{~S} ; \mathrm{MW}=431.50 \mathrm{~g} / \mathrm{mol} ; t_{\mathrm{R}, \mathrm{LCMS}}=2.61 \mathrm{~min}$ (96.2\%); MS (ESI+): m/z = $432[\mathrm{M}+\mathrm{H}]+$. HPLC purity $96.7 \%$.

1-[2-(3-benzyloxy-4-methoxyphenyl)-ethyl]-1,2,3,4-tetrahydropyrimidino[1,2-b]1,2,4benzothiadiazine 6,6-dioxyde (27d). Yield 51\%, $243 \mathrm{mg}$. White solid, mp 139-141 ${ }^{\circ} \mathrm{C}$. ${ }^{1} \mathrm{H}$ NMR $\left(300 \mathrm{MHz}, \mathrm{CDCl}_{3}\right): 1.98\left(2 \mathrm{H}, \mathrm{m}, \mathrm{CH}_{2}\right), 3.00\left(2 \mathrm{H}, \mathrm{t},{ }^{3} J=6.9 \mathrm{~Hz}, \mathrm{PhCH}_{2}\right), 3.13\left(2 \mathrm{H}, \mathrm{t},{ }^{3} J=5.9\right.$ $\left.\mathrm{Hz}, \mathrm{PhCH}_{2} \mathrm{CH}_{2}\right), 3.82\left(4 \mathrm{H}, \mathrm{m}, \mathrm{SO}_{2} \mathrm{NCH}_{2}, \mathrm{NCH}_{2}\right), 3.89\left(3 \mathrm{H}, \mathrm{s}, \mathrm{OCH}_{3}\right), 6.72\left(1 \mathrm{H}, \mathrm{d},{ }^{3} \mathrm{~J}=8.05 \mathrm{~Hz}\right.$, $\operatorname{Ar} H), 6.81-6.86(2 \mathrm{H}, \mathrm{m}, \operatorname{Ar} H), 7.12\left(1 \mathrm{H}, \mathrm{t},{ }^{3} J=7.55 \mathrm{~Hz}, \mathrm{CH}\right.$ thiadia $), 7.27-7.46(6 \mathrm{H}, \mathrm{m}, \mathrm{CH}$ thiadia, $\mathrm{Ar} H$ benz), $7.52\left(1 \mathrm{H}, \mathrm{t},{ }^{3} J=7.3 \mathrm{~Hz}, \mathrm{C} H\right.$ thiadia), $7.74\left(1 \mathrm{H}, \mathrm{d},{ }^{3} J=7.3 \mathrm{~Hz}, \mathrm{C} H\right.$ thiadia). ${ }^{1} \mathrm{H}$ NMR (75 MHz, $\mathrm{CDCl}_{3}$ ): 22.7, 33.1, 39.1, 47.4, 52.3, 56.0, 71.2, 112.7, 114.4, 120.8, 121.2, $121.5,123.9,125.6,127.3,127.8,128.5,132.5,133.5,137.2,144.7,146.7,146.9,149.8$. $\mathrm{C}_{26} \mathrm{H}_{27} \mathrm{~N}_{3} \mathrm{O}_{4} \mathrm{~S} ; \mathrm{MW}=477.57 \mathrm{~g} / \mathrm{mol} ; t_{\mathrm{R}, \mathrm{LCMS}}=3.08 \mathrm{~min}(97.2 \%) ; \mathrm{MS}(\mathrm{ESI}+): \mathrm{m} / \mathrm{z}=478[\mathrm{M}+\mathrm{H}]+$.

General Procedure for synthesis of compounds 26e and 27e. A solution of $26 \mathrm{~d}$ or $27 \mathrm{~d}(0.5$ $\mathrm{mmol})$ in EtOH $(100 \mathrm{~mL})$ is stirred with $10 \% \mathrm{Pd} / \mathrm{C}$ catalyst at room temperature under an 
atmospheric pressure of hydrogen for $72 \mathrm{~h}$. The catalyst is separated by filtration, the solvent evaporated under reduced pressure and the crude product is crystallized in $\mathrm{EtOH}$.

\section{1-[2-(3-hydroxy-4-Methoxyphenyl)-ethyl]-2,3-dihydroimidazo[1,2-b] 1,2,4-benzothiadiazine}

5,5-dioxide (26e). Yield 54\%, $101 \mathrm{mg}$. White solid, mp $172-173{ }^{\circ} \mathrm{C} .{ }^{1} \mathrm{H}$ NMR (300 MHz, $\left.\mathrm{CDCl}_{3}\right): 2.90\left(2 \mathrm{H}, \mathrm{t},{ }^{3} J=7.1 \mathrm{~Hz}, \mathrm{PhCH}_{2}\right), 3.43\left(2 \mathrm{H}, \mathrm{t},{ }^{3} J=7.1 \mathrm{~Hz}, \mathrm{PhCH}_{2} \mathrm{CH}_{2}\right), 3.70\left(2 \mathrm{H}, \mathrm{t},{ }^{3} J=\right.$ $\left.7.1 \mathrm{~Hz}, \mathrm{NCH}_{2}\right), 3.89\left(3 \mathrm{H}, \mathrm{s}, \mathrm{OCH}_{3}\right), 4.00\left(2 \mathrm{H}, \mathrm{t},{ }^{3} \mathrm{~J}=7.6 \mathrm{~Hz}, \mathrm{SO}_{2} \mathrm{NCH}_{2}\right) ; 5.65(1 \mathrm{H}, \mathrm{s}, \mathrm{OH}), 6.73$ $\left(1 \mathrm{H}, \mathrm{dd},{ }^{4} J=1.95 \mathrm{~Hz}\right.$ and $\left.{ }^{3} J=8.1 \mathrm{~Hz}, \operatorname{Ar} H\right), 6.81\left(1 \mathrm{H}, \mathrm{d},{ }^{3} J=8.2 \mathrm{~Hz}, \operatorname{Ar} H\right), 6.86\left(1 \mathrm{H}, \mathrm{d},{ }^{4} J=2.0\right.$ $\mathrm{Hz}, \mathrm{Ar} H), 7.17\left(1 \mathrm{H}, \mathrm{td},{ }^{4} J=1.1 \mathrm{~Hz}\right.$ and ${ }^{3} J=8.25 \mathrm{~Hz}, \mathrm{CH}$ thiadia $), 7.31\left(1 \mathrm{H}, \mathrm{dd},{ }^{4} J=0.7 \mathrm{~Hz}\right.$ and ${ }^{3} J=8.3 \mathrm{~Hz}, \mathrm{C} H$ thiadia), $7.54\left(1 \mathrm{H}, \mathrm{td},{ }^{4} J=1.5 \mathrm{~Hz}\right.$ and ${ }^{3} J=8.3 \mathrm{~Hz}, \mathrm{C} H$ thiadia $), 7.84\left(1 \mathrm{H}, \mathrm{dd},{ }^{4} J\right.$ $=1.25 \mathrm{~Hz}$ and ${ }^{3} J=7.9 \mathrm{~Hz}, \mathrm{CH}$ thiadia). ${ }^{13} \mathrm{C} \mathrm{NMR}\left(75 \mathrm{MHz}, \mathrm{CDCl}_{3}\right): 32.9,38.9,44.5,46.4,56.0$, $110.8,114.8,120.2,122.1,122.5,122.9,125.8,131.7,134.0,145.4,145.7,152.0 . \mathrm{C}_{18} \mathrm{H}_{19} \mathrm{~N}_{3} \mathrm{O}_{4} \mathrm{~S}$ $\mathrm{MW}=373.42 \mathrm{~g} / \mathrm{mol} ; t_{\mathrm{R}, \mathrm{LCMS}}=2.23 \mathrm{~min}(98.5 \%) ; \mathrm{MS}(\mathrm{ESI}+): \mathrm{m} / \mathrm{z}=374[\mathrm{M}+\mathrm{H}]+$. HPLC purity $95.4 \%$.

1-[2-(3-hydroxy-4-methoxyphenyl)-ethyl]-1,2,3,4-tetrahydropyrimidino[1,2-b] 1,2,4-

benzothiadiazine 6,6-dioxyde (27e). Yield 51\%, $243 \mathrm{mg}$. White solid, mp 149-151 ${ }^{\circ} \mathrm{C} .{ }^{1} \mathrm{H}$ NMR (300 MHz, $\left.\mathrm{CDCl}_{3}\right): 2.04(2 \mathrm{H}, \mathrm{m}, \mathrm{CH}), 2.97\left(2 \mathrm{H}, \mathrm{t},{ }^{3} \mathrm{~J}=7.35 \mathrm{~Hz}, \mathrm{PhCH}_{2}\right), 3.22\left(2 \mathrm{H}, \mathrm{t},{ }^{3} J=6.0\right.$ $\left.\mathrm{Hz}, \mathrm{PhCH}_{2} \mathrm{CH}_{2}\right), 3.79-3.87\left(4 \mathrm{H}, \mathrm{m}, \mathrm{SO}_{2} \mathrm{NCH}_{2}, \mathrm{NCH}_{2}\right), 3.88\left(3 \mathrm{H}, \mathrm{s}, \mathrm{OCH}_{3}\right), 5.66(1 \mathrm{H}, \mathrm{s}, \mathrm{OH})$, $6.72\left(1 \mathrm{H}, \mathrm{dd},{ }^{4} J=1.9 \mathrm{~Hz}\right.$ and $\left.{ }^{3} J=8.15 \mathrm{~Hz}, \operatorname{Ar} H\right), 6.80\left(1 \mathrm{H}, \mathrm{d},{ }^{3} J=8.15 \mathrm{~Hz}, \operatorname{Ar} H\right), 6.86(1 \mathrm{H}, \mathrm{d}$, $\left.{ }^{4} J=1.9 \mathrm{~Hz}, \mathrm{Ar} H\right), 7.12\left(1 \mathrm{H}, \mathrm{t},{ }^{3} J=8.1 \mathrm{~Hz}, \mathrm{C} H\right.$ thiadia $), 7.29\left(1 \mathrm{H}, \mathrm{d},{ }^{3} J=8.4 \mathrm{~Hz}, \mathrm{C} H\right.$ thiadia $)$, $7.52\left(1 \mathrm{H}, \mathrm{td},{ }^{4} J=1.35 \mathrm{~Hz}\right.$ and ${ }^{3} J=8.4 \mathrm{~Hz}, \mathrm{C} H$ thiadia $), 7.74\left(1 \mathrm{H}, \mathrm{dd},{ }^{4} J=1.2 \mathrm{~Hz}\right.$ and ${ }^{3} J=7.9$ $\mathrm{Hz}, \mathrm{CH}$ thiadia). ${ }^{1} \mathrm{H}$ NMR (75 MHz, $\left.\mathrm{CDCl}_{3}\right): 22.7,32.8,39.1,47.3,52.2,56.0,110.7,115.0$, $120.5,121.1,121.5,123.7,125.7,132.3,133.5,144.7,145.2,145.6,146.9 . \mathrm{C}_{19} \mathrm{H}_{21} \mathrm{~N}_{3} \mathrm{O}_{4} \mathrm{~S} ; \mathrm{MW}=$ $387.45 \mathrm{~g} / \mathrm{mol} ; t_{\mathrm{R}, \mathrm{LCMS}}=2.35 \mathrm{~min}(96.2 \%) ; \mathrm{MS}(\mathrm{ESI}-): \mathrm{m} / \mathrm{z}=386[\mathrm{M}+\mathrm{H}]+$. HPLC purity $98.5 \%$. 


\section{Biological Evaluation.}

2.1. Cell Proliferation on HT29 Cell Line. HT 29 Colon cancer cells were obtained from European Collection of Cell Cultures. FBS, medium, penicillin-streptomycin, and other agents used in cell culture studies were purchased from Invitrogen. Cancer cell lines were cultured, at $37{ }^{\circ} \mathrm{C}$ in a $\mathrm{CO}_{2}$ incubator, respectively in RPMI-1640, MEM and DMEM + Glutamax-I medium supplemented with $10 \%$ fetal bovine serum, penicillin $(100 \mathrm{IU} / \mathrm{mL})$ and streptomycin (100 $\mathrm{mg} / \mathrm{mL}$ ). Briefly, HT29 colon cancer cells were plated at a density of $3 \times 10^{3}$ cells/well in 96well plates for $24 \mathrm{~h}$. Then the medium was removed, and cells were treated with either DMSO as a control or at a $10 \mu \mathrm{M}$ single dose or various concentrations of compounds. The final concentration of DMSO in the medium was $<0.1 \%(\mathrm{v} / \mathrm{v})$. The plates were incubated for $72 \mathrm{~h}$ and cell proliferation was estimated by MTS colorimetric assay.

2.2. Cell Growth Inhibition. The compounds were tested against a panel of 60 human cancer cell lines at the National Cancer Institute (Rockville, MD). ${ }^{30}$ The cytotoxicity studies were conducted using a $48 \mathrm{~h}$ exposure protocol using the sulforhodamine B assay. ${ }^{54,55}$

2.3. Cell Cycle Analysis. Sk-Mel28 cells were seeded in complete RPMI medium and at a final concentration of $5 \times 10^{5}$ cells per well, $24 \mathrm{~h}$ prior to compound application. The following concentrations were applied for compound $16 \mathbf{a} ; 10^{-7}, 10^{-6}$ and $10^{-5} \mathrm{M}$. The vehicle solution (DMSO) was applied at 0.1 and $1 \%$ final concentration. After $24 \mathrm{~h}$ incubation, the cells were washed twice with PBS and fixed with cold ethanol $70 \%$ and stored at $-20^{\circ} \mathrm{C}$ until analysis. DNA content was evaluated by PI staining. The cells were stained with $50 \mu \mathrm{g} / \mathrm{mL}$ PI solution supplemented with $5 \mu \mathrm{g}$ RNAse stock. Analysis was carried out on a flow cytometer according

to the presented protocols. Fluorescence of the PI-stained cells was measured using CyAn ${ }^{\mathrm{TM}}$ ADP Analyzer (Beckman Coulter, Inc.) and Summit ${ }^{\circledR}$ software. After excluding cell debris and 
clumps from analysis by using an appropriate dot-plot gating area, the software program provided the estimate percentage of cells with fractional DNA and cells in G1, S, and G2/M phases of the cycle.

2.4. Immunocytochemistry. SK-Mel28 cells were grown on precoated poly-Llysine-4-well chamber slides (Lab-Tek, Nunc ${ }^{\circledR}$, Roskilde,Denmark). Approximately, $2.5 \times 10^{4}$ cells per well were seeded in complete RPMI medium (containing 10\% FBS, $1 \%$ antibiotics and $1 \%$ sodium pyruvate) and exposed to compound 16a $(1 \mu \mathrm{M})$ or vehicle. After $6 \mathrm{~h}$, the cells were fixed in cold acetone for $15 \mathrm{~min}$ at room temperature, washed three times with PBS containing 1\% BSA and permeabilized for $10-15 \mathrm{~min}$ at room temperature with $0.025 \%$ Triton-X-100 (SigmaAldrich). Nonspecific binding sites were blocked for $30 \mathrm{~min}$ at room temperature with a PBS solution containing 3\% BSA, 7\% FBS and $10 \%$ mouse specific IgG. The cells were then incubated with a monoclonal anti- $\beta$-tubulin antibody (clone TUB2.1, $2 \mu \mathrm{g} / \mathrm{mL}$, Sigma-Aldrich) for $1 \mathrm{~h}$ at room temperature, washed three times, and incubated for $1 \mathrm{~h}$ at room temperature with goat anti-mouse Alexa Fluor $488\left(2 \mu \mathrm{g} / \mathrm{mL}\right.$; Molecular Probes, Invitrogen $\left.{ }^{\circledR}\right)$ in 1\% BSA. Fluorescent microscopic analysis was performed with Leica DMRB microscope (Leica Microsystems), using a PL Plan-Leica Fluotar 40×/1.00 oil obJective. Pictures were taken with a DFC345FX digital camera and processed with Leica Application Suite (LAS v 3.7 software) (Leica Microsystems).

2.5. Tubulin Content Analysis. Cell content of the polymerized and soluble tubulin fraction was investigated by western blot analysis. Sk-Mel28 cells were seeded in $\mathrm{T} 25 \mathrm{~cm}^{2}$ culture flasks at a final concentration of $5 \times 10^{6}$ cells per flask $48 \mathrm{~h}$ prior to treatment. Control and compound 16a $(1 \mu \mathrm{M})$ were applied for $6 \mathrm{~h}$. Cells were then washed twice with PBS, harvested and protein extracts were prepared for western blot. Briefly, twenty micrograms of proteins was subJected to 
4-12\% SDS-NuPAGE polyacrylamide gel electrophoresis and transferred to nitrocellulose membrane (Thermo Fisher Scientific Inc., Waltham, MA) then incubated with antibodies directed against $\beta$-tubulin and HSC-70 (Santa-Cruz Biotechnology, Santa Cruz, CA). Finally, blots were visualized using the Amersham ECL Prime Western Blotting System on a Las 4000 biomolecular imager and further analyzed by ImageQuant ${ }^{\circledR}$ tools (GE Healthcare Europe GmbH, Velizy-Villacoublay, France) The experiment was performed four times $(n=4)$.

2.6. In Vitro Microtubule Polymerization Assay. In-vitro tubulin polymerization assays were performed on a fluorescence spectrometer (Varioskan flash, Thermo Scientific, Courtaboeuf, France), equipped with a half area 96 wells microplate (Corning Costar). Excitation and emission wavelengths were 360 and $420 \mathrm{~nm}$, respectively. All reagents were purchased from Cytoskeleton (Denver, CO, USA). For each inhibitor investigated, a series of ten concentrations (from 0.1 to $10 \mu \mathrm{M}$ ) was prepared in $100 \mu \mathrm{g}$ purified bovine tubulin and buffer containing $20 \%$ glycerol, $1 \mathrm{mM}$ GTP, $80 \mathrm{mM}$ PIPES (pH 6.9), $2.0 \mathrm{mM} \mathrm{MgCl}_{2}, 0.5 \mathrm{mM}$ EGTA and $5 \mathrm{nM}$ fluorescent reporter and kept at $0^{\circ} \mathrm{C}$. Then, the medium was incubated in the plate reader, at $37^{\circ} \mathrm{C}$, for $1 \mathrm{~h}$. A mixture without inhibitor exhibited an increase in fluorescent intensity as a function of incubation time corresponding to the inclusion of the probe inside the tubulin polymer. On the contrary, compounds which strongly inhibited microtubule formation were identified by a fluorescent signal remaining negligible along the experiment. The effect of inhibitor concentration on tubulin polymerization rate was studied and the $\mathrm{IC}_{50}$ value was defined as the concentration of product which inhibits the polymerization rate by a 50 -fold decrease. It was determined from three independent assays using GraphPad Prism ${ }^{\circledR}$ software.

2.7. Molecular Modeling Studies. Docking was performed into one $\beta$ subunit of compound 1bound tubulin crystal structure (PDB ID $3 \mathrm{HKC}^{33}$ ) using AutodockVina ${ }^{34}$ integrated into UCSF 
Chimera suite. ${ }^{37}$ With a search grid of 80 x 80 x 60 Å included the whole $\beta$ subunit, the docking process was achieved onto a MacBook Pro OS X 10.9.5 (Apple Inc.) using an energy range of 3, an exhaustiveness of 8 and 9 retained binding modes.

2.8. Cell Invasion Assay. ECGM medium + SupplementMix were purchased from Promocell. In vitro invasion assay was carried out using transwell chambers, precoated with Matrigel ${ }^{\circledR}$ matrix, with $6.4 \mathrm{~mm}$ diameter PET membrane ( 8 micron pore size, BD Biocat). The bottom chambers were filled with ECGM medium with $20 \mathrm{ng} / \mathrm{mL}$ VEGF and the top chambers were seeded with ECGM (without growth factors) and HUVEC ( 1 x 105 cells per well). The top chamber contained vehicle or compound at various concentrations $(0.001,0.01,0.1$ or $1 \mu \mathrm{M})$. Cells were allowed to migrate for $24 \mathrm{~h}$. Non migrated cells were scraped with a cotton swab, and migrated cells were fixed with $100 \%$ methanol and stained with $0.05 \%$ crystal violet. The number of HUVEC that penetrated the membrane was quantified by manual counting and

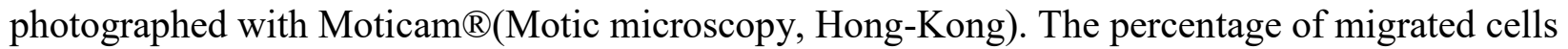
was expressed on the basis of vehicle control wells.

2.9. In Vitro Endothelial Tube Formation Assay. Geltrex ${ }^{\circledR}$ was thawed overnight at $4{ }^{\circ} \mathrm{C}$ in an ice bath, and then $100 \mu \mathrm{L}$ of solution was used to coat 24 -well plates. The plates were then incubated at $37^{\circ} \mathrm{C}$ for 30 min to ensure complete gelation of the matrix. HUVEC cells were then seeded into 96-well plates at a cell density of 50000 cells/well and allowed to incubate for $10 \mathrm{~h}$ at $37^{\circ} \mathrm{C}$. Cells were treated with different concentrations of compound $\mathbf{1 6 a}$ and $31(0.001,0.01$, 0.1 and $1 \mu \mathrm{M})$. The morphological changes on the cell structure and the formed tubes were observed under inverted microscope and photographed with Moticam ${ }^{\circledR}$.

2.10. Cell Migration Assay. Tumor cell motility was investigated using the "wound healing" assay of a confluent monolayer. Rapidly, Sk-Mel28 cells were seeded in complete medium and 
in 12-well plates at a final concentration of $8 \times 10^{4}$ cells per well until confluent monolayer was formed. Wound generation was performed using a $200 \mu \mathrm{L}$ pipet tips and each well was rinsed twice with PBS to remove the floating/ detached cells. Compound 16a or vehicle were then applied to each appropriate well and photographs of each well were taken at different time intervals $(\mathrm{t}+3, \mathrm{t}+6$ and $\mathrm{t}+9 \mathrm{~h})$ under a light microscope. Area analysis was performed using Image $\mathrm{J}$ software and the wound width was measured in three different wells. The reported area value was normalized to the initial width. The experiment was performed three times, in triplicates ( $\mathrm{n}=$ 3), at different time passages.

2.11. Microsomal Stability Assay. Stock solutions of test compounds ( $5 \mathrm{mM})$ were prepared in $\mathrm{ACN}$ and stored at $4^{\circ} \mathrm{C}$. Before performing the assay, the stock solutions were diluted with $\mathrm{H}_{2} \mathrm{O}$ to $100 \mu \mathrm{M}$. Kinetic of compounds $2 \mathbf{b} \mathbf{1}$ and $16 \mathbf{6 a}$ metabolism and the determination of Michaelis-Menten parameters were performed according to the protocol described by Bourdon et al. ${ }^{13}$ Briefly, compounds $2 \mathbf{b} 1$ and $16 \mathbf{a}$ were incubated at $10 \mu \mathrm{M}$ (for the kinetic of assay) or at various concentrations ranging from 0.4 to $20 \mu \mathrm{M}$ (for the $\mathrm{K}_{\mathrm{m}}$ determination), in rat liver microsomes (RLM), using a microsomal incubation assays kit from BDbiosciences. The composition of microsomal incubation mixture was $0.5 \mathrm{mg} \cdot \mathrm{mL}^{-1}$ microsomal protein, $1.55 \mathrm{mM}$ $\mathrm{NADP}^{+}, \quad 3.3 \mathrm{mM}$ glucose-6-phosphate, $3.3 \mathrm{mM} \quad \mathrm{MgCl}_{2}, \quad 0.2 \mathrm{U}$ glucose-6-phosphate dehydrogenase and $50 \mu \mathrm{M}$ sodium citrate in $100 \mathrm{mM}$ phosphate buffer ( $\mathrm{pH}$ 7.4). The mixture was pre-incubated at $37^{\circ} \mathrm{C}$ for $5 \mathrm{~min}$ without protein. The microsomal reaction was initiated by the addition of $12.5 \mu \mathrm{L}$ RLM and the mixture was heated at $37^{\circ} \mathrm{C}$ in a shaking bath for $120 \mathrm{~min}$ (kinetic assay) or for $10 \mathrm{~min}\left(\mathrm{~K}_{\mathrm{m}}\right.$ determination).The incubation was stopped by the addition of $500 \mu \mathrm{L}$ of ice cold acetonitrile containing IS (final concentration: $20 \mu \mathrm{M}$ ). The sample was vigorously stirred and kept on crushed ice. After centrifugation (13000 x g for $3 \mathrm{~min}$ ), a $20 \mu \mathrm{L}$ 
supernatant was collected and analyzed by LC-UV.Each experiment was repeated five times. Chromatographic analyses were performed on a Waters system equipped with a Waters gradient quaternary 600E pump model, a Waters on-line degasser apparatus, a 7125 Rheodyne inJector (20 $\mu \mathrm{L}$ loop) and a Waters 996 photodiode array detector (Milford, MA, USA). Data were collected and processed on a computer running with Empower software (version 2) from Waters. Separations were carried out on a reversed-phase Symmetry C18 $(150 \times 4.6 \mathrm{~mm}$ i.d., $5 \mu \mathrm{m})$ column from Waters preceded with a Lichrospher C18 (4 x 4 mm i.d., $5 \mu \mathrm{m})$ guard column from Merck (Fontenay-sous-bois, France), both kept at $25^{\circ} \mathrm{C}$. The analytes were eluted under isocratic conditions using a mobile phase composed of $\mathrm{ACN} / \mathrm{H}_{2} \mathrm{O} / \mathrm{HCOOH}(60: 40: 0.1 \mathrm{v} / \mathrm{v} / \mathrm{v})$ delivered at a flow rate of $1 \mathrm{~mL} \cdot \mathrm{min}^{-1}$. All compounds were detected at $318 \mathrm{~nm}$ ( $\lambda_{\max }$ for all compounds).

2.12. LogP Determination. The $\log P$ values of the investigated compounds were determined from retention time values ( $\mathrm{k}^{\prime}$ ) obtained by HPLC, according to the procedure described by Mirrlees et al. ${ }^{56}$ The test compounds were analyzed on C18 stationary phase $(150$ x $4.6 \mathrm{~mm}$ i.d., $5 \mu \mathrm{m}$ ) using various compositions of $\mathrm{ACN} / \mathrm{H}_{2} \mathrm{O}$ mobile phase delivered at a flow rate of 1 $\mathrm{mL} \cdot \mathrm{min}^{-1}$. All other chromatographic conditions were the same as those described in microsomal stability assay section.

2.13. Antitumor Assay In Vivo. In-vivo cytotoxic antitumor activity of the selected compounds was evaluated using a syngeneic murine melanoma model (B16F10) in C57BL/6 mice purchased from Charles River (Wilmington, Massachusetts, USA). Briefly, animals were randomly divided into six groups (A: Control $(\mathrm{n}=5), B$ : Vehicle $(\mathrm{n}=5), \mathrm{C}: \mathbf{1}(\mathrm{n}=5), \mathrm{D} 1, \mathrm{D} 2$ and D3: 16a: 5, 25 and $50 \mathrm{mg} / \mathrm{Kg} /$ day $(\mathrm{n}=10))$ and one million B16F10 melanoma cells were suspended in $100 \mu \mathrm{l}$ of PBS and inJected subcutaneously in the right flank of 8-week-old male mice. Tumor growth was quantified by Vernier caliper measurements every 3 or 4 days. Tumor 
volume was calculated as $0.5 \mathrm{x}$ length $\mathrm{x}$ width ${ }^{2}$. Seven days after inJection, individuals were chronically exposed to treatment by the use of Alzet ${ }^{\circledR}$ micro-osmotic pumps $(200 \mu \mathrm{L}$ total volume, model 2002, Charles River Laboratories, (Wilmington, Massachusetts, USA). Filling and preparation of the pumps for implantation was done as described by the manufacturer. The micro-osmotic pumps were engrafted on the upper-right dorsal skin area and under general anesthesia; each individual was administered with a single subcutaneous dose of Ketamine (80 $\mathrm{mg} / \mathrm{kg})$ and Xylazine $(16 \mathrm{mg} / \mathrm{kg})$. Each molecule was dissolved in the vehicle solution $(0.9 \%$ $\mathrm{NaCl}$ containing $5 \%$ polyethylene glycol 400 and $0.5 \%$ Tween 80$)^{57}$ and the pumping rate and pumping duration were $0.5 \mu 1 / \mathrm{h}$ and 14 days respectively. All the protocols were approved by the Regional Ethics Committee on Animal Experimentation and all the experiments complied with European Parliament Directive 2010/63/EU. The adequacy of anesthesia was confirmed by the lack of the tail pinch response.

2.14. Analysis of In Vivo Tumor Vascularization. Immunohistochemistry was performed using an automated protocol developed for the DISCOVERY XT automated slide staining system (Ventana Medical Systems, Inc.,). Tumors were harvested, weighted and formalin fixed paraffin embedded for immunohistochemical analysis. Histological $6-\mu \mathrm{m}$ thick tumor sections were deparafinized and incubated for $1 \mathrm{~h}$ with a rabbit anti-mouse CD31 polyclonal antibody (clone ab28364, Abcam $^{\circledR}$ ), then with Discovery UltraMap anti-Rabbit HRP (760-4315, Roche $^{\circledR}$ ) and Discovery ChromoMap DAB kit (760-159, Roche $\left.{ }^{\circledR}\right)$. Ten fields were examined per section. The percentage of vessel surface area and the number of vessels per square milimeter were quantified with Image J. Results were expressed as the percentage of vessel surface area (\%) and the number of vessels $/ \mathrm{mm}^{2}$. 
2.15. Statistical Analysis. Results are expressed as means \pm SEM. Data were analyzed using ANOVA followed by Fisher's PLSD post hoc test implemented with Graphpad Prism ${ }^{\circledR}$ and StatView software (SAS, Cary, NC, USA). Significance was assumed at $\mathrm{P}<0.05$ (*; $<<0.05$, **; $\mathrm{p}<0.01, * * * ; \mathrm{p}<0.005, * * * * ; \mathrm{p}<0.001)$

\section{ASSOCIATED CONTENT}

\section{Supporting Information}

${ }^{1} \mathrm{H}$ NMR, ${ }^{13} \mathrm{C}$ NMR of original compounds and HPLC purity data for tested compounds.

Molecular formula strings in csv format. This material is available free of charge via the Internet at http://pubs.acs.org.

\section{Accession Codes}

PDB code $3 \mathrm{HKC}$ was used for model docking of compound 16a and 27a. Authors will release the atomic coordinates and experimental data upon article publication.

\section{AUTHOR INFORMATION}

\section{Corresponding Author}

*For N.L.: phone, +33 (0)320 964 977; fax, +33 (0) 320964 913; e-mail, nicolas.lebegue@univlille2.fr. Websites: http://medchem-u1172.univ-lille2.fr/.

\section{Notes}

The authors declare no competing financial interest.

\section{ACKNOWLEDGMENT}


The authors gratefully acknowledge the National Cancer Institute (NCI) for biological evaluation of compounds on their 60-cell panel: the testing was performed by the Developmental Therapeutics Program, Division of Cancer Treatment and Diagnosis (the URL to the Program's website: http://dtp.cancer.gov). We are also thankful to Anna LokaJczyk and team UMR-S1140 Inserm for the graciously provided B16F10 cells, the flow cytometry core facility of BiCEL and Jean-Pierre Decavel, PLETHA, Institut Pasteur de Lille for their technical assistance.

\section{ABBREVIATIONS}

ADME, Absorption Distribution Metabolism and Excretion; BSA, bovine serum albumin; CA-4, combretastatin A-4; DCM, dichloromethane; DDQ, 2,3-dichloro-5,6-dicyano-p-benzoquinone; DMF, $N, N$-dimethyl-formamide; DMSO, dimethyl sulfoxide; DNA, deoxyribonucleic acid; ECGM, endothelial cell growth medium; EGTA, ethylene glycol tetraacetic acid; EtOAc, ethyl acetate; EtOH, ethanol; FBS, fetal bovine serum; GTP, guanosine triphosphate; MG-MID, mean graph midpoints; NCI, national cancer institute; NSCLC, non-small cell lung cancer; PBS, phosphate-buffered saline; PIPES, piperazine- $N, N^{\prime}$-bis(2-ethanesulfonic acid; RPMI medium, Roswell Park Memorial Institute medium; SAR, structure-activity relationships; THF, tetrahydrofurane; TLC, thin layer chromatography; VDA, vascular disrupting agent.

\section{REFERENCES}

(1) Honore, S.; Pasquier, E.; Braguer, D. Understanding microtubule dynamics for improved cancer therapy. Cell. Mol. Life Sci. 2005, 62, 3039-3056.

(2) Schiff, P. B.; Fant, J.; Horwitz, S. B. Promotion of microtubule assembly in vitro by taxol. Nature 1979, 277, 665-667. 
(3) Jordan, M. A.; Hadfield, J. A.; Lawrence, N. J.; McGown, A. T. Tubulin as a target for anticancer drugs: agents which interact with the mitotic spindle. Med. Res. Rev. 1998, 18, 259296.

(4) Li, Q.; Sham, H.; Rosenberg, S. Chapter 14. Antimitotic agents. Annu. Rep. Med. Chem. 1999, 34, 139-148.

(5) Nam, N. H. Combretastatin A-4 analogues as antimitotic antitumor agents. Curr. Med. Chem. 2003, 10, 1697-1722.

(6) Yoshino, H.; Ueda, N.; NiiJima, J.; Sugumi, H.; Kotake, Y.; Koyanagi, N.; Yoshimatsu, K.; Asada, M.; Watanabe, T.; Nagaau, T.; Tsukahara, K.; IiJima, A.; Kitoh, K. Novel sulfonamides as potential, systemically active antitumor agents. J. Med. Chem. 1992, 35, 2496-2497.

(7) Yoshimatsu, K.; Yamaguchi, A.; Yoshino, H.; Koyanagi, N.; Kitoh, K. Mechanism of action of E7010, an orally active sulfonamide antitumor agent: inhibition of mitosis by binding to the colchicine site of tubulin. Cancer Res. 1997, 57, 3208-3213.

(8) Segreti, J. A.; Polakowski, J. S.; Koch, K. A.; Marsh, K. C.; Bauch, J. L.; Rosenberg, S.H.; Sham, H. L.; Cox, B. F.; Reinhart, G. A. Tumor selective antivascular effects of the novel antimitotic compound ABT-751: an in vivo rat regional hemodynamic study. Cancer Chemother. Pharmacol. 2004, 54, 273-281.

(9) Jorgensen, T. J.; Hui, T.; Joseph, I. B.; Menon, K.; Frost, D. Chemosensitization and radiosensitization of human lung and colon cancers by antimitotic agent, ABT-751, in athymic murine xenograft models of subcutaneous tumor growth. Cancer Chemother. Pharmacol. 2007, 59, 725-732. 
(10) Lebegue, N.; Gallet, S.; Flouquet, N.; Carato, P.; Pfeiffer, B.; Renard, P.; Léonce, S.; Pierré, A.; Chavatte, P.; Berthelot, P. Novel benzopyridothiadiazepines as potential active antitumor agents. J. Med. Chem. 2005. 48, 7363-7373.

(11) Gallet, S.; Flouquet, N.; Carato, P.; Pfeiffer, B.; Renard, P.; Léonce, S.; Pierré, A.; Berthelot, P.; Lebegue, N. Benzopyridooxathiazepine derivatives as novel potent antimitotic agents. Bioorg. Med. Chem. 2009, 17, 1132-1138.

(12) Lecoeur, M.; Verones, V.; Vaccher, C.; Bonte, J. P.; Lebegue, N.; Goossens, J. F. Structural elucidation of degradation products of a benzopyridooxathiazepine under stress conditions using electrospray orbitrap mass spectrometry - Study of degradation kinetic. Eur. J. Pharm. Sci. 2012, 45, 559-569.

(13) Bourdon, F.; Lecoeur, M.; Verones, V.; Vaccher, C.; Lebegue, N.; Dine, T.; Kambia, N.; Goossens, J. F. In vitro pharmacokinetic profile of a benzopyridooxathiazepine derivative using rat microsomes and hepatocytes: Identification of phases I and II metabolites. J. Pharm. Biomed. Anal. 2013, 80, 69-78.

(14) Bourdon, F.; Lecoeur, M.; Lebegue, N.; Gressier, B.; Luyckx, M.; Odou, P.; Dine, T.; Goossens, J. F.; Kambia, N. Pharmacokinetic evaluation of a novel benzopyridooxathiazepine derivative as a potential anticancer agent. Pharmacology 2014, 94, 170-178.

(15) Evans, B. E.; Rittle, K. E.; Bock, M. G.; DiPardo, R. M.; Freidinger, R. M.; Whitter, W. L.; Lundell, G. F.; Veber, D. F.; Anderson, P. S.; Chang, R. S. L.; Lotti, V. J.; Cerino, D. J.; Chen, T. B.; Kling, P. J.; Kunkel, K. A.; Springer, J. P.; Hirshfield, J. Methods for drug discovery: development of potent, selective, orally effective cholecystokinin antagonists. J. Med. Chem. 1988, 31, 2235-2246. 
(16) Horton, D. A.; Bourne, G. T.; Smythe, M. L. The combinatorial synthesis of bicyclic privileged structures or privileged substructures. Chem. Rev. 2003, 103, 893-930.

(17) DeSimone, R. W.; Currie, K. S.; Mitchell, S. A.; Darrow, J. W.; Pippin, D. A. Comb. Privileged structures: applications in drug discovery. Chem. High Throughput Screening 2004, 7, 473-494.

(18) Sharma, P.C.; Kaur, G.; Pahwa, R.; Sharma, A.; RaJak, H., Quinazolinone analogs as potential therapeutic agents. Curr. Med. Chem., 2011, 18, 4786-4812.

(19) Khan, I.; Ibrar, A.; Ahmed, W.; Saeed, A. Synthetic approaches, functionalization and therapeutic potential of quinazoline and quinazolinone skeletons: the advances continue. Eur. J. Med. Chem. 2015, 90, 124-169.

(20) Hamel, E.; Lin, C. M.; Plowman, J.; Wang, H. K.; Lee, K. H.; Paull, K. D. Antitumor 2,3dihydro-2-(aryl)-4(1H)-quinazolinone derivatives. Interactions with tubulin. Biochem. Pharmacol. 1996, 51, 53-59.

(21) Yang, J. S.; Hour, M. J.; Kuo, S. C.; Huang, L. J.; Lee, M. R. Selective induction of G2/M arrest and apoptosis in HL-60 by a potent anticancer agent, HMJ-38. Anticancer Res. 2004, 24, 1769-1778.

(22) Jiang, J. B.; Hesson, D. P.; Dusak, B. A.; Dexter, D. L.; Kang, G. J.; Hamel, E. Synthesis and biological evaluation of 2-styrylquinazolin-4(3H)-ones, a new class of antimitotic anticancer agents which inhibit tubulin polymerization. J. Med. Chem. 1990, 33, 1721-1728.

(23) Hour, M. J.; Huang, L. J.; Kuo, S. C.; Xia, Y.; Bastow, K.; Nakanishi, Y.; Hamel, E.; Lee, K. H. 6-Alkylamino- and 2,3-dihydro-3'-methoxy-2-phenyl-4-quinazolinones and related 
compounds: their synthesis, cytotoxicity, and inhibition of tubulin polymerization. J. Med. Chem. 2000, 43, 4479-4487.

(24) Liu, J. F.; Wilson, C. J.; Ye, P.; Sprague, K.; Sargent, K.; Si, Y.; Beletsky, G.; Yohannes, D.; Ng, S. C. Privileged structure-based quinazolinone natural product-templated libraries: identification of novel tubulin polymerization inhibitors. Bioorg. Med. Chem. Lett. 2006, 16, 686-690.

(25) Hess, H.-J.; Cronin, T. H.; Scriabine, A. Antihypertensive 2-amino-4(3H)-quinazolinones. J. Med. Chem. 1968, 11, 130-136.

(26) Murdoch, R.; Roger Tully, W.;* Westwood, R. Synthesis of $[1,2,4]$ triazoloquinazolinones and imidazoquinazolinones. J. Heterocycl. Chem. 1986, 23, 833-841.

(27) (a) Chern, J. W.; Rong, J. G. 1,2,4 Benzothiadiazine 1,1-dioxide. V: ${ }^{1}$ synthesis of built-in hydroxuguanidine tricycles as potential anticancer agents. Tetrahedron Lett. 1991, 32, 2935 2938. (b) Chern, J. W.; Liaw, Y. C.; Chen, C. S.; Rong, J. G.; Huang, C. L.; Chan, C. H.; Wang, A. H. J. Studies on 1,2,4-benzothiadiazine 1,1-dioxides VII and quinazolinones IV: synthesis of novel built-in hydroxyguanidine tricycles as potential anticancer agents. Heterocycles 1993, 36, 1091-1103.

(28) Verones, V.; Flouquet, N.; Farce, A.; Berthelot, P.; Lebegue, N. Unexpected heteroannelation and chlorination of benzothiadiazine derivatives mediated by DDQ. Synthesis 2014, 46, 235-241. 
(29) Nguyen, T. L.; McGrath, C.; Hermone, A. R.; Burnett, J. C.; Zaharevitz, D. W.; Day, B. W.; Wipf, P.; Hamel, E.; Gussio, R. A. A common pharmacophore for a diverse set of colchicine site inhibitors using a structure-based approach. J. Med. Chem. 2005, 48, 6107-6116.

(30) Shoemaker, R. H. The NCI60 human tumour cell line anticancer drug screen. Nat. Rev. Cancer 2006, 6, 813-823 (and references cited therein).

(31) Beauregard, D. A.; Pedley, R. B.; Hill, S. A.; Brindle, K. M. Differential sensitivity of two adenocarcinoma xenografts to the anti-vascular drugs combretastatin A4 phosphate and 5,6dimethylxanthenone-4-acetic acid, assessed using MRI and MRS. NMR Biomed. 2002, 15, 99105.

(32) Franklin, T. J.; Jacobs, V.; Jones, G.; Plé, P.; Bruneau, P. Glucuronidation associated with intrinsic resistance to mycophenolic acid in human colorectal carcinoma cells. Cancer Res. 1996, $56,984-987$.

(33) Dorléans, A.; Gigant, B.; Ravelli, R. B. G.; Mailliet, P.; Mikol, V.; Knossow, M. Variations in the colchicine-binding domain provide insight into the structural switch of tubulin. Proc. Natl. Acad. Sci. U. S. A. 2009, 106, 13775-13779.

(34) Trott, O.; Olson, A. J. AutoDock Vina: Improving the speed and accuracy of docking with a new scoring function, efficient optimization, and multithreading. J. Comput. Chem. 2010, $31,455-461$.

(35) Wang, Y.; Zhang, H.; Gigant, B.; Yu, Y.; Wu, Y.; Chen, X.; Lai, Q.; Yang, Z.; Chen, Q.; Yang, J. Structures of a diverse set of colchicine binding site inhibitors in complex with tubulin provide a rationale for drug discovery. FEBS J. 2016, 283, 102-111. 
(36) Bai, R.; Covell, D. G.; Pei, X.-F.; Ewell, J. B.; Nguyen, N. Y.; Brossi, A.; Hamel, E. Mapping the binding site of colchicinoids on $\beta$-tubulin. J. Biol. Chem. 2000, 275, 40443-40452.

(37) Pettersen, E. F.; Goddard, T. D.; Huang, C. C.; Couch, G. S.; Greenblatt, D. M.; Meng, E. C.; Ferrin, T. E. UCSF Chimera-A visualization system for exploratory research and analysis. J. Comput. Chem. 2004, 25, 1605-1612.

(38) Baeriswyl, V.; Christofori, G. The angiogenic switch in carcinogenesis. Semin. Cancer Biol. 2009, 19, 329-337.

(39) Tozer, G. M.; Kanthou, C.; Baguley, B. C. Disrupting tumour blood vessels. Nat. Rev. Cancer 2005, 5, 423-435.

(40) Schwartz, E. L. Antivascular actions of microtubule-binding drugs. Clin. Cancer Res. 2009, 15, 2594-2601.

(41) Lindsay, C. R.; MacPherson, I. R.; Cassidy, J. Current status of cediranib: the rapid development of a novel anti-angiogenic therapy. Future Oncol. 2009, 5, 421-432.

(42) Hotchkiss, K. A.; Ashton, A. W.; Mahmood, R.; Russel, R. G.; Sparano, J. A.; Schwartz, E. L. Inhibition of endothelial cell function in vitro and angiogenesis in vivo by docetaxel (Taxotere): association with impaired repositioning of the microtubule organizing center. Mol. Cancer Ther. 2002, 1, 1191-1200.

(43) Bouvard, C.; Segaoula, Z.; De Arcangelis, A.; Galy-Fauroux, I.; Mauge, L.; Fischer, A.M.; Georges-Labouesse, E.; Helley, D. Tie2-dependent deletion of $\alpha 6$ integrin subunit in mice reduces tumor growth and angiogenesis. Int. J. Oncol. 2014, 45, 2058-2064. 
(44) Koyanagi, N.; Nagasu, T.; FuJita, F.; Watanabe, T.; Tsukahara, K.; Funahashi, Y.; FuJita, M.; Taguchi, T.; Yoshino, H.; Kitoh, K. In vivo tumor growth inhibition produced by a novel sulfonamide, E7010, against rodent and human tumors. Cancer Res. 1994, 54, 1702-1706.

(45) Palazzo, S.; Giannola, L. I.; Neri, M. Synthesis of 5H-[1,2]-benzisothiazolo[2,3a]quinazolin-5-one. J. Heterocycl. Chem. 1975, 12, 1077-1078.

(46) Sun, Z.; Wang, H.; Wen, K.; Li, Y.; Fan, E. Solvent-free or low-solvent large-scale preparation of chloropyrimidine and analogues. J. Org. Chem. 2011, 76, 4149-4153.

(47) Prashad, M.; Har, D.; Hu, B.; Kim, H-Y.; Girgis, M. J.; Chaudhary, A.; Repic, O.; Blacklock, T. J.; Marterer, W. Process development of a large-scale synthesis of TKA731: A tachykinin receptor antagonist. Org. Process Res. Dev. 2004, 8, 330-340.

(48) Shen, L.; Sun, D. Total synthesis and structural revision of engelhardione. Tetrahedron Lett. 2011, 52, 4570-4574.

(49) Batsomboon, P.; Phakhodee, W.; Ruchirawat, S.; Ploypradith, P. Generation of orthoquinone methides by $\mathrm{p}-\mathrm{TsOH}$ on silica and their hetero-Diels-Alder reactions with styrenes. J. Org. Chem. 2009, 74, 4009-4012.

(50) Sasaki, H.; Taguchi, H.; Endo, T.; Yosioka, I.; Higashiyama, K.; Otomasu, H. The Glycosides of Martynia louisiana MILL. A new phenylpropanoid glycoside, martynoside. Chem. Pharm. Bull. 1978, 26, 2111-2121.

(51) Gupton, J. T.; Clough, S. C.; Miller, R. B.; Lukens, J. R.; Henry, C. A.; Kanters, R. P. F.; Sikorski, J. A. The application of vinylogous iminium salt derivatives to the synthesis of Ningalin B hexamethyl ether. Tetrahedron, 2003, 59, 207-215. 
(52) McDonald, E.; Suksamrarn, A. Design of the substrate for oxidative phenol coupling. An efficient synthesis of the C-homoerythrinan skeleton. J. Chem. Soc., Perkin Trans. 1, 1978, 440446.

(53) Friary, R.; Gold, E. H. Dihydroimidazobenzothiadiazine dioxides. Heterocycles, 1977, 7, $765-771$.

(54) Skehan, P.; Storeng, R.; Scudiero, D.; Monks, A.; McMahon, J.; Vistica, D.; Warren, J. T.; Bokesch, H.; Kenney, S.; Boyd, M. R. New colorimetric cytotoxicity assay for anticancerdrug screening. J. Natl. Cancer Inst. 1990, 82, 1107-1112.

(55) Boyd, R. B. The NCI in vitro anticancer drug discovery screen. In anticancer drug development guide: preclinical screening, clinical trials, and approval, $1^{\text {st }}$ ed.; Teicher, B.; Humana Press Inc.: Totowa, NJ, 1997; pp. 23-42.

(56) Mirrlees, M. S.; Moulton, S. J.; Murphy, C. T.; Taylor, P. J. Direct measurement of octanol-water partition coefficients by high-pressure liquid chromatography. J. Med. Chem. 1976, 19, 615-620.

(57) Romagnoli, R.; Baraldi, P. G.; Salvador, M. K.; Prencipe, F.; Bertolasi, V.; Cancellieri, M.; Brancale, A.; Hamel, E.; Castagliuolo, I.; Consolaro, F.; Porcù, E.; Basso, G.; Viola, G. Synthesis, antimitotic and antivascular activity of 1-(3',4',5'-trimethoxybenzoyl)-3-arylamino-5amino-1,2,4-triazoles. J. Med. Chem. 2014, 57, 6795-6808. 

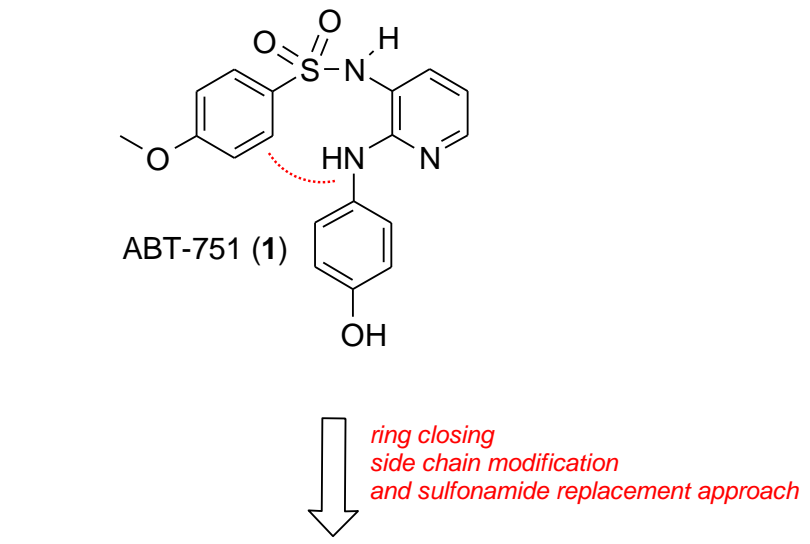<smiles>[R]c1ccc2c(c1)N=C1C(=CC=CN1C)CN2S(=O)(=O)O</smiles>

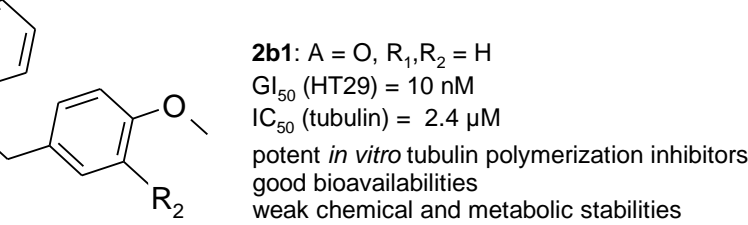

2a: $\mathrm{A}=\mathrm{N}-\mathrm{CH}_{3}$

2b: $\mathrm{A}=\mathrm{O}$

$\mathrm{R}_{1}=\mathrm{H}, \mathrm{Cl}, \mathrm{CH}_{3}, \mathrm{OCH}_{3}$

weak chemical and metabolic stabilities

$\mathrm{R}_{2}=\mathrm{H}, \mathrm{OH}, \mathrm{OCH}_{3}$
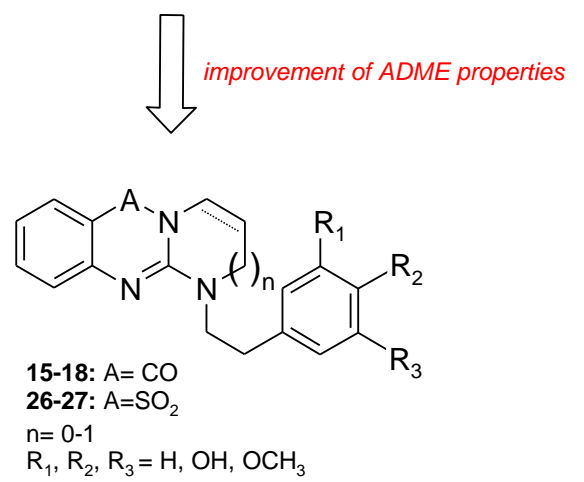

Figure 1. Rational design of compounds 15-18 and 26-27. 


\title{
Scheme 1. Synthesis of Investigated Compounds $(15-18)^{a}$
}

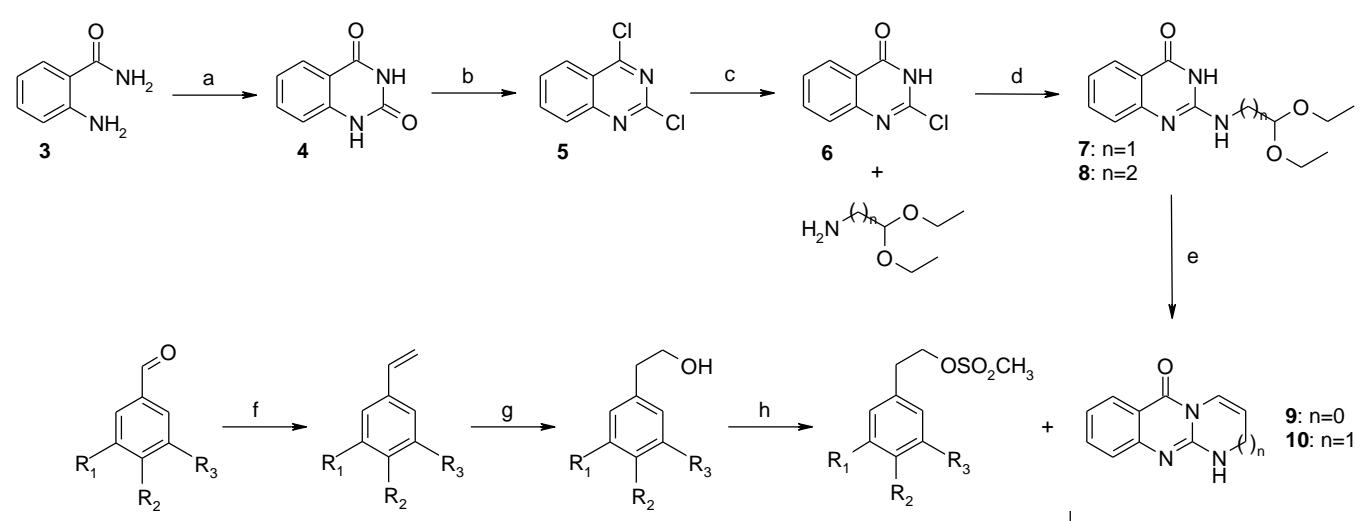

\begin{abstract}
11b-d
$\mathrm{R}_{1}=\mathrm{H}, \mathrm{OBn}, \mathrm{OCH}_{3}$
$\mathrm{R}_{2}=\mathrm{OCH}_{3}$

$\mathrm{R}_{3}=\mathrm{H}, \mathrm{OCH}_{3}$
\end{abstract}

12b-d
$\mathrm{R}_{1}=\mathrm{H}, \mathrm{OBn}, \mathrm{OCH}_{3}$

$\mathrm{R}_{2}=\mathrm{OCH}_{3}$

$\mathrm{R}_{3}=\mathrm{H}, \mathrm{OCH}_{3}$
13a-d
$\mathrm{R}_{1}=\mathrm{H}, \mathrm{OBn}, \mathrm{OCH}_{3}$

$\mathrm{R}_{2}=\mathrm{OCH}_{3}$

$\mathrm{R}_{3}=\mathrm{H}, \mathrm{OCH}_{3}$
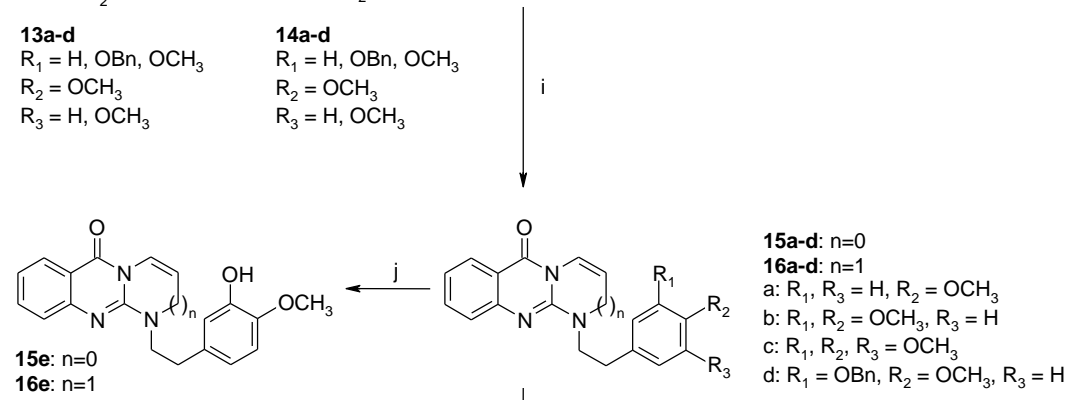

16: $: n=1$

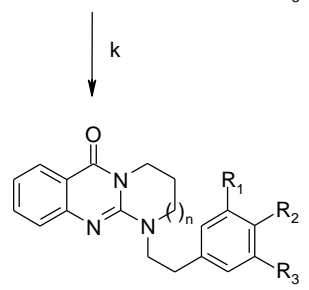

17a-d: $n=0$

18a-d: $n=1$

a: $R_{1}, R_{3}=H, R_{2}=\mathrm{OCH}_{3}$

b: $\mathrm{R}_{1}, \mathrm{R}_{2}=\mathrm{OCH}_{3}, \mathrm{R}_{3}=\mathrm{H}$

c: $\mathrm{R}_{1}, \mathrm{R}_{2}, \mathrm{R}_{3}=\mathrm{OCH}_{3}$

d: $\mathrm{R}_{1}=\mathrm{OH}, \mathrm{R}_{2}=\mathrm{OCH}_{3}, \mathrm{R}_{3}=\mathrm{H}$

aReagents and conditions: (a) $\mathrm{KOCN}, \mathrm{AcOH}, \mathrm{H}_{2} \mathrm{O}, 35^{\circ} \mathrm{C}, 74 \%$; (b) $\mathrm{POCl}_{3}, \mathrm{~N}, \mathrm{~N}$-dimethylaniline, reflux, $88 \%$; (c) $2 \% \mathrm{NaOH}, 30^{\circ} \mathrm{C}, 83 \%$; (d) $\mathrm{EtOH}$, reflux, $71-88 \%$; (e) conc $\mathrm{H}_{2} \mathrm{SO}_{4}$, room temperature, 60-89\%; (f) $\mathrm{H}_{3} \mathrm{CP}+(\mathrm{Ph})_{3} \mathrm{l}^{-}$, tBuOK, THF, $0^{\circ} \mathrm{C}$ to room temperature, $71-90 \%$; (g) i: $1 \mathrm{M} \mathrm{BH} \mathrm{B}_{3} \cdot \mathrm{THF}, \mathrm{N}_{2}, \mathrm{THF}, 0^{\circ} \mathrm{C}, \mathrm{ii}: 10 \% \mathrm{NaOH}, 35 \% \mathrm{H} \mathrm{O}_{2}, 75-87 \%$; (h) $\mathrm{ClSO}_{2} \mathrm{CH}_{3}, \mathrm{NEt}_{3}, \mathrm{DCM}, 0^{\circ} \mathrm{C}$ to room temperature, 69-83\%; (i) $\mathrm{NaH}, \mathrm{DMF}, 20-26 \%$; (j) $33 \% \mathrm{HBr}, \mathrm{AcOH}$, room temperature, 56-63\%; (k) $\mathrm{HCOONH}$, $\mathrm{Pd} / \mathrm{C}, \mathrm{EtOH}, 60^{\circ} \mathrm{C}$, $43-69 \%$. 


\section{Scheme 2. Synthesis of Benzothiadiazine Analogues (26-27) ${ }^{a}$}
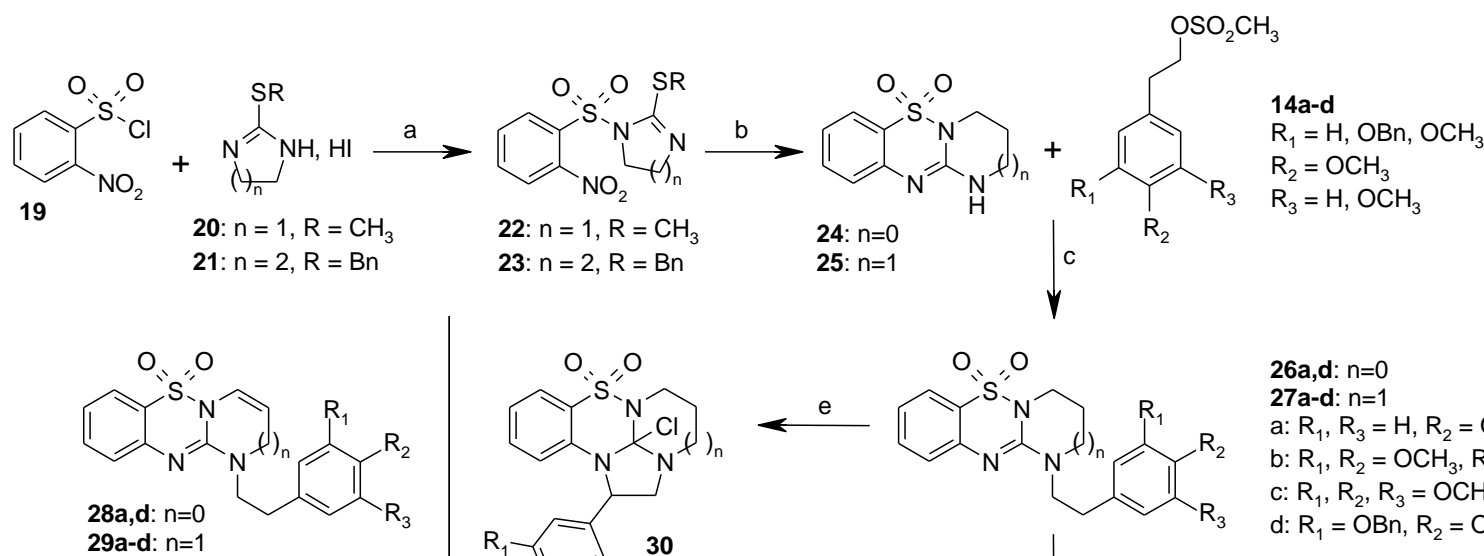

not observed
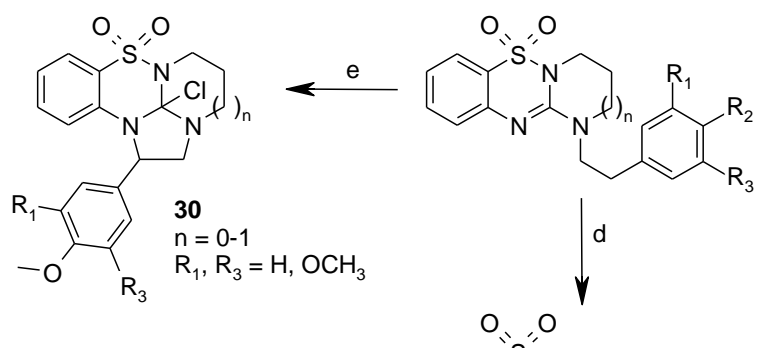

26a,d: $n=0$

27a-d: $n=1$

a: $R_{1}, R_{3}=H, R_{2}=\mathrm{OCH}_{3}$

b: $\mathrm{R}_{1}, \mathrm{R}_{2}=\mathrm{OCH}_{3}, \mathrm{R}_{3}=\mathrm{H}$

c: $\mathrm{R}_{1}, \mathrm{R}_{2}, \mathrm{R}_{3}=\mathrm{OCH}_{3}$

d: $R_{1}=O B n, R_{2}=O_{3}, R_{3}=H$

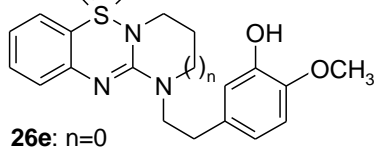

27e: $n=1$

aReagents and conditions: (a) $\mathrm{NEt}_{3}, \mathrm{DCM}$, room temperature, 62-91\%; (b) $\mathrm{SnCl}_{2}, \mathrm{HCl}, \mathrm{EtOH}$, reflux, 47-62\%; (c) $\mathrm{NaH}, \mathrm{DMF}, 70^{\circ} \mathrm{C}, 48-69 \%$; (d) $\mathrm{HCOONH}{ }_{4}, \mathrm{Pd} / \mathrm{C}, \mathrm{MeOH}, 50^{\circ} \mathrm{C}, 51-54 \%$; (e) DDQ, toluene, reflux, $21-25 \%$. 
Table 1. Structures, inhibition of tubulin polymerization and in vitro proliferation inhibition percentage against human colon adenocarcinoma HT29 cell line of compounds 15a-e, 16a-e, 17a-d, 18a-d, 26a,e and 27a-e.

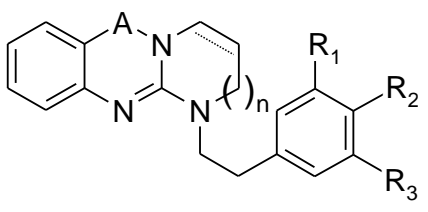

\begin{tabular}{|c|c|c|c|c|c|c|c|c|}
\hline Compd & A & $m^{m}$ & $\mathrm{n}$ & $\mathrm{R}_{1}$ & $\mathrm{R}_{2}$ & $\mathrm{R}_{3}$ & $\begin{array}{c}\text { \% inhibition or } \\
\mathrm{IC}_{50}(\mu \mathrm{M})^{a}\end{array}$ & $\begin{array}{c}\mathrm{IC}_{50} \text { TPI } \\
(\mu \mathrm{M})^{b}\end{array}$ \\
\hline $15 a$ & $\mathrm{C}=\mathrm{O}$ & $\mathrm{CH}=\mathrm{CH}$ & 0 & $\mathrm{H}$ & $\mathrm{OCH}_{3}$ & $\mathrm{H}$ & 7.77 & $>10$ \\
\hline $15 b$ & $\mathrm{C}=\mathrm{O}$ & $\mathrm{CH}=\mathrm{CH}$ & 0 & $\mathrm{OCH}_{3}$ & $\mathrm{OCH}_{3}$ & $\mathrm{H}$ & $7 \%$ & $>10$ \\
\hline $15 \mathrm{c}$ & $\mathrm{C}=\mathrm{O}$ & $\mathrm{CH}=\mathrm{CH}$ & 0 & $\mathrm{OCH}_{3}$ & $\mathrm{OCH}_{3}$ & $\mathrm{OCH}_{3}$ & $0 \%$ & $>10$ \\
\hline $15 e$ & $\mathrm{C}=\mathrm{O}$ & $\mathrm{CH}=\mathrm{CH}$ & 0 & $\mathrm{OH}$ & $\mathrm{OCH}_{3}$ & $\mathrm{H}$ & 4.73 & $>10$ \\
\hline $16 a$ & $\mathrm{C}=\mathrm{O}$ & $\mathrm{CH}=\mathrm{CH}$ & 1 & $\mathrm{H}$ & $\mathrm{OCH}_{3}$ & $\mathrm{H}$ & 0.042 & $0.812 \pm 0.11$ \\
\hline $16 \mathrm{~b}$ & $\mathrm{C}=\mathrm{O}$ & $\mathrm{CH}=\mathrm{CH}$ & 1 & $\mathrm{OCH}_{3}$ & $\mathrm{OCH}_{3}$ & $\mathrm{H}$ & 0.766 & $0.373 \pm 0.07$ \\
\hline $16 \mathrm{c}$ & $\mathrm{C}=\mathrm{O}$ & $\mathrm{CH}=\mathrm{CH}$ & 1 & $\mathrm{OCH}_{3}$ & $\mathrm{OCH}_{3}$ & $\mathrm{OCH}_{3}$ & $0 \%$ & $>10$ \\
\hline $16 e$ & $\mathrm{C}=\mathrm{O}$ & $\mathrm{CH}=\mathrm{CH}$ & 1 & $\mathrm{OH}$ & $\mathrm{OCH}_{3}$ & $\mathrm{H}$ & 4.05 & $0.65 \pm 0.08$ \\
\hline $17 \mathbf{a}$ & $\mathrm{C}=\mathrm{O}$ & $\mathrm{CH}_{2}-\mathrm{CH}_{2}$ & 0 & $\mathrm{H}$ & $\mathrm{OCH}_{3}$ & $\mathrm{H}$ & $0 \%$ & $>10$ \\
\hline $17 b$ & $\mathrm{C}=\mathrm{O}$ & $\mathrm{CH}_{2}-\mathrm{CH}_{2}$ & 0 & $\mathrm{OCH}_{3}$ & $\mathrm{OCH}_{3}$ & $\mathrm{H}$ & $0 \%$ & $>10$ \\
\hline $17 \mathrm{c}$ & $\mathrm{C}=\mathrm{O}$ & $\mathrm{CH}_{2}-\mathrm{CH}_{2}$ & 0 & $\mathrm{OCH}_{3}$ & $\mathrm{OCH}_{3}$ & $\mathrm{OCH}_{3}$ & $0 \%$ & $>10$ \\
\hline 17d & $\mathrm{C}=\mathrm{O}$ & $\mathrm{CH}_{2}-\mathrm{CH}_{2}$ & 0 & $\mathrm{OH}$ & $\mathrm{OCH}_{3}$ & $\mathrm{H}$ & 7.78 & $>10$ \\
\hline $18 \mathbf{a}$ & $\mathrm{C}=\mathrm{O}$ & $\mathrm{CH}_{2}-\mathrm{CH}_{2}$ & 1 & $\mathrm{H}$ & $\mathrm{OCH}_{3}$ & $\mathrm{H}$ & 0.16 & $1.29 \pm 0.18$ \\
\hline $18 b$ & $\mathrm{C}=\mathrm{O}$ & $\mathrm{CH}_{2}-\mathrm{CH}_{2}$ & 1 & $\mathrm{OCH}_{3}$ & $\mathrm{OCH}_{3}$ & $\mathrm{H}$ & $47 \%$ & $>10$ \\
\hline $18 \mathrm{c}$ & $\mathrm{C}=\mathrm{O}$ & $\mathrm{CH}_{2}-\mathrm{CH}_{2}$ & 1 & $\mathrm{OCH}_{3}$ & $\mathrm{OCH}_{3}$ & $\mathrm{OCH}_{3}$ & $0 \%$ & $>10$ \\
\hline 18d & $\mathrm{C}=\mathrm{O}$ & $\mathrm{CH}_{2}-\mathrm{CH}_{2}$ & 1 & $\mathrm{OH}$ & $\mathrm{OCH}_{3}$ & $\mathrm{H}$ & 5.73 & $>10$ \\
\hline $26 a$ & $\mathrm{SO}_{2}$ & $\mathrm{CH}_{2}-\mathrm{CH}_{2}$ & 0 & $\mathrm{H}$ & $\mathrm{OCH}_{3}$ & $\mathrm{H}$ & $0 \%$ & $>10$ \\
\hline $26 e$ & $\mathrm{SO}_{2}$ & $\mathrm{CH}_{2}-\mathrm{CH}_{2}$ & 0 & $\mathrm{OH}$ & $\mathrm{OCH}_{3}$ & $\mathrm{H}$ & $21 \%$ & $>10$ \\
\hline $27 \mathbf{a}$ & $\mathrm{SO}_{2}$ & $\mathrm{CH}_{2}-\mathrm{CH}_{2}$ & 1 & $\mathrm{H}$ & $\mathrm{OCH}_{3}$ & $\mathrm{H}$ & 0.2 & $0.27 \pm 0.03$ \\
\hline $27 b$ & $\mathrm{SO}_{2}$ & $\mathrm{CH}_{2}-\mathrm{CH}_{2}$ & 1 & $\mathrm{OCH}_{3}$ & $\mathrm{OCH}_{3}$ & $\mathrm{H}$ & $0 \%$ & $>10$ \\
\hline
\end{tabular}




\begin{tabular}{|c|c|c|c|c|c|c|c|c|}
\hline $27 \mathrm{c}$ & $\mathrm{SO}_{2}$ & $\mathrm{CH}_{2}-\mathrm{CH}_{2}$ & 1 & $\mathrm{OCH}_{3}$ & $\mathrm{OCH}_{3}$ & $\mathrm{OCH}_{3}$ & $0 \%$ & $>10$ \\
\hline $27 \mathrm{e}$ & $\mathrm{SO}_{2}$ & $\mathrm{CH}_{2}-\mathrm{CH}_{2}$ & 1 & $\mathrm{OH}$ & $\mathrm{OCH}_{3}$ & $\mathrm{H}$ & $32 \%$ & $0.461 \pm 0.046$ \\
\hline $2 \mathrm{b1}^{c}$ & & & & & & & 0.010 & 2.4 \\
\hline $\mathbf{1}^{c}$ & & & & & & & 0.21 & 2.2 \\
\hline
\end{tabular}


Table 2. Results of the in vitro human cancer cell growth inhibition ${ }^{a}$ for compounds 16a, 18a and 27a.

\begin{tabular}{|c|c|c|c|c|}
\hline Cell type & Compound & $16 a$ & $18 \mathbf{a}$ & $27 \mathbf{a}$ \\
\hline & Cell line & $\begin{array}{l}\mathrm{GI}_{50} \mathrm{~b}^{\mathrm{b}} \\
(\mathrm{nM})\end{array}$ & $\begin{array}{l}\mathrm{GI}_{50}^{\mathrm{b}} \\
(\mathrm{nM})\end{array}$ & $\begin{array}{l}\mathrm{GI}_{50}{ }^{\mathrm{b}} \\
(\mathrm{nM})\end{array}$ \\
\hline \multirow[t]{3}{*}{ Leukemia } & HL-60(TB) & 13.4 & 41.7 & 317 \\
\hline & K-562 & 21.0 & 42.2 & 196 \\
\hline & CCRF-CEM & 26.7 & 145 & 444 \\
\hline \multirow{4}{*}{$\begin{array}{l}\text { Non Small Cell Lung } \\
\text { (NSCL) cancer }\end{array}$} & A549/ATCC & 41.9 & 89.7 & 800 \\
\hline & HOP-62 & 47.0 & 128 & 556 \\
\hline & NCI-H226 & 13.9 & 2720 & 8250 \\
\hline & NCI-H522 & 14.2 & 44.3 & 278 \\
\hline \multirow[t]{4}{*}{ Colon cancer } & COLO 205 & 28.9 & 53.1 & 329 \\
\hline & HCT-116 & 33.8 & 48.7 & 443 \\
\hline & НCT-15 & 17.0 & 46.0 & 342 \\
\hline & HT29 & 31.9 & 37.0 & 323 \\
\hline \multirow{3}{*}{$\begin{array}{l}\text { Central nervous system } \\
\text { (CNS) cancer }\end{array}$} & SF-295 & 26.4 & 61.4 & 389 \\
\hline & SNB-75 & 16.8 & 80.9 & 296 \\
\hline & $\mathrm{U} 251$ & 36.8 & 67.8 & 387 \\
\hline \multirow[t]{4}{*}{ Melanoma } & M14 & 22.9 & 45.1 & 322 \\
\hline & MDA-MB-435 & $<10$ & 19.4 & 73.0 \\
\hline & SK-MEL-5 & 22.4 & 30.4 & 357 \\
\hline & UACC-62 & 18.8 & 605 & 744 \\
\hline \multirow[t]{4}{*}{ Ovarian cancer } & IGROV1 & 47.7 & 122 & 1510 \\
\hline & OVCAR-3 & 20.4 & 34.0 & 348 \\
\hline & NCI/ADR-RES & 13.2 & 35.5 & 300 \\
\hline & SK-OV-3 & 66.9 & 666 & 552 \\
\hline \multirow[t]{4}{*}{ Renal cancer } & $786-0$ & 43.6 & 218 & 651 \\
\hline & A498 & 18.2 & 11.1 & 195 \\
\hline & RXF 393 & 30.9 & 200 & 622 \\
\hline & UO-31 & 64.3 & 888 & 913 \\
\hline \multirow[t]{2}{*}{ Prostate cancer } & PC-3 & 31.2 & 213 & 529 \\
\hline & DU-145 & 38.6 & 234 & 496 \\
\hline \multirow[t]{3}{*}{ Breast cancer } & MCF7 & 30.2 & 30.7 & 329 \\
\hline & HS 578T & 30.7 & 256 & 577 \\
\hline & MDA-MB-468 & 51.3 & 26.5 & 312 \\
\hline MG-MID $^{c}(\mathrm{nM})$ & & 58.9 & 199.5 & 645 \\
\hline
\end{tabular}

${ }^{a}$ Data obtained from NCI's in vitro 60 cell screening [30-32].

${ }^{b} \mathrm{GI}_{50}$ is the molar concentration of synthetic compound causing 50\% growth inhibition of tumor cells.

${ }^{c}$ Average activity parameter over all cell lines for the tested compounds. 
Figure 2. Typical DNA content frequency histograms representing the effect of $\mathbf{1 6 a}$ vs. vehicle on cell cycle G2/M blockade among SK-Mel28 cells from the untreated cultures (CTRL, Vehicle) and from the cultures treated with 16a: cells were fixed with cold ethanol $70 \%$ and stored at $-20^{\circ} \mathrm{C}$ until analysis. The cells were stained with $50 \mu \mathrm{g} / \mathrm{mL}$ propidium iodide (PI) solution supplemented with $50 \mu \mathrm{L}$ of $100 \mu \mathrm{g} / \mathrm{ml}$ RNAse stock. (A) Analysis was carried out on a flow cytometer according to the presented protocols. Fluorescence of the PI-stained cells was measured using CyAnTM ADP Analyzer (Beckman Coulter, Inc.) and Summit software. (B) The software programs provide the estimate of percentage of cells with fractional DNA content and cells in G1, S, and G2/M phases of the cycle.

A
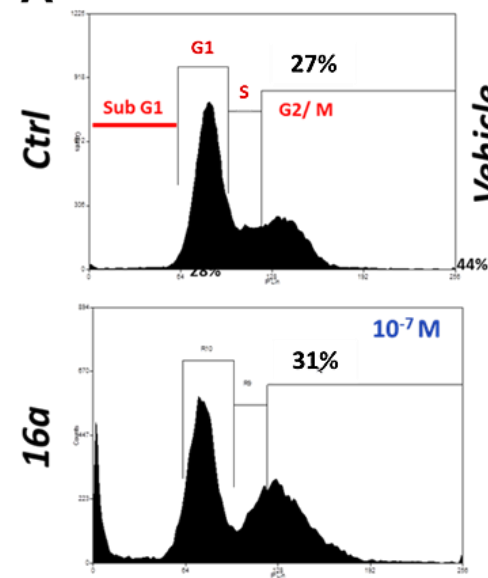
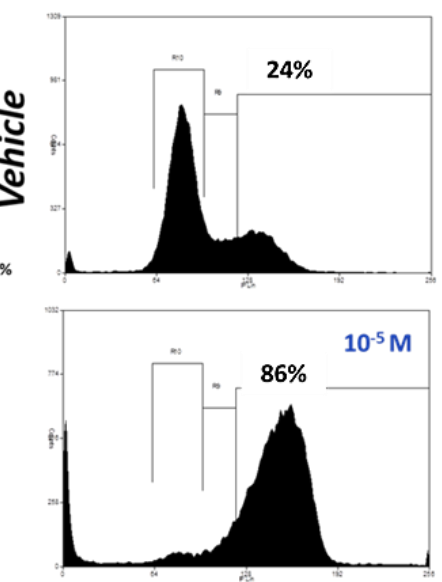

B

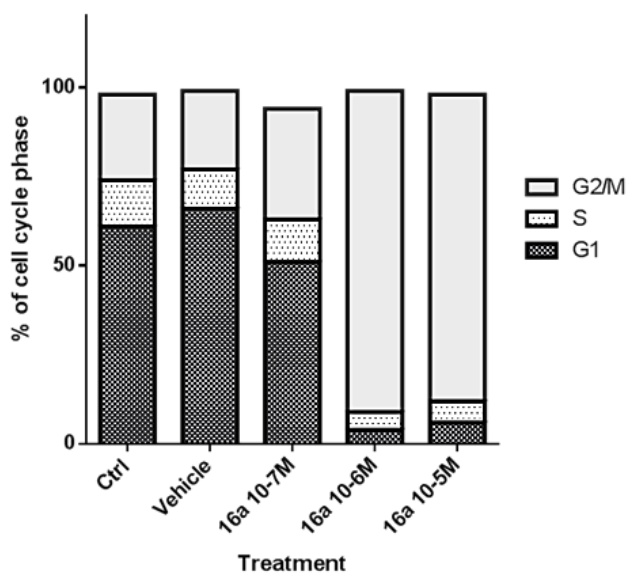


Figure 3. Effects of 16a vs. vehicle on cytoskeleton organization showing decreased microtubule assembly; SK-Mel28 cells were seeded $24 \mathrm{~h}$ in labteck chambers prior to treatment in $10 \%$ FCS supplemented complete medium. Drug were applied for $3 \mathrm{~h}$ in $37^{\circ} \mathrm{C}$ and $5 \% \mathrm{CO} 2$ incubator, as described in material and method section and cells were then stained using anti- $\square$ tubulin antibodies (AF488), and Hoechst to stain nuclei. Immunofluorescence (IF) was assessed and images were taken using Leica DMRB fluorescent microscope and Leica software.
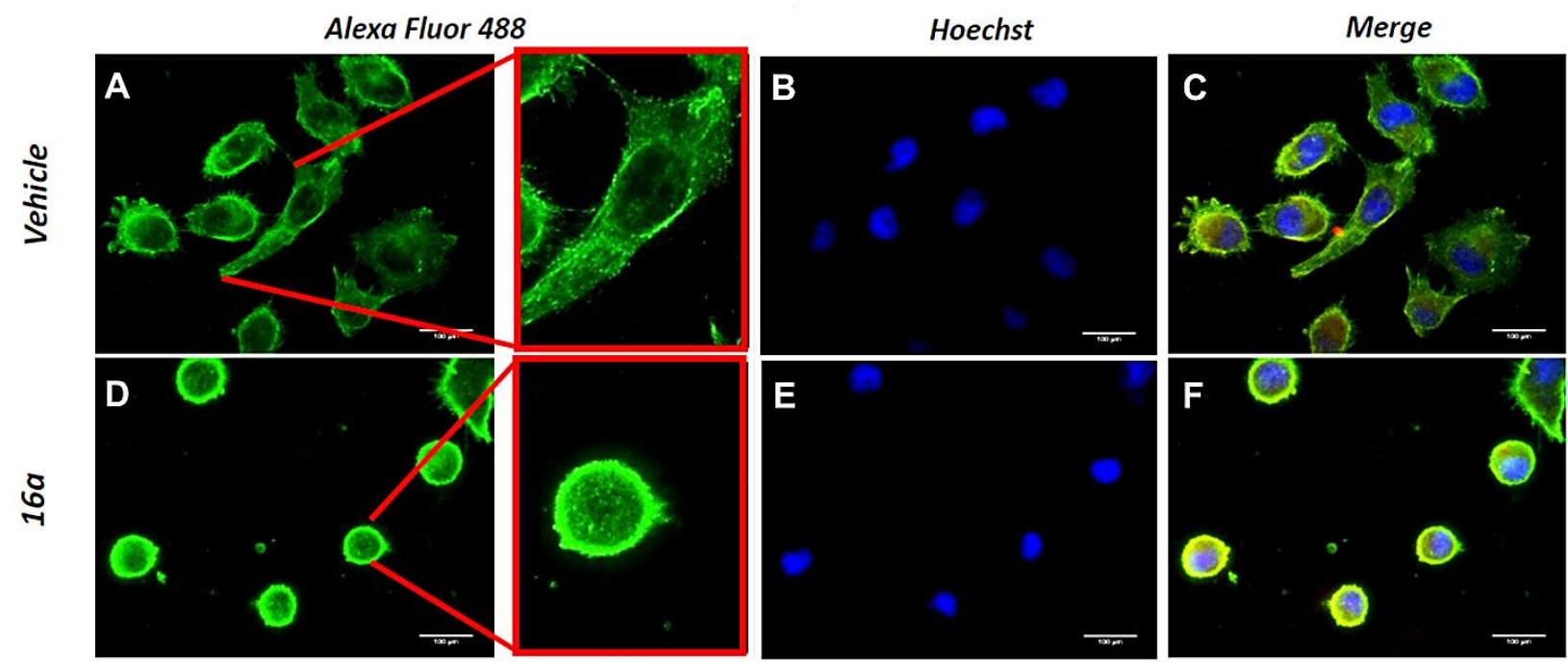
Figure 4. Tubulin content analysis. (A) The effects of compound 16a on tubulin polymerization in SK-Mel28 cells are depicted. Cells were incubated for $6 \mathrm{~h}$ with $\mathbf{1 6 a}$ or vehicle as described in the experimental section. Cells were then harvested and protein extracts were prepared for the analysis using anti $\beta$-tubulin antibody ( $\mathrm{S}$ : soluble, $\mathrm{P}$ : polymerized isoform). (B) The relative fluorescence intensity was normalized by dividing the sum of $\beta$-tubulin value to HSC-70 constitutive protein.

A

Vehicle $16 a$

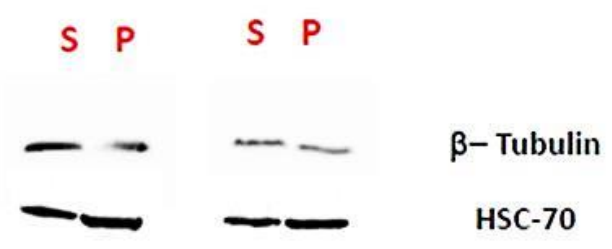

B
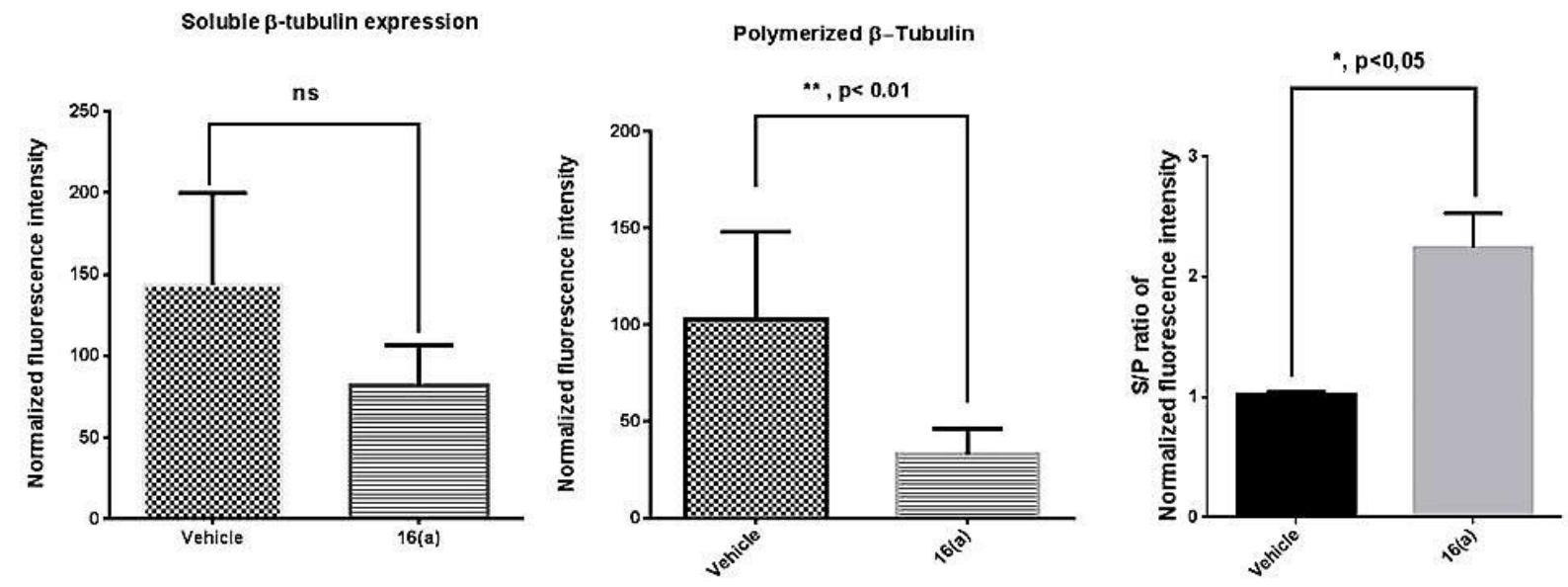
Figure 5. Predicted binding mode of (a): 16a (green stick) and (b): 27a (purple) with tubulin (PDB ID 3HKC) and overlapping with 1 (cyan, the bound ligand of 3HKC). Surrounding amino acid side chains are shown in brown stick format and are labeled. Illustrations were made with UCSF Chimera v1.10.2. ${ }^{37}$

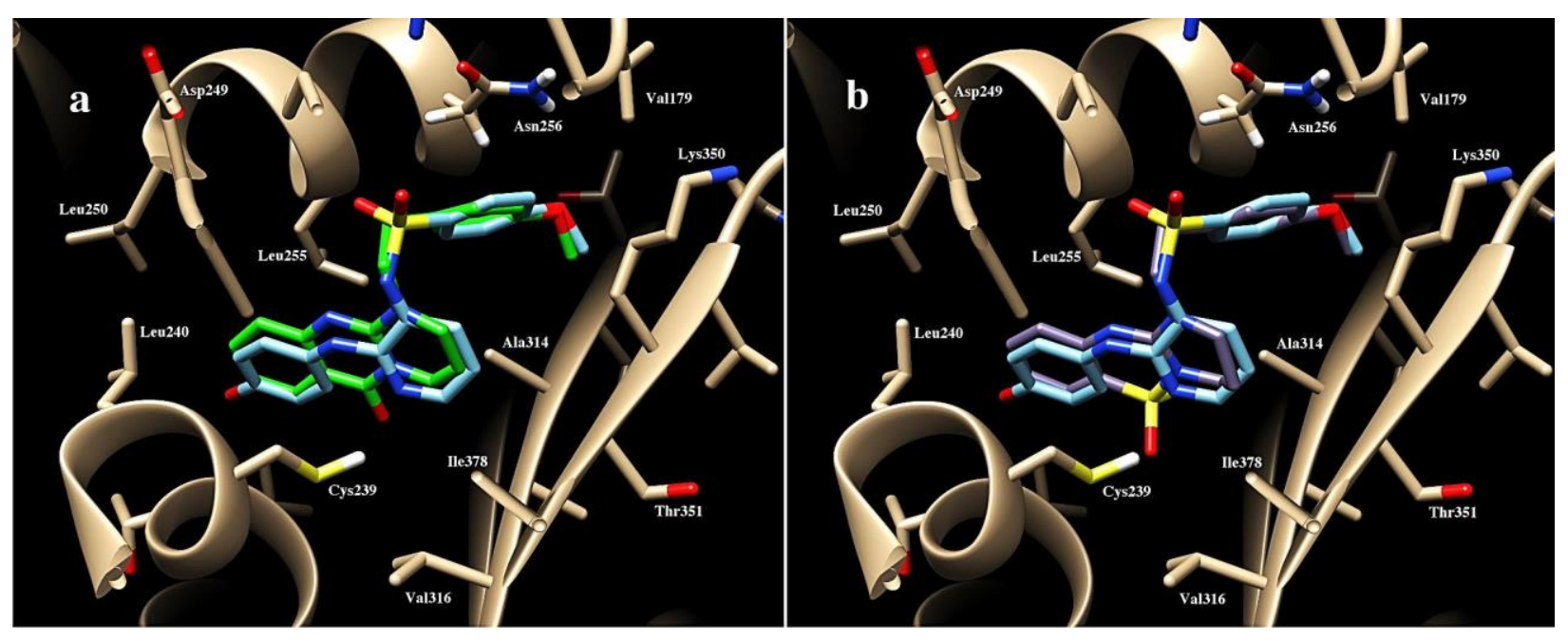


Figure 6. Invasion inhibition on HUVEC in a Boyden chamber assay of reference $\mathbf{3 1}$ and compound 16a. (A) Images depicting the penetration of HUVEC through the filter membrane. (B) The number of HUVEC that penetrated the membrane was quantified. ANOVA and post-hoc Tukey-Kramer analysis was performed using GraphPad Prism ${ }^{\circledR}$ software. Data are represented as the mean $\pm \mathrm{SEM}$ of three different experiments: ns (non-significant) $*(\mathrm{P}<0.05) * *(\mathrm{P}<0.01)$, and $* * * *(\mathrm{p}<0.001)$ versus control.
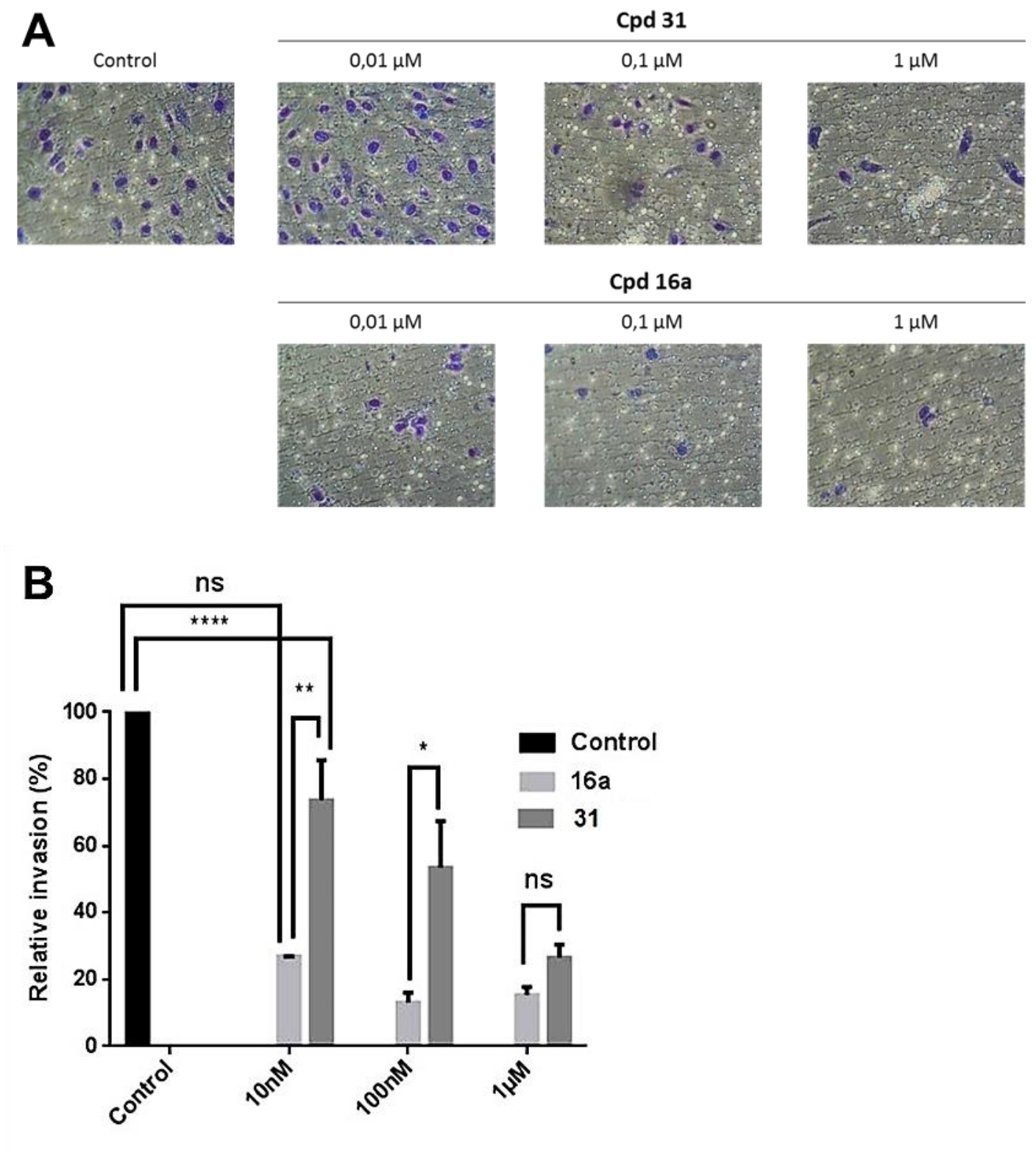
Figure 7. Effect of reference 31 and compound 16a on tube formation. Images depicting the formation of HUVEC capillary-like tubular network by treatment with $\mathbf{3 1}$ or $\mathbf{1 6 a}(0.001,0.01$, 0.1 and $1 \mu \mathrm{M})$.
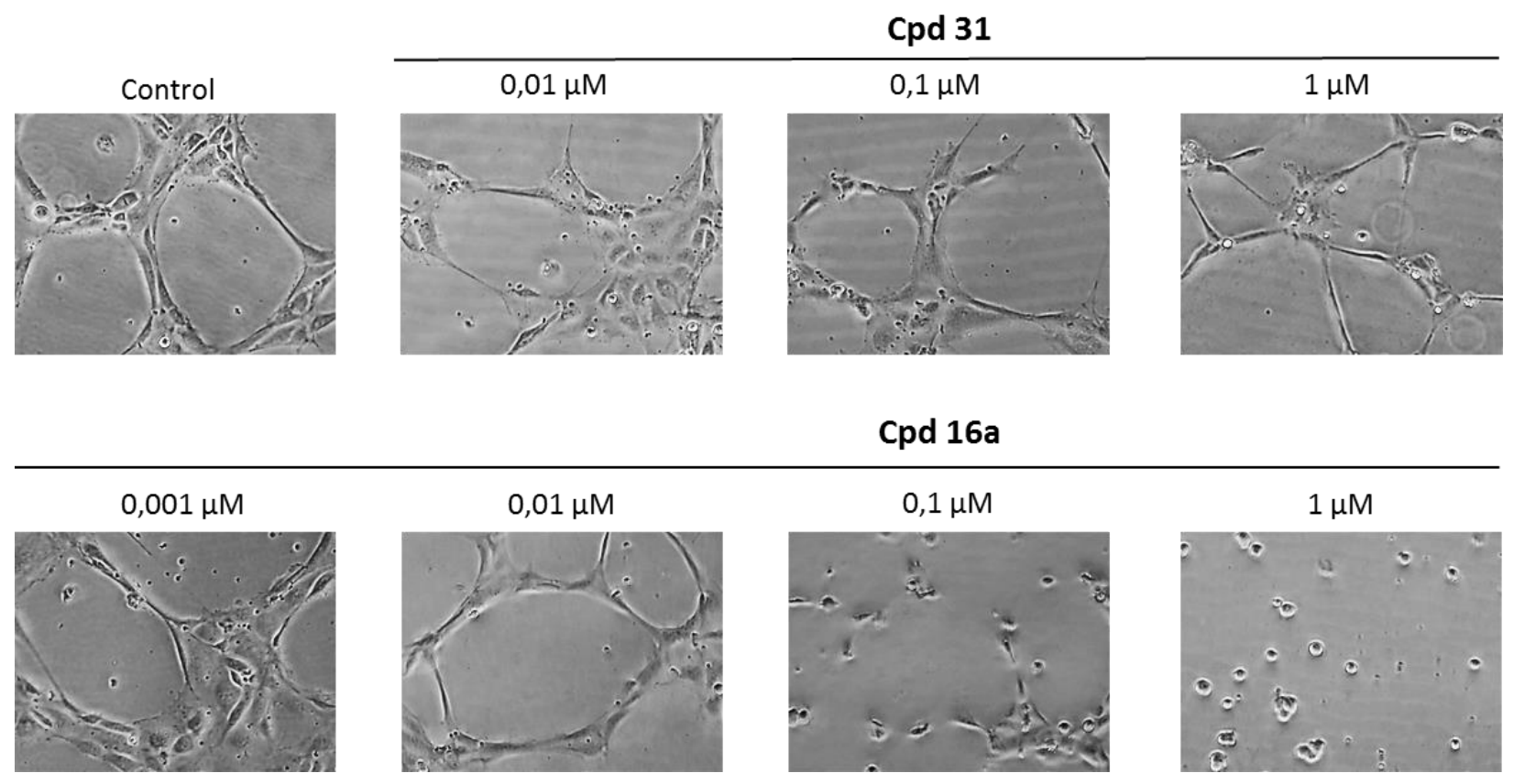
Figure 8. Inhibition of SK-Mel28 cell migration in a wound healing assay. Cells were wounded and then treated with vehicle $(1 \%$ DMSO) or $16 a(1 \mu \mathrm{M})$ for $9 \mathrm{~h}$ in $10 \%$ FBS-containing medium. At 0h (immediately after scratching) and 3, 6 and 9h, phase-contrast pictures of the wounds were taken and then, percentage of cells migrating in the wound area were evaluated using Image $J ®$ software. Results represent the mean of three measures of each wounded area, obtained on triplicate biological samples $(n=3)$. Error bars indicate s.e.m. Statistical analysis was performed using statview SAS and Graphpad Prism ${ }^{\circledR}$ programs: ns (non-significant) $*(\mathrm{P}<0.05)$ $* *(\mathrm{P}<0.01), * * *(\mathrm{P}<0.005)$ and $* * * *(\mathrm{p}<0.001)$.
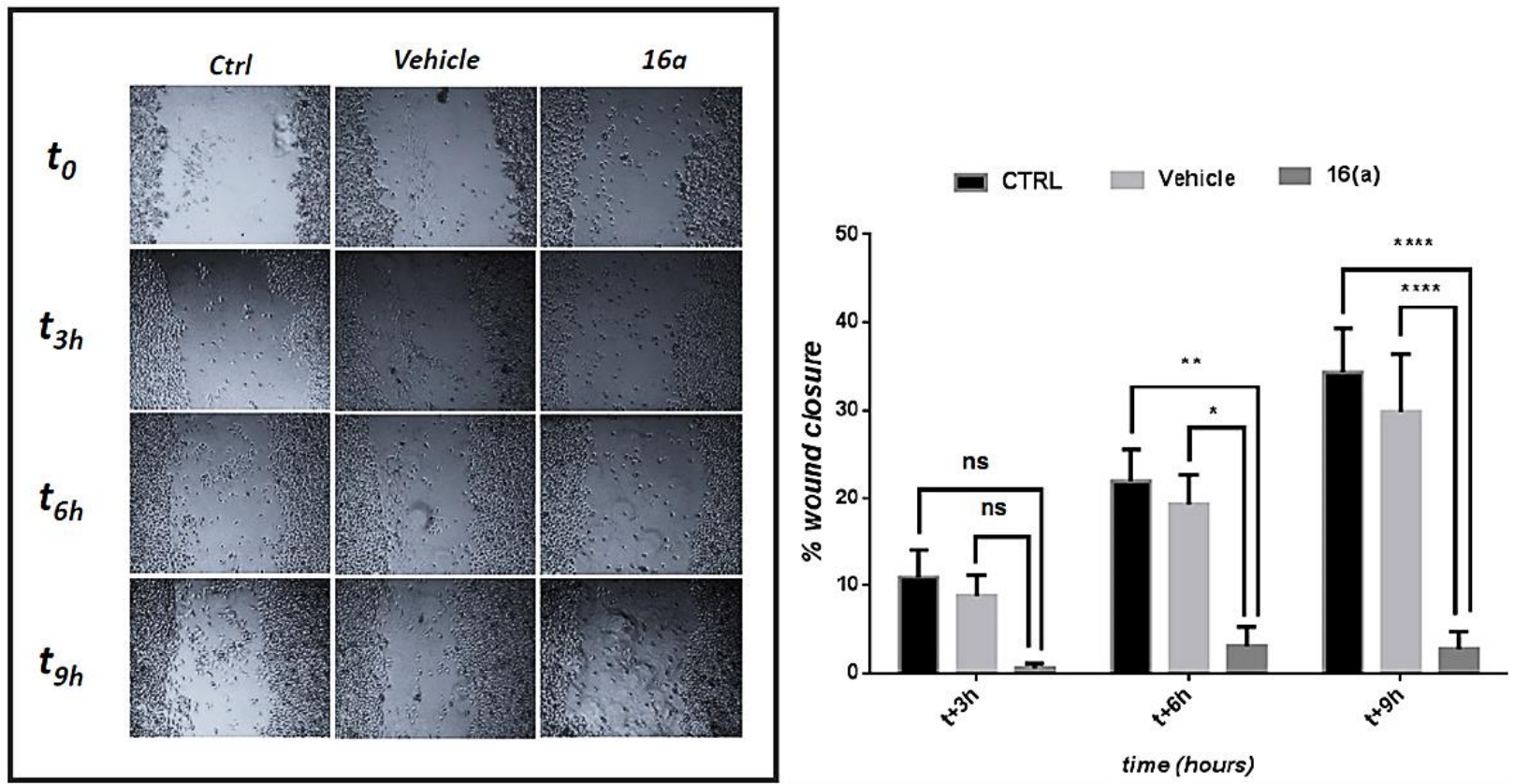
Figure 9. Anticancer activity of compound 16a in a xenograft model of B16F10 murine melanoma cancer cells. (A) Male mice were inJected subcutaneously in their right flank region with B16F10 cells, a syngeneic melanoma cell line. Tumor-bearing mice were administered the vehicle, as control, or the indicated doses of $\mathbf{1 6 a}$ or $\mathbf{1}$ as reference compound at the concentration of $50 \mathrm{mg} / \mathrm{kg}$. Administration was given subcutaneously using osmotic pumps starting on day 7 . The figures show (B) the average measured tumor volumes and $(\mathrm{C})$ tumor weights of the mice recorded at the end of the treatments. ${ }^{*} \mathrm{p}<0.05,{ }^{*} \mathrm{p}<0.01, * * * * \mathrm{p}<0.001$ vs. control.

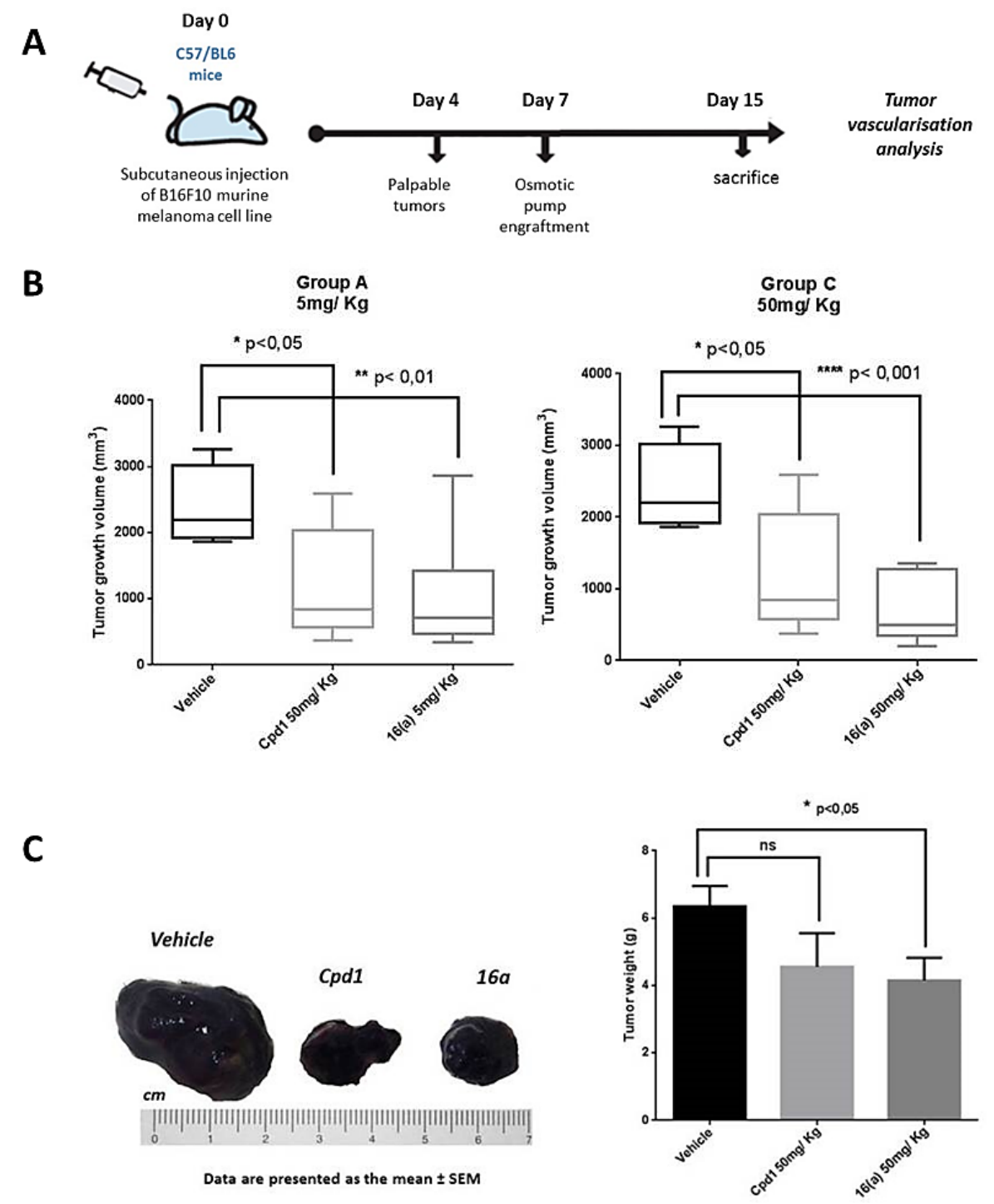


Figure 10. In vivo effects of 16a on tumor angiogenesis. B16F10 murine melanoma cells were injected in the right flank of C57BL/6 mice as described in the experimental section. Tumor tissues were fixed in formalin and embedded in paraffin for immunohistochemistry: (A) Hematoxylin-eosin (HE) and CD31 immunohistochemistry staining of tumor after treatment with 5 and $50 \mathrm{mg} / \mathrm{kg}$ of 16a (microscope objective x20). (B) Quantitative analysis of tumor section stained with CD31 for blood vessel number. Data are represented as the mean $\pm \mathrm{SEM}$ of five mice per group: ${ }^{*} \mathrm{p}<0.05,{ }^{* *} \mathrm{p}<0.01,{ }^{* * *} \mathrm{p}<0.005, * * * * \mathrm{p}<0.001$ vs. control.
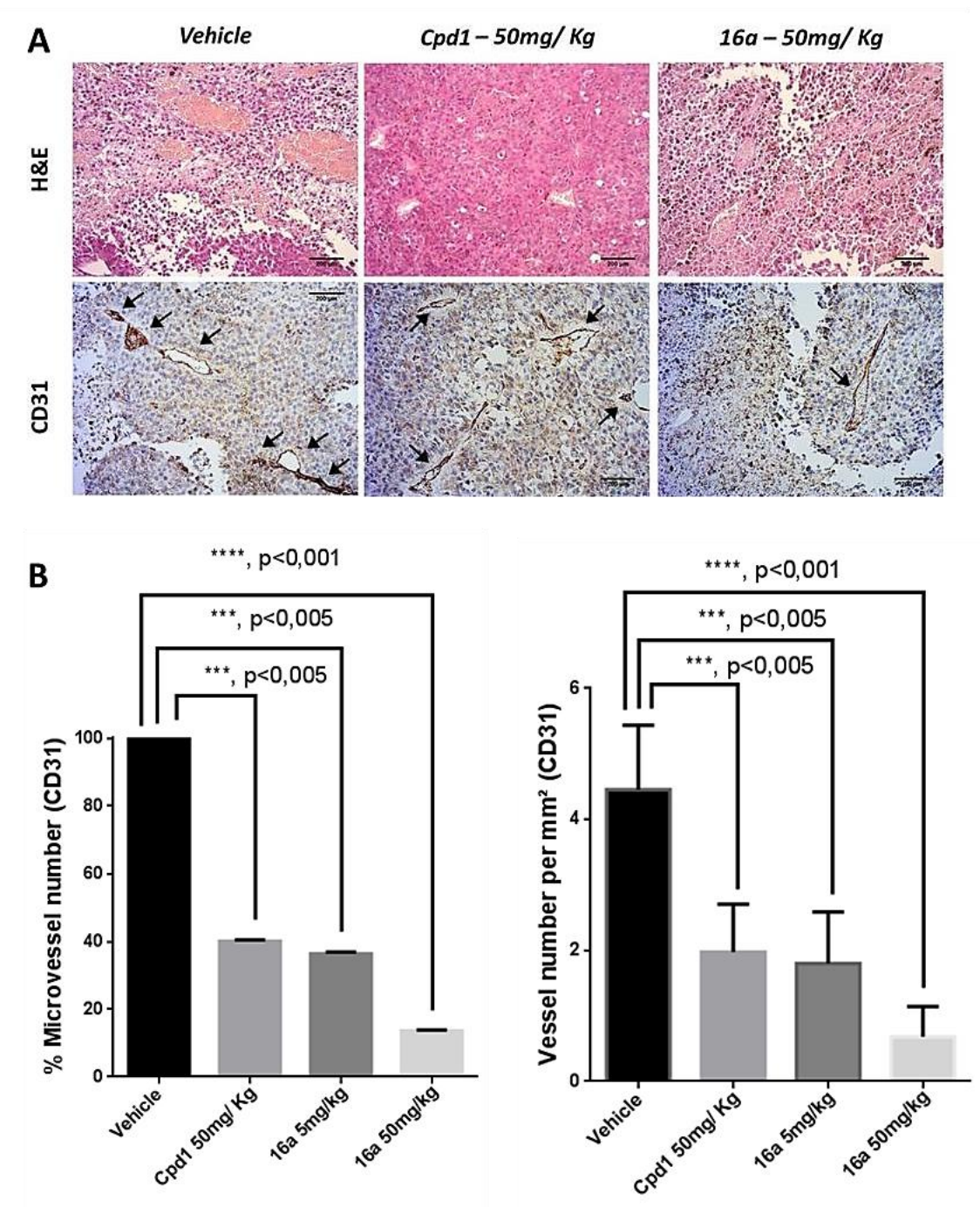


\section{Table of Contents Graphic}

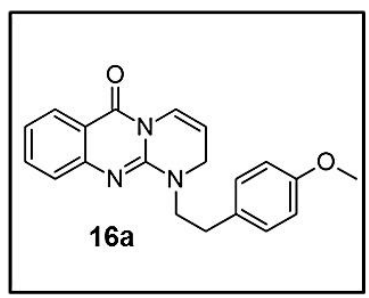

Inhibition of tubulin polymerization:

$\mathrm{IC}_{50}=0,812 \mu \mathrm{M}$
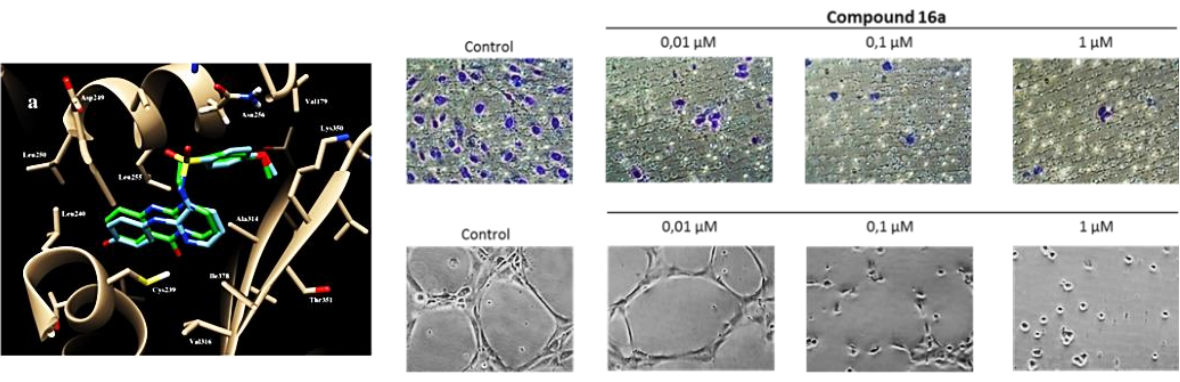

Potent in vitro and in vivo tubulin inhibitor and vascular disrupting agent 